University of Rhode Island

DigitalCommons@URI

Open Access Dissertations

1974

\title{
A Cost-Production Analysis of Trap and Hand Line Fishing in Puerto Rico
}

Jean Francois Abgrall

University of Rhode Island

Follow this and additional works at: https://digitalcommons.uri.edu/oa_diss

\section{Recommended Citation}

Abgrall, Jean Francois, "A Cost-Production Analysis of Trap and Hand Line Fishing in Puerto Rico" (1974). Open Access Dissertations. Paper 414.

https://digitalcommons.uri.edu/oa_diss/414

This Dissertation is brought to you for free and open access by DigitalCommons@URI. It has been accepted for inclusion in Open Access Dissertations by an authorized administrator of DigitalCommons@URI. For more information, please contact digitalcommons-group@uri.edu. 


\section{A COST-PRODUCTION ANALYSIS OF TRAP \\ AND FIAND LINE FISHING IN PUERTO RICO}

BY

JEAN-FRANCOIS ABGRALL

A DISSERTATION SUBMITTED IN PARTIAL FULFILLMENT OF THE REQUIREMENTS FOR THE DEGREE OF DOCTOR OF PHILOSOPHY

IN

ECONOMICS-MARINE RESOURCE OPTION

UNIVERSITY OF RHODE ISLAND

1974 
DOCTOR OF PHILOSOPHY THESIS

OF

JEAN-FRANCOIS ABGRALL

Approved :

Thesis Committee:

Major Professor
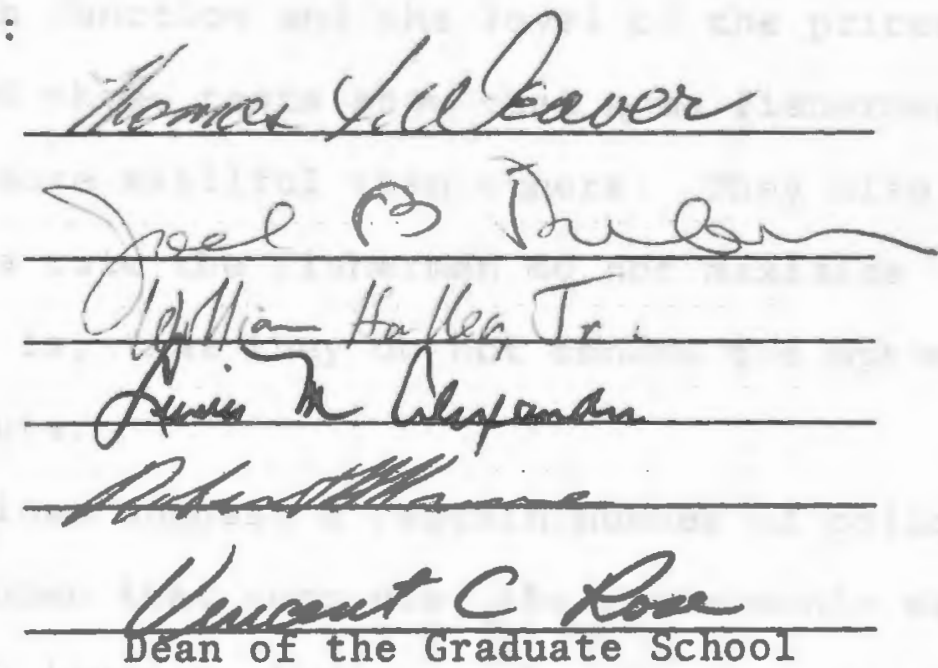

UNIVERSITY OF RHODE ISLAND 


\section{ABSTRACT}

This study analyzes the cost-production relationship of trap and hand line fishing in Puerto Rico. A model of the fishing family firm is designed which is similar to the traditional neo-classical model of the fishing industry. The catch functions, of the cobb-Douglas type, are estimated using the single least squares methods. Tests of technical efficiency and tests of price efficiency are then conducted to establish if some groups of fishermen are more efficient than others and to verify if the fishermen maximize their profit, given the technical coefficients of the catch function and the level of the prices.

The results of those tests show that some fishermen are significantly more skillful than others. They also indicate that, as a rule the fishermen do not maximize their profit, that is, that they do not choose the optimum combination of inputs.

Those conclusions suggest a certain number of policy measures. It is shown that improving the fishermen's skill would substantially increase their catch. The same results would be obtained if, with proper advice, they selected the optimum combination of inputs. 
Given the lack of sufficient data on the fish population it was not possible to measure the precise extent of the effects of those policy measures. However this study provides a useful guide for the policy makers. 
Table of Contents

List of Tables. . . . . . . . . . . . . . iv

List of Illustrations. . . . . . . . . . . . vii

Acknowledgements . . . . . . . . . . . . . viii

I. Introduction . . . . . . . . . . . . 1

I. The Artisan Fishery in Puerto Rico . . . . . 4

II. Trap and Hand Line Fishing . . . . . . . 10

III. The Different Steps of the Analysis. . . . 16

II. The Puerto Rican Fishing Grounds and The

Areas Surveyed . . . . . . . . . . . 21

I. The North Coast. . . . . . . . . . 26

II. The West Coast.............. 28

III. The South Coast. . . . . . . . . . 35

IV. The East Coast . . . . . . . . . . . . 37

V. Description of the Sample. . . . . . . 39

III. Review of the Iiterature . . . . . . . . 4 47

I. An Economic Model of the Fishing Industry . . . . . . . . . . . . . . . 49

II. Definition of a Catch Function and

III. Estimating the Catch Function. . . . . . 59

IV. Definition of the Catch Function and the

Tests of Efficiency: A Theoretical Approach . . 73

I. Definition of the Catch Functions. . . . . 75

II. Econometric Formulation of the Catch Function .. . . . . . . . . . . 81

III. The Measures of Efficiency . . . . . . 87

IV. The Cost Equation. . . . . . . . . . 96

V. Estimation of the Catch Function... . . . . 99

I. Choice of the Independent Variables. . . . 101

II. The Dependent Variable. . . . . . . . .124 
VI. Tests of Efficiency . . . . . . . . . . . 129

I. Technical Efficiency. . . . . . . . . .130

II. Price Efficiency. . . . . . . . . . . . . .141

III. Comparison of the Price Efficiency

For Various Groups of Fishermen . . . . . .146

IV. Investing in a Winch. . . . . . . . . . .152

VII. Some Policy Suggestions to Increase the Income

of the Puerto Rican Fishermen . . . . . . . 155

I. The Present Economic Performance. . . . . .156

II. Use of the Model for Policy Development . . .162

III. Policy Direction: Increasing Technical

Efficiency for the Trap Fishermen . . . . . 165

IV. Policy Directions for both Trap and Iine

Fishermen ...............170

Conclusion . . . . . . . . . . . . . 181

Appendix 1 Data Collection and Field Method . . 185

I. The Sale Tickets . . . . . . . . . 188

II. The Questionnaires.......... . . . 190

Bibliography . . . . . . . . . . . . 192 
Income and Employment in the Puerto Rican Economy and in the Artisanal Fishery . . . . . . . . . . . . 5

I-2 Percentage of Total Catch of Fish and Shellfish by Fishing Gear Reported in Puerto Rico in 1972 . . . . . . . . . . Il

Comparison of the Catch Composition from Traps and Hand Lines in 1971. . . . . 14

II-1 Some Characteristics of the Ports Surveyed and Comparison with the Rest of the Island... . . . . . . 23

II-2 Number of Interviews per Municipality in 1973-1974............ . . 24

II-3 Number of Interviews in Each Community of Cabo Rojo, 1973 ........ . . 30

II-4 Characteristics of Fishing Family Firms in the Areas Surveyed. . . . . . . . 40

II-5 Characteristics of Trap Fishing Enterprises According to the Power of Engines. . . . 42

II-6 Characteristics of Line Fishing Enterprises According to the Power of The Engine . . . 43

II-7 Characteristics of Fishing Enterprises According to the Number of Men on Board. .

IV-1 The Use of Dummy Variables When Two Independent Criteria Divide the Sample in Several subsets... . . . . . 89 
Table

Page

IV-2 Coefficient of the Dumy Variables in Each Subset. . . . . . . . . . 90

V-la Comparison of Regressions Using Various Measures of the Boats and Its Characteristics for Trap Fishing. . . . . . . .104

$\mathrm{V}-1 \mathrm{~b}$

Comparison of Regressions Using Various Measures of the Boats and Its Characteristics for Hand Line Fishing . . . . . .106

V-2 Comparisons of Regressions Using Pounds and Dollars to Measure the Catch . . . . .125

$\mathrm{V}-3$

Changes in the Constant Term of the Regression Corrected for the Missing Sale Tickets . . . . . . . . . . . 127

VI-1 Tests of Technical Efficiency (using the length of the boat as an independent variable) . . . . . . . . . . 133

$\mathrm{VI}-2$

Tests of Technical Efficiency (using the present value of the boat and the motor as an independent variable) . . . 139

VI-3 Comparison of Price Efficiency Between Groups of Fishermen . . . . . . . 147

VI-4 t-Tests for Comparing Price Efficiency Among Groups of Fishermen . . . . . . 149

VII-1 Economic Returns to the Trap Fishing Operations in 1972 . . . . . . . . . . 159

VII-2 Economic Returns to the Line Fishing Operations in 1972 ............160

VII-3 Economic Returns to the Fishermen

Using Both Trap and Hand Lines in 1972 . .161 
VII-4 Potential Returns to the Trap Fishermen After Additional Training and Using Boats Equipped with a Winch . . . . . . . . . . . . .167

VII-5 Potential Returns to the Trap Fishermen Provided that they Used the Optimum Number of Traps Given the Present Level of the Other Inputs . .173 


\section{LIST OF ILLUSTRATIONS}

\section{Page}

Map II-1 Puerto Rico: The Areas Surveyed and The Continental Shelf . . . . . 25 


\section{ACKNOWLEDGMENTS}

I wish to express my thanks to Professor T. F. Weaver who supervised the preparation of the thesis.

I also would like to express my gratitude to Professor L. M. Alexander, Professor J. B. Dirlam, Professor W. Haller Jr., and Professor R. B. Hume for commenting on various drafts, to Dr. J. A. Suarez-Caabro and to his staff at the Commercial Fisheries Laboratory of Cabo Rojo, Puerto Rico, particularly to $\mathrm{Mr}$. J. Alvarez for sharing their experience of the Puerto Rican fisheries and for allowing me to use unpublished data, and to $\mathrm{Mr}$. C. Jusino Rivera of the Puerto Rican Department of Agriculture for his help during my stays in Puerto Rico.

I am deeply indebted to the fishermen of Puerto Rico who provided information on their fishing operations.

I also wish to thank Mrs. M. J. Keefe and Miss M. Boudreau for their assistance in finishing the last draft. Finally I would like to express my most sincere thanks to my wife Jeannette, to my son Riowen, and to my parents for waiting for me all that time. 


\section{INTRODUCTION}

This study is a cost-production analysis of the two most important methods of catching fish in the artisanal fishery of Puerto Rico, namely, hand line fishing and trap fishing. The estimation of costs and of returns, in addition to the description of the economic behavior of the fishermen, will lead to suggesting policy orientations.

For many years Puerto Rico has been importing most of its food products including fish. ${ }^{1}$ Recently, efforts have been undertaken to reduce this dependency on outside suppliers. In this context the Puerto Rican Department of Agriculture has initiated various programs ${ }^{2}$ to help the artisanal fisherman.

This study provides the decision makers with information, not otherwise available, concerning the productivity of some fishing methods as well as the economic behavior of the fishermen. It shows what can be expected from a change in the input combinations presently adopted

Harvey S. Perloff, Puerto Rico's Economic Future, (The University of Chicago Press, Chicago, Illinois, 1950), pp. 314-316.

2 Rafael Pico, Nueva Geografia de Puerto Rico, (Editorial Universitaria, Universidad de Puerto Rico, 1969). 
by the fishermen as well as some of the effects which could result from improving their fishing skills. These are tools which will help design the policies necessary to improve the economic situation of the fishermen and to develop the artisanal fishery.

Several approaches were considered. For the purpose of policy making, a dynamic model would have probably been more appropriate. However, insufficient data were available on the fish population. In addition, it would have been very difficult to obtain information on the levels of input used by fishermen for more than one or two years. For several inputs the direct interviews were the only source of data, and, in many occasions, the fishermen had difficulties remembering their past investments. Finally, the statistics gathered by the Puerto Rican Department of Agriculture were reliable only after 1969, limiting possible use of a time series. For those reasons, it was decided to use a static model despite the limitations of such a framework.

The cost-production analysis was conducted for 1972 . From the economic performance and behavior revealed by this study it was possible to deduce some policy suggestions. Because of the framework chosen here the effects of those policies could not be measured with precision and it needs to be emphasized that the results of this part of the study should be interpreted with circumspection. 
The present chapter gives a description of trap and hand line fishing in Puerto Rico, showing in Secion I the importance of the artisan fishery. In section II the attention is more specifically directed toward trap and hand line fishing. Finally, section III summarizes the various steps of the cost-production analysis. 
I The Artisan Fishery in Puerto Rico

I The economic setting

The artisan fishery represents only a small part of the Puerto Rican economy. Yet it is responsible for the entirety of the local catch. There is also a tuna fishing industry, operating mainly out of Mayaguez, but owned by continental Americans and Japanese. The tuna is canned in Puerto Rico and exported to other markets. These two sectors of the Puerto Rican fishery are totally independent and to date there are no fishing operations of an intermediate size between the tuna industry and artisanal fishery. Table I-I compares the artisanal fishery industry with the total economy and the agricultural sector. As shown in Table I-l the artisanal fishery employs only a small amount of the total labor force, and it produces an even smaller part of the Island income.

The local fishery is one of the less developed sectors of the economy. Using the aggregate figures of Table I-I it is possible to roughly compare the average productivities of labor. In the total economy it is around $\$ 6200$ (column I divided by column 4). In agriculture it is slightly over $\$ 3200$ while in the fishery it is only about $\$ 2000$. The actual difference is even larger since for the fisheries gross income is used instead of net income. For the United 


\section{INCOME AND EMPLOYMENT IN THE PUERTO RICAN ECONOMY}

AND IN THE ARTISANAL FISHERY

Employment

$\begin{array}{lllll}\text { National - Net Income } & \text { Gross Value of Total } & \text { Artisanal } \\ \text { Income (1) from Agric. (2) } & \text { the Catch (4) } & \text { Economy (2) Agric. (2) } & \text { Fishery (3) }\end{array}$

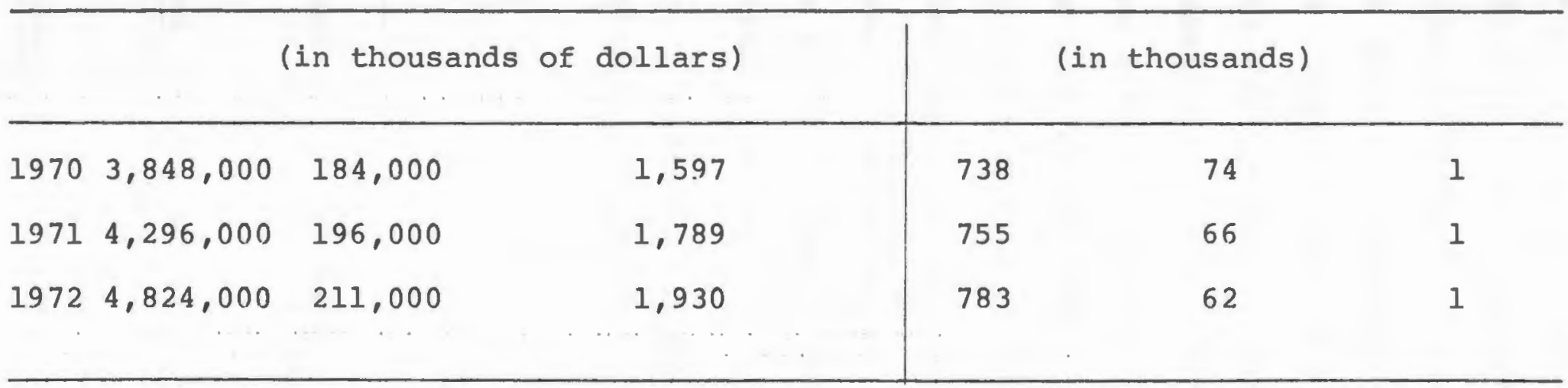

Sources: (1) Department of the Treasury. A Publication of the Commonwealth of Puerto Rico Economy and Finances Puerto Rico, $1972, \mathrm{p}$. 6.

(2) Ibid., p. 7

(3) Commonwealth of Puerto Rico, Department of Agriculture, status of Fisheries in Puerto Rico, 1972, by Jose A. Suarez Caabro, Agricultural and Fisheries Contributions, Vol. V, No. 3, Cabo Rojo, Puerto Rico, p. 47 .

(4) Ibid., p. 48 
States as a whole, the same computations give respectively: $\$ 6400$ for the total economy, $\$ 5500$ for agriculture and $\$ 4600$ for the fisheries. ${ }^{3}$ These are only aggregate figures and one should be careful when deriving conclusions, yet they emphasize the need to improve the productivity of the Puerto Rican agriculture and especially that of the fisheries.

At the same time, there is in Puerto Rico an important demand for fish and shellfish and the local catch represents only $5 \%$ of the total consumption. ${ }^{4}$ In an effort to develop the artisanal fishery the government of the Commonwealth has instituted various loan and credit programs to provide capital for the fishermen. 5

Some of these programs have been operating for more than ten years. Still, much remains to be done to improve the fishing methods and the commercialization of the catch.

3 Figures computed from U.S. Bureau of the Census statisTical Abstract of the United States, 1972 (93rd Edition) Washington, D.C., 1972.

\footnotetext{
4uerto Rico and the Sea, An Action Program for Marine airs (Preprint) A Report to the Governor, San-Juan, 1972 , p. 57.

${ }^{5}$ Rafael Pico, Nueva Geografia de Puerto Rico.
} 
II The cultural context

Two monographs on Puerto Rican fishing communities are apparently the only sociological studies of the artisanal fishery. One ${ }^{6}$ deals with four fishing villages in southwest Puerto Rico. The other ${ }^{7}$ is based on a survey of a single village, and includes more interesting detail. The studies indicate that, as compared with other population groups, the average fisherman had larger families, was older, and had fewer years of schooling. ${ }^{8}$ These characteristics suggest a traditional society in which custom and social inertia influence the fishermen's economic decisions. The more detailed study ${ }^{9}$ confirms the general impression, but suggests a growing heterogeneity among the group, with more and more fishing family firms becoming integrated with the market economy.

${ }^{6}$ Federico G. Blay, A study of the Relevance of Selected Ecological Factors Related to water Resources and the Social Organization of Fishing Villages in Puerto Rico. (Water Resources Research Institute, University of Puerto Rico, Mayaguez, Puerto Rico, 1972).

${ }^{7}$ Irving A. Spaulding, Puerto Rico Fisheries and Mariculture Mevelopment Project (Unpublished Inter Agency Report, aniversity of Rhode Island, 1974).

${ }^{8}$ Blay, The Social Organization of Fishing Villages in Puerto Rico.

${ }^{9}$ Spaulding, Puerto Rico Fisheries and Mariculture Development Project. 
The incomes of the fishermen reflect this to some extent. Ninety-one percent of the fishermen, and 55 percent of the non-fishermen have annual incomes in the $\$ 1000$ $\$ 3999$ range, while 30 percent of the fishermen and 27.3 percent of the others have incomes between $\$ 4000$ - $\$ 5999$. This suggests that a few fishermen are earning fairly good incomes. At the same time none of the fishermen, but 18.2 percent of the non-fishermen, have incomes less than $\$ 1000$. The traditional character of the fishery is also revealed by the fact that "in general, the part-time fishermen and the non-fishermen showed a somewhat more prevalent tendency than did the full-time fishermen for continuing to work at a different job if their current occupation could no longer be followed (in that situation) 47.8 percent of the full-time fishermen and 41.7 percent of the nonfishermen indicated that they would not work". 10 This is further emphasized by the fishermen's justifications for not working if they could not fish any longer. Forty-two point seven percent indicated that they knew nothing else, while only 22.2 percent of the non-fishermen justified their answer in this way. 11

${ }^{10}$ Ibid., p. 16.

${ }^{11}$ Ibid., Table 15b. 
From those observations it appears that the artisanal fishery in Puerto Rico is still largely traditional, and that most of the fishermen are not fully integrated into the market economy.

While some fishermen are modernizing their operations and introducing new techniques of fishing or of management, most of them are still attached to the traditional methods. 
As shown in Table I-2, together, trap and hand line fishing are responsible for nearly 60 percent of the total landings. Hand line fishing is practiced all around the island, while trap fishing is more concentrated in some areas. Of the 8,105 traps reported in 1972, 3,160 (39 percent) could be found on the west Coast while only 224 (2.8 percent) belonged to fishermen on the North Coast. 12

In Puerto Rico the most common fish trap is the arrow-head type. They are made of chicken wire around a frame of either mangrove wood or iron rods. "Normally, it is fished in shallower depth (less than twenty fathoms) because of the lack of mechanical hauling equipment". 13 In addition, the boats have no navigation equipment to aid the captain in finding his traps. Land marks are used which_is very inefficient as soon as it is misty or foggy. On fishing grounds known for their high productivity there

${ }^{12}$ Commonwealth of Puerto Rico Department of Agriculture, Status of Fisheries in Puerto Rico, 1972 by Jose A. pez Caabro, Agricultural and Fisheries Contributions, vol. V, No. 3, Cabo Rojo, Puerto Rico, p. 47.

13

Estado Libre Asociado de Puerto. Rico Departamento de Agricultura, A Report of Exploratory Fishing and Cear Tests in Puerto Rico from 1969 to 1972 by Rolf uhl Contribuciones Agropecuarias y Pesqueras vol. IV, No. 3, Cabo Rojo Puerto Rico, p. 5. 
PERCENTAGE OF TOTAL CATCH OF FISH AND SHELLFISH BY FISHING GEAR IN PUERTO RICO IN 1972

GEAR

Fish Pot

Spiny Lobster Pot

Beach Seine

Gill Net

Hand Line

Troll Line

Spear

Trot Line

By Hand

Cast Net

\section{PERCENT}

(of the total catch)

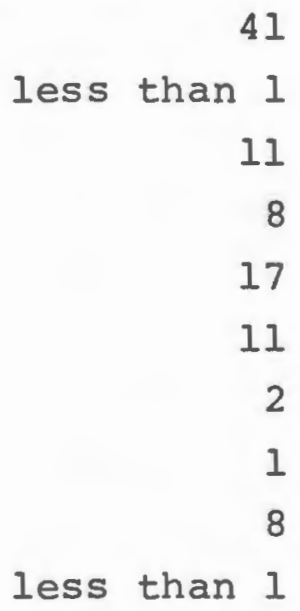

41

less than 1

11

8

17

11

2

1

8

less than 1

Source: Estado Libre Asociado de Puerto Rico, Departamento de Agricultura, A Report on Fisheries Statistics Program in Puerto Rico from 1967 to 1972, by Rolf Juhl and Jose A. Suarez Caabro Agricultural and Fisheries Contributions, Vol. IV, No. 4, San Juan Puerto Rico, p. 22. 
are often a very large number of traps and sometimes it is necessary to navigate carefully to avoid cutting the ropes tying the buoys to the traps. Generally, the fish pots are not deliberately baited but sometimes the fishermen will leave inside some fish which are too small to sell or for which there is no demand.

Hand line fishing "while requiring a small investment requires considerable more ability and knowledge of fish habits". 14 In this type of fishing the fishermen use long lines ( 300 to 500 feet).

" At the end of the line 4, 6, 8 hooks are hung from a hard frame of galvanized wire, with a three $15^{\circ}$ five pound lead attached to the center".

Those hooks are baited with small fish which the fishermen catch with their cast nets. When fishing with hand lines, some of the fishermen will let the boat'- drift once they are on the fishing grounds. Others prefer to keep the boat still, and in some areas there will be one man in the boat whose sole task is to steer the boat while the others are fishing.

14 Study of the Fisheries Potential of the Virgin Islands, Special Report, Caribbean Research Institute Contribution, No. I Virgin Island Ecological Research Station, August, 1969 , p. 41 .

15

Estado Libre Asociado de Puerto Rico Departamento de Agricultura Contribuciones Agropecuarias y Pesqueras, Vol. II, No. 1, San Juan Puerto Rico, p. 28. 
In areas where conditions are suitable for trap and hand line fishing many fishermen practice both methods. There is a significant difference between the species caught by traps and the species caught by lines. The largest source of revenue from traps is lobster (35.5 percent of the total value of the catch from traps in 1971).16 But, lobsters aside, the difference in the species composition of the fin-fish catch from traps and hand lines is important.

While the weight of the fish caught with traps is 60 percent larger than the weight of the landing from lines, this difference is reduced in value to 22 percent. (Table I-3). Even taking into account lobsters in 1971, the average price per pound of fish and shellfish caught by traps was $36 \mathrm{c}$ against $44 \mathrm{c}$ for hand lines. 17 For hand lines 50 percent of landings were silk snappers which sold for more than $60 \mathrm{f}$ a pound. Still, trap fishing is more common probably for the reasons mentioned earlier regarding the ability and knowledge required to use hand lines effectively.

\section{6}

Commowealth of Puerto Rico Department of Agriculture, Status of Fisheries in Puerto Rico, 1971 by Rolf JuhI and A. Suarez Caabro Agricultural and Fisheries Contriburis, Vol. IV, No. I San Juan Puerto Rico, p. 45.

17 Ibid., pp. 45-46. 
COMPARISON OF THE CATCH COMPOSITION FROM TRAPS AND HAND LINES IN 1971

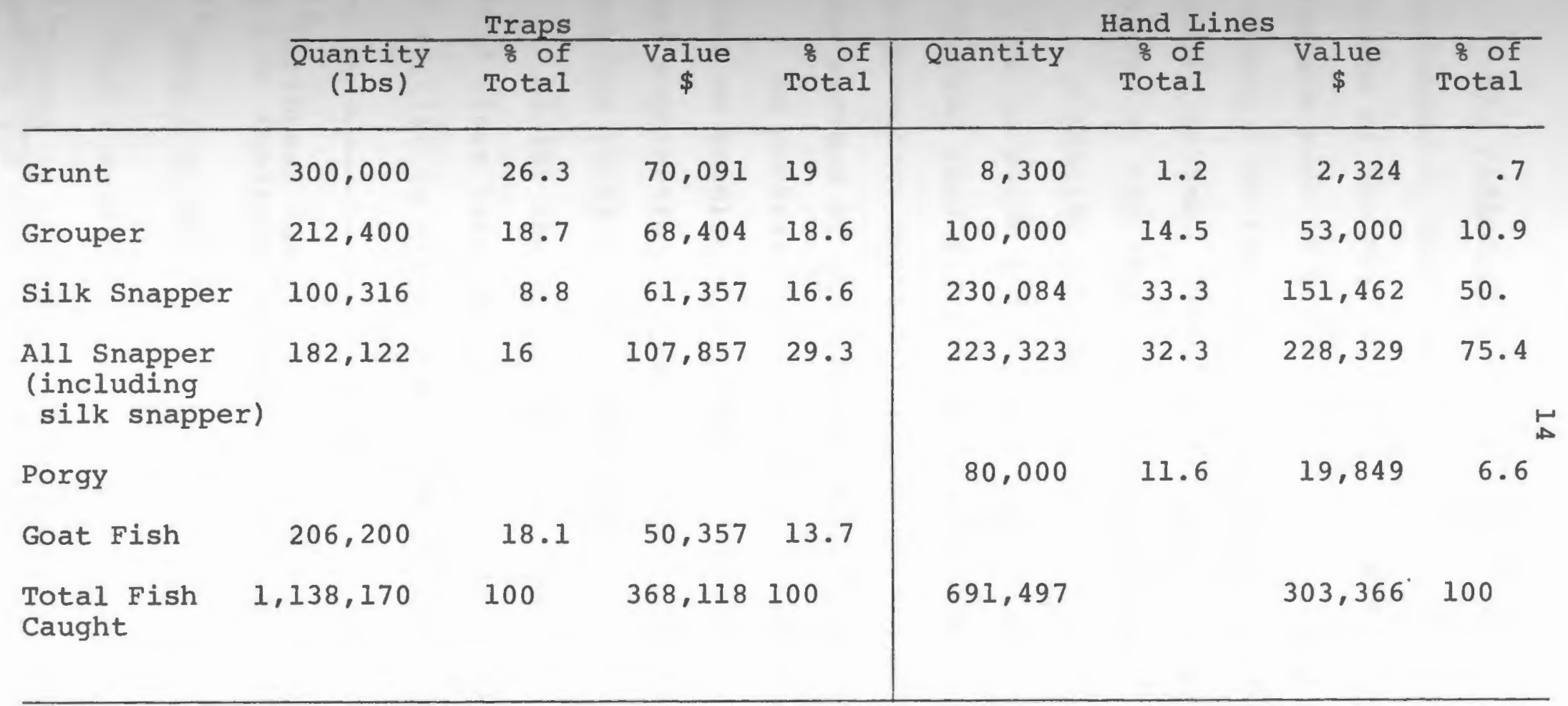

Source: Commonwealth of Puerto Rico, Department of Agriculture, Status of Fisheries in Puerto Rico, 1971 by Rolf Juhl and Jose A. Suarez Caabro, Agricultural and Fisheries Contributions, Vol. IV, No. 1, San Juan, Puerto Rico, pp. $45-46$. 
The different composition of the catches can be partly explained by the behavior and in particular the feeding habits of the various species. The traps catch bottom feeders such as grunts which, when they are young "feed primarily on the animals of the plankton within a few feet of the bottom. These food habits are retained to a large degree by the adults (of some species)". 18

A similar explanation applies to the goatfish which "live in close association with sand or mud bottoms... The food consists primarily of a great variety of small invertebrate animals, many of which normally live beneath the surface of the sand or mud". 19

In contrast porgies "do not seek shelter in reefs but rely on keeping a considerable distance between themselves and a potential source of danger". 20 This explains why they are not found in the fish traps.

As for the silk snappers, the majority are caught with hand lines because they are "a deeper-water species than most, (it is often found between) 300 and 800 feet". $^{21}$

${ }^{18}$ Caribbean Reef Fishes, John E. Randall (Jersey City: T.F.H. Publications, Inc., 1968), p. 128.

19

Ibid., p. 153.

20

Ibid., p. 141 .

21 -hes of the Bahamas and Adjacent Tropical Waters, b and Chaplin (Wynnewood: Livingston Publishing witny, 1968), p. 351 . 
Chapter II provides a detailed description of the areas surveyed. Each of the communities visited are described, and their degree of representativeness of the various coasts is discussed. In addition the composition of the sample is presented here and some characteristics of the group of fishermen interviewed are explained.

Chapter III reviews the latest neo-classical models of the fishing industry but earlier articles are often mentioned for their contributions. Although the models often dealt with the industry, it was possible to use their approach to analyze the firm's behavior. It was also necessary, however to refer to more practical works where catch functions had been estimated for various fisheries. They provided examples of the variables which were most often chosen to explain the catch, as well as various means to measure some of these inputs.

The econometric problems raised by the estimation of the catch function also needed to be examined. A long series of articles, starting with Marschak and Andrew's 22

\footnotetext{
22 Jacob Marschak and William H. Andrews, Jr., "Random Simultaneous Equations and the Theory of Production," fonometrica, 12 (July/October, 1944).
} 
offered various ways of estimating production functions in general. Furthermore, they emphasized some properties of those various approaches, which could be used to measure management.

In addition to reviewing articles on the economics of the fishing industry, Chapter III surveys the more technical works where catch functions were estimated and the articles dealing with econometric problems inherent to this kind of study.

The theoretical model is displayed in Chapter IV. The latest developments of the neo-classical model on the fishing industry are introduced to devise a framework suitable to analyze trap fishing and hand line fishing. Perfect competition is assumed throughout the study.

A method is proposed to estimate the catch function and to conduct various statistical tests concerning the economic behavior of the fishermen, particularly to see if profit is maximized.

The synthesis of the various levels of research undertaken up to then starts with chapter V. The theoretical model and the data gathered in Puerto Rico are combined to estimate catch functions. The need to conciliate the logic of the model and the limits imposed by the data collected led to computing many regressions. 
Several measures of the same variables fore often available but due to the practical difficulties of estimating them, a priori, none could be preferred. Chapter V exposes the advantages and drawbacks for the various variables and it shows the regressions obtained when using those different measures. In some cases the low significance of the regressions $\left(R^{2}\right)$ leads to rejecting some of the possibilities. However, the quality of the various regressions is very often, quite comparable and several of them can be regarded as very satisfactory. This makes it possible to avoid a choice between those equations in the subsequent chapters some of which will be more useful according to the type of analysis conducted. Chapter $V$ only describes the catch function. Chapter VI analyzes the behavior of the fishermen in more detail. To test for differences in technical efficiency among groups of fishermen, other regressions are computed. Assuming that all the groups of fishermen have the same catch function, except for the possibility of different technical efficiencies, a dumm variable is introduced to account for this effect. When the coefficient of this variable is significantly different from zero the groups do not have the same technical efficiency. 
Tests were then conducted to see if the fishermen are price efficient, that is, if they choose the optimum combination of inputs given the set of input and output prices. This test is first conducted for all the trap fishermen as one group and for all the line fishermen as another. Later on, sub-groups are defined, using the same criteria as the ones already selected when dividing the fishermen to test for technical efficiency. The tests of price efficiency are conducted again, this time to see if there are differences in the price efficiencies of the various sub-groups.

The various findings concerning technical and price efficiencies lead, in Chapter VII, to propose some policy orientations which could be chosen to improve the profits of the fishermen. However, before making those suggestions, and in order to be able to compare the possible effects of those policies to the present situation, some time is devoted to present some of the economic performances of the fishermen. Since the chapters have analyzed their behavior, it is now possible to show the results of those practices and to compare them to what may happen if they are changed. The limitations of the comparative static framework are recalled and emphasized. Given those warnings, the direction of changes to be expected from several possible policy measures are analyzed. 
A conclusion summarizes the various results. It emphasizes the need for futher research and suggests some avenues which should be explored. 
II THE PUERTO RICAN FISHING GROUNDS AND THE AREAS SURVEYED

One of the reasons explaining the relatively low development of the Puerto Rican fisheries is the limited number of productive banks around the island.

In this chapter the Island's coast is divided into four areas which are described successively. In addition, more specific details are presented for the communities surveyed on each of the coasts.

In order to be able to generalize the results of the study to the whole Island, a survey was conducted in six municipalities chosen for their representativeness for trap or hand line fishing or both. Of those six municipalities, one, Arecibo, is situated on the North Coast; two, Aguadilla and Cabo Rojo are on the West Coast; two others, Guanica and Salinas are on the South Coast; and one, Naguabo, is on the East Coast. Before describing those municipalities it must be noted that in the municipality of Cabo Rojo, six fishing villages were surveyed, while in each of the other municipalities only one fishing community was included in the study. Differences between the six villages of Cabo Rojo suggested that important additional 
information would be obtained by studying all of them, while in each of the other municipalities the various fishing communities were quite similar.

The representativeness of the sample is suggested by the figures in Table II-1. In 1972, the fish caught in the six municipalities represented 51 percent of the total value landed in Puerto Rico. In addition, 35 percent of the fuerto Rican fishermen lived in those six areas.

The number of personal interviews conducted in each of the municipalities is shown in Table II-2. 


\section{TABLE 23 II I}

SOME CHARACTERISTICS OF THE PORTS SURVEYED AND COMPARISON WITH THE REST OF THE ISLAND.

Quantity Value Fishermen No. of No of No.of landed lbs. landed \$ Boats Traps Lines (1)

(2)

(3)

(4) (5)

(6)

\begin{tabular}{|c|c|c|c|c|c|c|}
\hline $\begin{array}{l}\text { North Coast } \\
\text { Arecibo }\end{array}$ & $\begin{array}{r}301,100 \\
42,429\end{array}$ & $\begin{array}{r}170,842 \\
30,179\end{array}$ & $\begin{array}{r}292 \\
42\end{array}$ & $\begin{array}{r}198 \\
32\end{array}$ & $\begin{array}{r}224 \\
12\end{array}$ & $\begin{array}{r}289 \\
96\end{array}$ \\
\hline $\begin{array}{l}\text { West Coast } \\
\text { Cabo Rojo } \\
\text { Aguadilla }\end{array}$ & $\begin{array}{r}1,627,799 \\
1,111,322 \\
322,145\end{array}$ & $\begin{array}{l}624,763 \\
402,090 \\
114,922\end{array}$ & $\begin{array}{r}275 \\
111 \\
69\end{array}$ & $\begin{array}{r}247 \\
93 \\
58\end{array}$ & $\begin{array}{r}3160 \\
2649 \\
102\end{array}$ & $\begin{array}{r}219 \\
44 \\
112\end{array}$ \\
\hline $\begin{array}{c}\text { South coast } \\
\text { Salinas } \\
\text { Guanica }\end{array}$ & $\begin{array}{l}431,279 \\
106,830 \\
137,201\end{array}$ & $\begin{array}{r}214,145 \\
61,965 \\
63,586\end{array}$ & $\begin{array}{r}245 \\
48 \\
47\end{array}$ & $\begin{array}{r}211 \\
38 \\
39\end{array}$ & $\begin{array}{r}2464 \\
499 \\
296\end{array}$ & $\begin{array}{r}117 \\
12 \\
18\end{array}$ \\
\hline $\begin{array}{c}\text { East Coast } \\
\text { Naguabo }\end{array}$ & $\begin{array}{c}1,321,290 \\
311,334\end{array}$ & $\begin{array}{l}564,034 \\
133,512\end{array}$ & $\begin{array}{r}156 \\
19\end{array}$ & $\begin{array}{r}141 \\
17\end{array}$ & $\begin{array}{r}2257 \\
343\end{array}$ & $\begin{array}{r}137 \\
14\end{array}$ \\
\hline Island Totals & $53,681,468$ & $1,573,784$ & 968 & 797 & 8105 & 762 \\
\hline $\begin{array}{l}\text { Total in area } \\
\text { surveyed }\end{array}$ & $2,031,261$ & 806,254 & 336 & 277 & 3901 & 296 \\
\hline of of the isla & 558 & $51 \%$ & 358 & $35 \%$ & $48 \%$ & $39 \%$ \\
\hline
\end{tabular}

Source:

Columns (1) to (5): Commonwealth of Puierto Rico. Department of Agriculture. Status of Fisheries in Puerto Rico, 1972 by Jose A. Suarez-Caabro. Agricultural and Fisheries Contributions Vol. V No. 3 Cabo Rojo, Puerto Rico p. 47.

Column (6) Estado Libre Asociado de Puerto Rico. Departmento de Agricultura Contribuciones Agropecuarias y Pesqueras. Vol II, No. 1. San Juan, Puerto Rico. p.27. 


\section{TABLE II-2}

\section{NUMBER OF INTERVIEWS PER MUNICIPALITY}

IN $1973-74$

$\begin{array}{cccc} & \text { Men not } & \text { Refused } & \text { Actual number } \\ \text { Intended } & \text { fishing } & \text { to } & \text { of } \\ \text { Sample size } & \text { anymore } & \text { answer } & \text { responses }\end{array}$

\begin{tabular}{lrrrr}
\hline Cabo Rojo & 41 & 6 & 1 & $74^{*}$ \\
Aguadilla & 8 & 1 & 1 & 8 \\
Arecibo & 11 & 2 & 5 & 6 \\
Naguabo & 9 & 4 & 9 \\
Salina & 10 & 4 & 2 & 50 \\
Guanica & 11 & 2 & 2 \\
\multicolumn{1}{c}{ Total } & 80 & 19 & \\
\hline
\end{tabular}

*In addition 17 had no sale tickets and 3 did not fish with 1 ines nor traps. 
MAP II -1

PUERTO RICO: THE MUNICIPALITIES SURVEYED

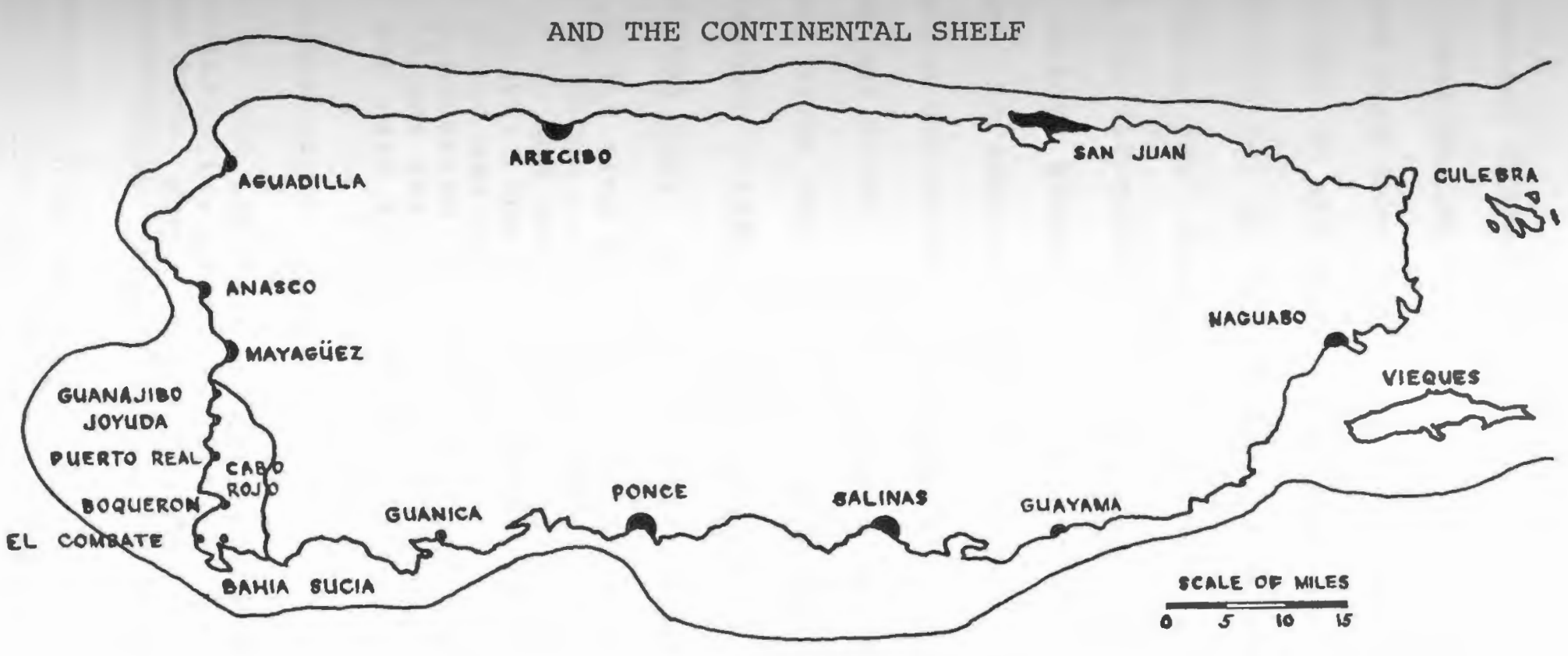

Source: Rafael Pico, Nueva Geografia de Puerto Rico (Editorial Universitaria, Universidad de Puerto Rico, 1969), p. 57 . 
I The North Coast ${ }^{1}$

I General Characteristics

Considering that the richest marine life develops in waters less than 100 fathoms deep, it is significant to note that on the North Coast the 100 fathom limit is no more than one or two miles from the shore. This explains why along that coast there is little fishing and that very few fishermen there use fish traps. Instead they use various kinds of lines, mainly hand lines and troll lines. In addition, the weather is often rough and the currents are strong making it difficult for the fishermen to go out often. Finally the coast line offers few protected areas which could be used as harbours. In many places the cliffs are high and it is often difficult to reach the sea. For all those reasons,

"This area only produced $8 \%$ of the total landings,... In $1972,301,000$ pounds of fish and shellfish were taken in the north coast. The average ex-vessel price per pound was $\$ .56$. This was the lowest fish production of the island and conversely, it was the area where the highest price was paid for fish".

Much of the information concerning the geographical characteristics of the various areas and derived from Rafael Pico, Nueval Geografia du Puerto Rico (Editorial Universitaria. Universidad de Puerto Rico, 1969). 2 ommonwealth of Puerto Rico, Department of Agriculture,
Status of Fisheries in Puerto Rico, 1972, by Jose A.
S-Cabro, Agricultural and Fisheries Contributions,
V. No. 3, Cabo Rojo, Puerto Rico, p. 37. 
This last remark can be explained to a large extent by the high proportion in the catch of fish with a high price per pound (Snappers) rather than by different market characteristics. ${ }^{3}$ Finally, it should be noted that during a large part of the year when the sea conditions do not allow fishing trips many fishermen frequently use haul seines at the mouth of the rivers.

The municipality chosen to represent the North Coast was Arecibo.

\section{Arecibo}

Most of the fishermen live in barrios outside of this large torn. As with most of the fishermen on the North Coast their most common fishing technique is hand line fishing. For this they use boats which are between 16 and 18 feet with motors between 16 and 20 horsepowers. 
II The West Coast

\section{General Characteristics}

The characteristics of part of the west coast are similar to those of the north coast. To the north of Anasco the continental shelf is also very narrow and consequently few fishermen use fish traps in that area. They use hand lines and, particularly in Aguadilla, they also have troll lines with which they catch tuna.

To the south of Mayaguez the continental shelf is wider, the 100 fathom line going as far as 17 miles from the shore. Here are found some of the riches fishing grounds in Puerto Rico. Various types of gear are used by the fishermen and some of the most successful fishermen, by Puerto Rican standards, fish off the southern part of the west coast. Puerto Real, in Cabo Rojn, is the most important fishing port of the island. One should also mention the presence of large mangrove areas in and around the bay of Boqueron (Cabo Rojo) where the fishermen catch mangrove oysters. In fact, Boqueron is the largest center for the production of oysters in Puerto Rico.

"The west coast produced 448 of the landings in 1972... A total of $1,628,000$ pounds of fish and shellfish were landed with an average ex-vessel price per pound of \$.39. This was the lowest recorded price on the island". 
There too, the composition of the catch is largely responsible for the low price of the fish. Using traps the fishermen catch a lot of low priced goatfish.

Two municipalities were surveyed on this coast, Cabo Rojo and Aguadilla.

II Cabo Rojo

Cabo Rojo is situated at the south western end of the island. Because of the wide continental shelf and the numerous bays it is a region very favorable to the fishing industry. Six communities of the fishermen are found in that municipality: Puerto Real, El Combate, Bahia Sucia, Boqueron, Joyuda, and Guanajibo: Interviews were conducted with a number of fishermen in each of those communities.

Puerto Real is the most important fishing port in Puerto Rico. Most of the boats used here are 28 to 32 feet long with inboard engines and a sail, and the majority are equipped with mechanical pot haulers. The flshermen primarily fish with traps and hand lines although a few own or use other kinds of fishing gear. With their large boats many fishermen are able to go far off shore and take advantage of the wide continental shelf. Some even fish off Mona Island which is 50 miles to the southwest of Mayaguez. In that case they often leave for a week and establish a base on the island from which they go fishing every day. 
TABLE II-3

NUMBER OF INTERVIEWS IN EACH COMMUNITY

OF CABO ROJO

\begin{tabular}{|c|c|c|c|c|c|c|}
\hline & $\begin{array}{l}\text { Intended } \\
\text { Sample } \\
\text { Size }\end{array}$ & $\begin{array}{l}\text { Men } \\
\text { not } \\
\text { fishing } \\
\text { anymore }\end{array}$ & $\begin{array}{l}\text { Men } \\
\text { without } \\
\text { sale } \\
\text { tickets }\end{array}$ & $\begin{array}{l}\text { Refused } \\
\text { to } \\
\text { answer }\end{array}$ & $\begin{array}{l}\text { Men not } \\
\text { fishing } \\
\text { with traps } \\
\text { or Iines }\end{array}$ & $\begin{array}{l}\text { Actual } \\
\text { Number } \\
\text { of } \\
\text { responses }\end{array}$ \\
\hline Puerto Real & 12 & 2 & 5 & & & 5 \\
\hline E1 Combate & 12 & 2 & 4 & & 2 & 4 \\
\hline Bahia Sucia & in & 2 & 5 & & & 3 \\
\hline Boqueron & 3 & & 2 & & 1 & \\
\hline Joyuda & 2 & & 1 & & & 1 \\
\hline Guanajibo & .2 & & & 1 & & 1 \\
\hline Total & 41 & 6 & 17 & 1 & 3 & 14 \\
\hline
\end{tabular}


In Puerto Real there are three dealers who buy the fish from the fishermen. These dealers play an important role in the economic life of the community. In addition to buying the fish, they also provide gas and ice to the fishermen and at least one of them owns several boats for which he hires captains. As part of the contract the captains fishing on the dealer's boats receive a lower price per pound for the fish caught. Although this situation is not unique to Puerto Real it is quite rare in the other fishing ports.

There are few other economic activities in Puerto Real besides fishing. There are a small number of tourists and some fishermen combine their fishing activities with providing boat rides particularly to Mona Island.

In El Combate one finds this same combination of fishing and tourism, although the latter activity is more important here than in Puerto Real. The fishermen of El Combate can be divided in two groups according to the size of their operation. Some have large and powerful boats as in Puerto Real. Those men fish mainly with traps and hand lines, and their boats are often equipped with pot haulers. The other group owns smaller boats with less powerful, outboard motors. These fishermen often used several types of gear (various types of nets in particular) besides the fish pots and hand lines. 
In El Combate, too, the fish is sold to dealers none of whom seem to have the economic power of the dealers of Puerto Real.

Bahia Sucia is situated on the southern coast but it is still in the municipality of Cabo Rojo. Fishing is the most important activity in this village. Here the boats are smaller than in Puerto Real or El Combate (12 to 16 feet). This village presents the largest diversity of gears used; every kind of net or line used in Puerto Rico can be found in Bahia Sucia. Still, trap fishing is the most common method. Since April 1973 fishing activity has been hampered by an oil spill off the coast. One of the consequences of this accident was the formation of an association of the fishermen initially for the sole purpose of representing their interests, but which is now providing other services including marketing of practically the whole catch of Bahia sucia.

Boqueron is situated between Puerto Real and El Combate. Tourism is one of the main economic resources here, but there is also some fishing, especially for mangrove oysters. Few fishermen of Boqueron use traps or lines and most do not catch anything besides oysters. Guanajibo and Joyuda are two small villages to the south of Mayaguez. Few fishermen were reported in either 
of these two places. The fishermen surveyed in Guanajibo were operating large boats as in Puerto Real and also fishing with both traps and hand lines. In Joyuda, on the contrary, most fishermen have smaller boats, much like those in Bahia Sucia and fish primarily with traps.

Some general patterns can be isolated for Cabo Rojo as a whole. There are two classes of fishermen, some with big boats, others with small boats, but whatever the size of their boats in all the villages, the fishermen favor fishing with traps. In addition, some fish with hand lines, and, most of the time, whether they own other types of gear or not, trap fishing and hand line fishing are their most important sources of landings.

II Aguadilla

Aguadilla is situated in a bay, on the west coast to the north of Mayaguez. In that area the continental shelf does not extend very far and consequently there is little trap fishing out of Aguadilla. The fishermen mainly use lines: troll lines and hand lines. Usually their boats are between 16 and 18 feet but since the waves are bigger here than in the south the bottom of the boat is curved from front to back. This type of boat, which orginated here but which is also used all along the north coast, is referred to as the "yola Aguadilla." 
The motors are often powerful for this size of boat; 20 to 25 horsepower is not uncommon. The fishermen say that they need such motors because of the type of fishing they do (troll lines) and because of the rough weather. 
III

\section{The South Coast}

I General Characteristics

Along the south coast the continental shelf is not very wide except from Guayama to Ponce. Yet, almost everywhere, it is large enough so that the fishermen can practice trap fishing along with line fishing. One of the problems facing the fishing industry along the south coast is the competition with other industries for the use of the shore line. This is particularly so around Ponce and Guanica where there are refineries and chemical plants. Besides being a potential source of pollution, these industries are responsible for much of the maritime traffic along the south coast. At times, this creates a problem for the fishermen who lose their traps because the buoy lines are cut by the merchant ships.

"In 1972, 431,000 pounds of fish and shellfish were landed (on the south coast). The average ex-vessel price per pound was $\$ .48$."

Salinas and Guanica were surveyed as representative of the South coast.

II Salinas

One could say of Salinas that it is the average fishing port of Puerto Rico. It is a small town of the southern

5 Ibid., p. 37 . 
coast situated in a bay which offers good protection to the small boats. The continental shelf is not very wide here but it is sufficient to allow trap fishing. Most fishermen have around 40 to 50 traps. The boats are usually 16 to 18 feet long.

\section{Guanica}

Guanica was the last community surveyed. Here too the fishermen use traps but in fewer numbers than in the other ports. Most of the fishermen own only 20 or 30 traps. The boats and motors too are usually smaller than in the rest of the island. This is probably related to the fact that most fishermen go fishing alone in their boats. In none of the other communities visited is this a common practice.

In one of the barrios where the fishermen live, some condominiums and summer houses are now being built. This presently provides jobs to some fishermen and is a welcomed second source of income. However, many of the fishermen interviewed resent the development of tourism in that area. They view it as an infringement of their freedom. 
IV The East Coast

\section{General Characteristics}

Finally, the east coast is, with the west coast, the most favorable for fishing. Here the continental shelf is very large (1500 square miles) and the depth is never beyond 40 fathoms. 6 The weather is usually more clement than along the other coasts and, in addition, there are numerous small bays which provide natural harbours.

Many fishermen who live on the main Island go fishing around the smaller islands of Vieques and Culebra. The fishermen of the east coast are practically the only ones using lobster pots. They also use many fish traps. This type of flshing is very well adapted to the natural conditions on this coast.

"This (region) ranks second among Puerto Rico's fisheries area. In 1972, a total of 1,321,000 pounds of fish and shellfish were landed with an average ex-vessel price of $\$ .43$ per pound. This area produced $36{ }_{7}$ percent of the total landings of Puerto Rico".

Naguabo was the municipality studied on the East Coast. II Naquabo

Naguabo was chosen to represent the east coast. It

\section{${ }^{6}$ Rafael Pico, Nueva Geografia de Puerto Rico, p. 145.}

${ }^{7}$ Commonwealth of Puerto Rico. Department of Agriculture Statur of Fisheries in Puerto Rico 1972 , by Jose A. Suarez Agricultural and Fisheries Contributions Vol. V, Cabo Rojo, Puerto Rico, p. 39. 
is one of the largest fishing centers on that side of the Island. The continental shelf extends quite far here and consequently trap fishing is the most common way of fishing. The boats are bigger (18-24 feet) and the engines more powerful (25-40 horsepower) than in most other places. The fishermen also have more traps than in many other centers: 100 to 200 traps is not uncommon.

The traps are frequently laid all the way from Naguabo to the island of Culebra which is situated 20 miles east of Naguabo. In those cases the fishermen may go lift some traps, stay in Culebra overnight, and come back the next day while lifting more traps. Despite the fact that the fishermen of that area own many traps only two of them have mechanical pot haulers.

In Naguabo one of the big problems faced by the fishermen is the loss of traps. There is a considerable marine traffic around the areas where the traps are laid and often the ropes tying the buoys to the fish pots are cut. For some fishermen the number of traps lost in 1972 was close to half the number of the traps they keep in the water. Finally, in all the communities surveyed only the ftghermen of Puerto Real and some in El Combate brought ice with them on the fishing trip. Usually these trips are not very long, and in Arecibo some fishernen fish at night. still, there is little doubt that the quality of the fish would be much improved if better care was taken of the catch. 
Table II-4 summarizes part of the information and gives some indications concerning other aspects of the fishing family firms in the different communities. A word of caution is necessary when interpreting the average number of trap fishing days or line fishing days. When this number is low it usually means that only 1 or 2 fishermen practice this method of fishing. It is less often the case that many fishermen will practice one method most of the year and the other one a few days a year.

In Table II-5 and Table II-6 the sample is divided into homogeneous subsets according to the power of the boats.

Table II-5 concerns the fishermen fishing with traps, while Table II- 6 gives the same information for those fishing with lines.

The data show that, in general, the large boats go to sea more often. Their annual revenue, from traps and lines combined, reflects this behavior. This is to be expected: the owners of large boats have to finance greater investments. This comparatively large investment is not only due to the boat and its motor but also to the fact that they fish more traps and use mechanical winches.

Another important finding is that most fishermen fish mainly with either traps or with lines. As a general rule they do not divide their time equally between both methods. 
Total number of

captains surveyed

Boats with motor $<30 \mathrm{hp}$

Boats with motor $>30 \mathrm{hp}$

Average length of the boats in $f t$.

Average power of the motor in hp

Average number of traps owned

Average number of men in the boat

Average number of trap fishing days
a year

Average number of line fishing days

a year

Net average annual

revenue from trap

Net average annual

revenue from line

Number of fishermen

using a winch
14

7

7

6

8

21.1

17.7

16.9

46.8

21.3

18.9

78.4

8.4

0

1.9

2.1

2.1

114.2

10

0

3.2

49.3

123

7933.1

356.6

0

324.1

1412.77

2066.4

Source: Data obtained by the author during a field survey 1973-1974 of 50 fishermen 
TABLE II-4 (continued)

CHARACTERISTICS OF FISHING FAMILY FIRMS IN THE AREAS SURVEYED

Naguabo

Total number of captains surveyed

Boats with motor $>30 \mathrm{hp}$

Boats with motor $<30 \mathrm{hp}$

Average length of the boats in $f t$. Average power of the motor in hp

Average number of traps owned

Average number of men in the boat

Average number of trap fishing days a year

Average number of line fishing days

a year

Net average annual
Salinas

Guanica 103

5

3

2

19.6

31.2

2.2

156

130

112

0

0.2

0.2 revenue from trap

Net average annual

revenue from line

Number of fishermen

using a winch

10553.1

0

7.1

0.4

4523.2

1548.2

Source:
Data obtained by the author during a field survey 1973-1974 of 50 fishermen 
TABLE II-5

CHARACTERISTICS OF TRAP FISHING ENTERPRISES ACCORDING TO THE POWER OF ENGINES

\begin{tabular}{|c|c|c|c|c|}
\hline$E$ & $\begin{array}{l}\text { Motor } \\
>30 \mathrm{HP}\end{array}$ & $\begin{array}{l}\text { Motor } \\
\leqslant 30 \mathrm{HP}\end{array}$ & $\begin{array}{l}\text { Motor } \\
>40 \mathrm{HP}\end{array}$ & $\begin{array}{l}\text { Motor } \\
<40 \mathrm{HP}\end{array}$ \\
\hline Total number of boats & 12 & 38 & 6 & 44 \\
\hline $\begin{array}{l}\text { Boats used for trap } \\
\text { fishing }\end{array}$ & 12 & 27 & 6 & 33 \\
\hline $\begin{array}{l}\text { Boats used for trap } \\
\text { and line fishing }\end{array}$ & 5 & 4 & 4 & 5 \\
\hline $\begin{array}{l}\text { Average length of } \\
\text { the boats (ft) }\end{array}$ & 23.5 & 16.6 & 27.8 & 17.0 \\
\hline $\begin{array}{l}\text { Average power of } \\
\text { the motor (HP) }\end{array}$ & 60.4 & 15.3 & 80.8 & 19.8 \\
\hline $\begin{array}{l}\text { Average number of } \\
\text { traps owned }\end{array}$ & 89.5 & 41.4 & 132.3 & 52.1 \\
\hline $\begin{array}{l}\text { Average number of } \\
\text { men in the boat }\end{array}$ & 2.2 & 1.6 & 2.2 & 1.7 \\
\hline $\begin{array}{l}\text { Average number of trap } \\
\text { fishing days in a year }\end{array}$ & 100.1 & 76.1 & 126.8 & 76 \\
\hline $\begin{array}{l}\text { Average number of line } \\
\text { fishing days in a year }\end{array}$ & 3.8 & 2.5 & 5.5 & 2.5 \\
\hline $\begin{array}{l}\text { Net annual revenue } \\
\text { from traps }\end{array}$ & 10,854 & 3,139 & 14,506 & 2662 \\
\hline $\begin{array}{l}\text { Net annual revenue } \\
\text { from lines }\end{array}$ & 435.8 & 54.1 & 745.7 & 67.1 \\
\hline $\begin{array}{l}\text { Number of fishermen } \\
\text { using a winch }\end{array}$ & 7 & 3 & 5 & 5 \\
\hline
\end{tabular}

Source: Field survey of 30 fishermen, 1973-74 and Department of Agriculture sale tickets for the period. 
TABLE II-6

CHARACTERISTICS OF LINE FISHING ENTERPRISES

ACCORDING TO THE POWER OF THE ENGINE

\section{Motor Motor Motor Motor}

$>30 \mathrm{HP} \leq 30 \mathrm{HP}>40 \mathrm{HP} \leq 40 \mathrm{HP}$

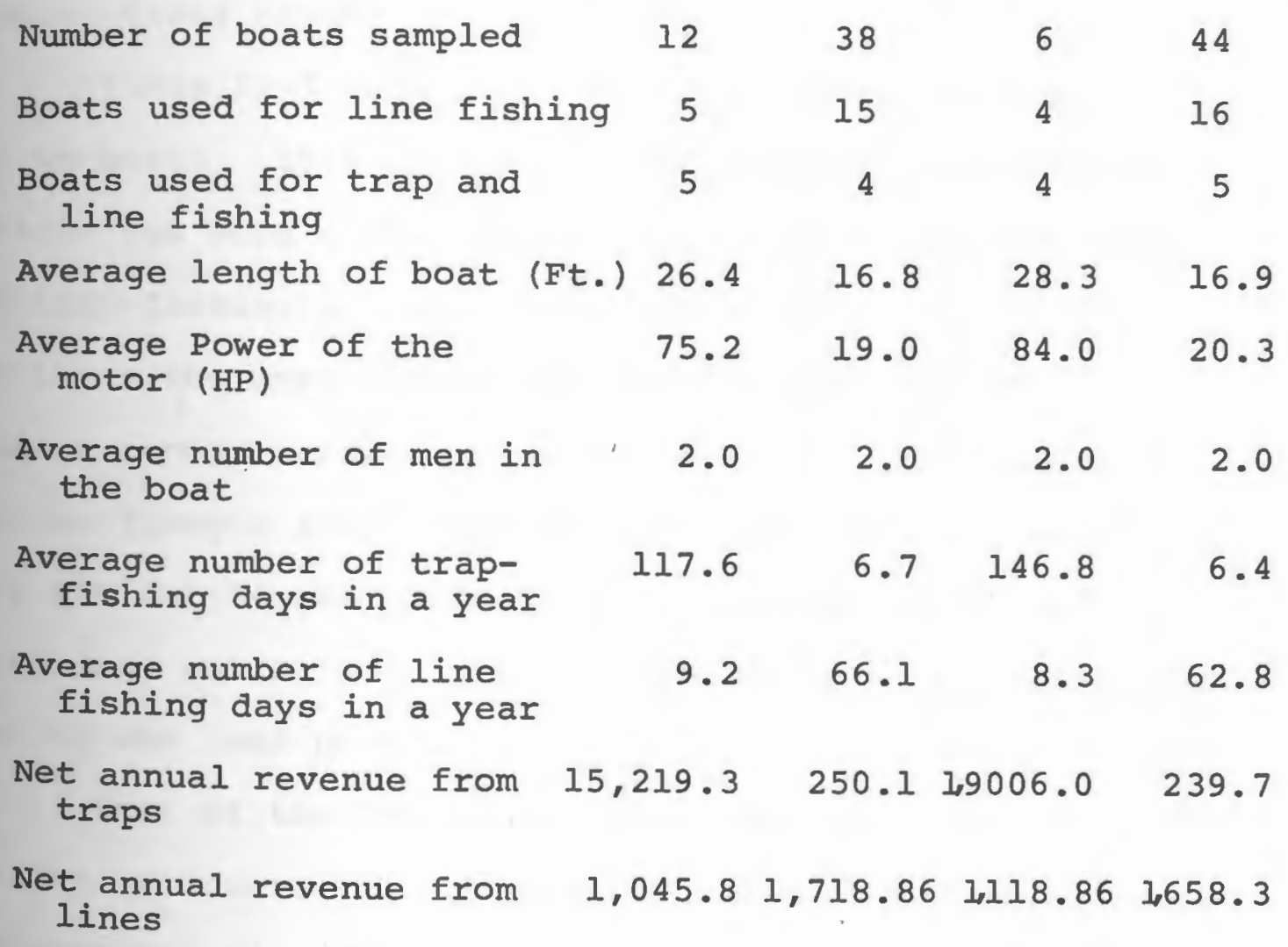

Source: Field survey of 20 fishermen, 1973-74 and Department of Agriculture sale tickets for the period. 
This may be due to the preference of the fishermen, but it also reflects the natural conditions around the ports where the fishermen live. This tends to be confirmed by the fact that all the large boats were found in areas of trap fishing (see Table II-4) where they are used for that type of fishing. In addition, larger boats are able to go to or beyond the edge of the continental shelf where most line fishing takes place.

Table II-7 shows that most of the boats have two men on board. This class of boats is also the one which goes to sea more often (122.2 days between line fishing and trap fishing). This is probably one of the reasons why it is the most successful economically with the average annual income by far the highest. The characteristics (length and power) of the boats with two men is very similar to the characteristics of the boats with three men, while the boats with one man are, on the average smaller and less powerful.

Most of the boats with three men are used for line fishing exclusively or in combination with trap fishing. On the contrary the boats with only one man are often used exclusively for trap fishing. During the interviews it appeared that many of the fishermen fishing alone seemed older than the others. Although their age was not recorded. One exception must be noted, however. It was mentioned earlier that 
CHARACTERISTICS OF FISHING ENTERPRISESACCORDING TO THE NUMBER OF MEN ON BOARD

Total Boats with Boats with Boats with sample one man two men three men on board on board on board

\begin{tabular}{|c|c|c|c|c|}
\hline Number of boats & 50 & 14 & 30 & 6 \\
\hline $\begin{array}{l}\text { Boats used for trap } \\
\text { fishing }\end{array}$ & 39 & 12 & 23 & 3 \\
\hline $\begin{array}{l}\text { Boats used for hand } \\
\text { line fishing }\end{array}$ & 20 & 3 & 13 & 4 \\
\hline $\begin{array}{l}\text { Boats used for trap and } \\
\text { hand line fishing }\end{array}$ & d 9 & 1 & 6 & 1 \\
\hline $\begin{array}{l}\text { Average length of the } \\
\text { boats (ft) }\end{array}$ & 18.3 & 16.5 & 19.03 & 19.2 \\
\hline $\begin{array}{l}\text { Average power of the } \\
\text { engine (HP) }\end{array}$ & 26.78 & 11.86 & 32.43 & 33.3 \\
\hline $\begin{array}{l}\text { Average number of } \\
\text { traps owned }\end{array}$ & 44.2 & 24.3 & 56.3 & 30.0 \\
\hline $\begin{array}{l}\text { Average number of trap } \\
\text { fishing days in a year }\end{array}$ & 87.1 & 92.8 & 93.7 & 40.9 \\
\hline $\begin{array}{l}\text { Average number of line } \\
\text { fishing days in a year }\end{array}$ & 27.7 & 10.1 & 28.5 & 64.1 \\
\hline $\begin{array}{l}\text { Annual revenue from } 48 \\
\text { traps and hand lines }\end{array}$ & 859.03 & 2918.96 & 6299.53 & 4049.19 \\
\hline $\begin{array}{l}\text { Number of boats equip- } \\
\text { ped with a winch }\end{array}$ & 11 & 4 & 7 & 0 \\
\hline
\end{tabular}

Source: Data obtained by the author during a field survey 1973-1974 of 50 fishermen 
in Guanica, many of the fishermen were alone in their boats regardless of their age.

From the present data it is not possible to deduce that one of the classes of boats is more traditional than the other. The boats with only one man have a lower annual income and go at sea less often. However, the fact than one third of those fishing with traps in that class are equipped with a winch tend to indicate that those boats are owned by fishermen who are open to technical inovations. IOnIy II boats out of the 39 fishing with traps in the whole sample have a winch). The difference between the performance of the various types of firms, particularly between those using more powerful boats and those using less powerful boats, suggest that many factors influence the catch of the fishermen.

An econometric analysis of the data based on a theoretical model of the fishing family firm will show the relative importance of the various inputs.

A priori, Table II-7 does not provide any reason to suspect that the economic behavior of the fishemen varies from one class of boats to another. 
The model of the fishing enterprise should show the costs of production as well as the returns to the firms. For the fishing industry and necessarily for the firm, the analysis must recognize the effects of fishing effort on the stock. Thus, a catch function which takes into account the effects of fishing effort on the growth of the fish population must be established. In the case of a static framework, which is what will be developed here, some notion of the biological equilibium at a given level of effort must be answered.

Various models of the fishing industry have been Peveloped which deal with various degrees of success with the special problems associated with a fish growth function which is affected by so called fishing externalities. These models all have the form of a system of equations showing the relationship between the level of the catch, the cost and the fish population growth.

After the presentation of the catch function and the cost function it will be possible to turn to more practical problems. To estimate a catch function it is necessary to specify its form as well as the variables which will be chosen to enter in the regressions. In the fishery economic 
literature, the usual form of the catch function is a cobbDouglas type production function. Dependent upon the fisheries, various independent variables have been selected to explain the level of the catch. Several surveys estimating catch functions will be examined.

When the model has been devised, and the form of the catch function as well as the variables have been chosen, a last problem remains. Since 1940 an abundant literature has been devoted to the statistical difficulties of estimating production functions. It seems to have reached a consensus in the mid-1960's. Many of the articles written on the subject will be reviewed and the present state of the agreement will be exposed. A theoretical model of the fishing industry is presented in section $I$. Studies, which have dealt with the choice of a catch function and the selection of the variables are reviewed in Section II. Finally, Section III is a discussion of the econometric questions raised by the estimation of production functions. 
The first economic model of the fishing industry was proposed by Gordon. ${ }^{1}$ It presented the economics of the fishery in the context of a comparative static analysis. This model was subsequently developed by various authors including scott ${ }^{2}$ Turvey ${ }^{3}$ and Smith. ${ }^{4}$

The model used in this study includes the latest developments proposed by those economists. It is composed of three equations:

(1) a recruitment rate function $d x / d t=f(x, m, k x)$

$\mathrm{X}$ biomass

m mesh size

$k$ number of vessels in the fishery

$\mathrm{x}$ average vessel catch

In a simpler model $\mathrm{m}$, which introduces mesh externalities; can be ignored.

${ }^{1}$. Scott Gordon, "The Economic Theory of a Common-Property Resource: The Fishery", pp. 124-142.

${ }^{2}$ Anthony scott, "The Fishery: The objectives of Sole Ownership", Journal of Political Economy, 63 (April, 1955) pp. $116-124$.

3alph Turvey, "Optimization in Fishery Regulation", American Economic Review, 54 (March, 1964), pp. 64-76.

"Vernon L. Smith, "On Models of Commercial Fishing", Jarmal of Political Economy, 77 (March/April, 1969), p 181-198. 
(2) a catch function

$$
\mathrm{x}=\mathrm{g}(\mathrm{z}, \mathrm{x}, \mathrm{k})
$$

$\mathrm{x}$ average vessel catch

$\mathrm{z}$ input vector

$\mathrm{X}$ biomass

$k$ number of vessels in the fishery

In this equation, $k$, which represents crowding externalities, can be ignored to simplify the model.
a cost function
$\mathrm{C}=\mathrm{w} \mathbf{z}$
C total cost
w vector of input prices
$z$ input vector

A question arises concerning the possibility of applying a classical model such as this one to a traditional economic activity. It was mentioned earlier that the artisan fishermen in Puerto Rico belonged for the most part to a traditional sector of the society, and, consequently, that many of their decisions were influenced by customs and common practice in the community. As a result it would not be appropriate to postulate that those fishermen are always economically rational, or, for instance, to assume that they are able to maximize their profits. However, it will be shown in the last section of this chapter, that provisions can be made to have the classical model account for 
the lack of knowledge or the distorted perception of the economic environment (prices, technical coefficients) resulting from the social constraints. 
The definition of a catch function raises questions which are often specific to the fishing industry investigated and to the species caught by that industry. However, much can be learned in reviewing earlier studies in which catch functions were estimated. Two kinds of information can be derived from the literature. One concerns the type of catch function fitted to the data; the other regards the choice of the dependent and independent variables.

Most of the production studies assume that the external diseconomies (Resource stock, crowding, mesh externalities) are negligeable. ${ }^{5}$ In only one instance does Bell

5rederick W. Bell, "The Relation of the Production Function to the Yield on Capital for the Fishing Industry," Developments and Research in Fisheries Economics, T.W. Bell and J.E. Hazelton (Dobbs Ferry, New York: recana Publications, Inc., 1967).

U.S. Department of Commerce, National oceanic and Atmospheric Administration, "Gross Section Production Functions of North Atlantic Ground Fish and Tropical Tuna Seine Fisheries". Earnest W. Carlson in Ocean Fishery hent: Discussions and Research, Ed. by A.A. Sokoloski, chnical Report 371, November, 1970 (Seattle, Washrigton, April 1973), pp. 42-56.

Bruno G. Noetzel and Virgil J. Norton, Cost and Earn-

4-the Boston Large-Trawler Fleet, Economics of Resources, 8(University of Rhode Island Experiment actorn No. 1329, Kingston, Rhode Island, 1969). 
account for resource stock externalities. ${ }^{6}$ When external diseconomies are ignored, the catch functions used are of the Cobb-Douglas type.

${ }^{6}$ Frederick W. Bell, "Technological Externalities and Common roperty Resources: An Empirical Study of the U.S. Northern Lobster Fishery". Journal of Political Economy, 80

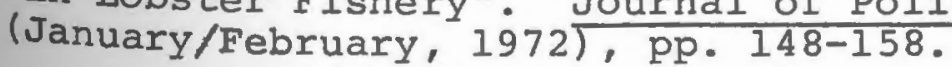


I The Dependent Variable

The variables introduced in the catch function vary according to the fishery investigated. The dependent variable is usually the value of the landings ${ }^{7}$ although sometimes the weight of the catch is preferred. ${ }^{8}$ Carlson $^{9}$ shows that when the fishermen have the choice of catching different species they "take into account expected prices, expected catch rates, and steaming time to the grounds and make decisions as to where to go and what to fish."10 In that case the value of the catch is a better measure of output (an example of such a situation is the New England trawler fleet). On the other hand, for the tropical tuna seine fisheries, the weight of the catch is a better measure of output because in the case of tropical tuna fisheries, "the species are... joint products. That is, the fishermen take as much of both species (Yellow-fin and

7Bell, "The Relation of the Production Function to the Yield on Capital for the Fishing Industry."

Bell, "Technological Externalities and Common Property Resources."

${ }^{8}$ Noetzel and Norton, Cost and Earnings in the Boston Trawler Fleet.

${ }^{9}$ Carlson, "Cross-section Production Functions."

10 Ibid., p. 47 . 
skyjack) as they can in an effort to fill their holds as quickly as possible."ll

II The Independent Variables

The independent variables always include one or more measures of capital. Physical measures are chosen more frequently than monetary ones. Gross tonnage of the vessel and horsepower of the main engine are the most commonly chosen.

In many studies some monetary value of the fixed asset is used as an independent variable. This has the advantage that it allows for a more immediate estimate of the return on capital. The problem then arises of choosing among various measures of the value of capital. This difficulty is not specific to the fishing industry and the literature dealing with that question is abundant. Bell uses historical book value of assets but he notes that this method, "presents many difficulties. First each balance sheet reflects different prices depending on the date of acquisition of the assets. Most fishing vessels are sold often during their lifetimes and (historical book values) actually reflect the last purchase or resale price."12 For those reasons he also

${ }^{1}$ Carlson, "Cross-section Production Function." p. 49. 12 Bell, "The Relation of the Production Function to its Yield on Capital for the Fishing Industry", p. 91 . 
suggests a method of adjusting historical prices to constant dollars. This approach is questionable since it does not take into account the life of the boat. Usually, some measure of depreciation is preferred to a mesure of total assets. In estimating agricultural production functions.

The historical tendency has been... to measure the input of durable assets by the actual maintenance and depreciation costs associated with their use rather than py their capital value on an inventory basis.

If this measure of capital is selected some difficulties remain, however, since there are various alternatives to compute depreciation costs. "A practicable measure of the true cost of using a machine for a particular purpose is the return from the next most profitable use of replacement-cost depreciation, whichever is higher". 14

Opting for replacement-cost hardly solves the problem, for "Reproduction cost is an imaginary cost" 15 and one has to decide upon a definition of replacement cost. For instance, should it be "the current cost of a new

13 Earl O. Heady and John L. Dillon, Agricultural Production Function (Ames, Iowa: Iowa State University Press, 1961), p. 221 . 14 H. Speight, Economics and Industrial Efficiency (London: MacMilian \& Co. Itd., 1962), p. 184. 15 Charles F. Phillips Jr., The Economics of Regulation (Fomewood, Illinois: Richard D. Irwin, 1969), p. 235. 
vessel to replace a similar vessel in the fleet"16 or the current cost of a similar used vessel?

Given the difficulties discussed above, present market value of the asset appears to be especially useful given its practical advantage of being relatively easily determined. In Holmsen's study of the small trawler fleet.

The owner of the vessel was asked what he considered the market value. This figure was checked with the last appraisal of the vessel by an independent surveyor either for a bank or for an insurance firm. The rate of depreciation was determined by asking the owner how long the thought he would keep the vessel and, assuming a constant price level, what he thought the different components then would be worth. (sales value or salvage value).

This approach is particularly useful in the case of

an artisanal fishery where some of the boats are built by the fishermen themselves.

Another problem arising when estimating catch functions is the measurement of management. This has received little attention in fisheries studies. Bell 18 and Noetzel and

\section{${ }^{16}$ Crutchfield and Zellner, Economic Aspects of the Pacific} libut Fishery, p. 78 .

17.

Andreas A. Holmsen, "The Economics of the Small Trawler Fleet, "Recent Developments and Research in Fisheries Economics, Ed. by F.W. Bell and J.E. Hazleton (Dobbs ferry, New York: Oceana Publications Inc., 1967) p. 126. 18

Bell, "The Relation of the Production Function to the Yield on Capital for the Fishing Industry." 
Norton ${ }^{19}$ differenciate between various classes of boats by introducing dummy variables for different sizes. This method is similar to the one used to test for differences of technical efficiency among groups of producers. Although Bell finds a significant difference between the economic performance of the small boats and of the big boats $^{20}$ he believes that the data available are not sufficient to decide what causes this disparity.

More numerous examples of attempts at measuring panagement can be found in farm management studies. In most of this work the methodology used is directly linked to the mean chosen to estimate the production functions. For that reason it will be treated in the next section which deals with estimation of the catch function.

19

Noetzel and Norton, Costs and Earnings in the Boston Trawler Fleet.

${ }^{20}$ Bell, "The Relation of the Production to the Yield on Capital for the Fishing Industry," p. 114. 
Cobb-Douglas functions are those most frequently used to describe catch functions. This section will consider the problems associated with estimating a function of that form. Then some remarks will follow dealing with the actual measurement of diverse types of managerial abilities.

I Estimating a Cobb-Douglas Production Function. Marschak and Andrews are among the first economists to have given much attention to the difficulties of properly estimating production functions. 21 They show that "the economist is confronted not only with a single equation, but'with a system of (...) equations none of which he can ignore." 22

This system of equations contains a "production equation." In a two-input case it will have the form:

$$
\text { (3-1) } \quad x_{0}=\phi\left(x_{1}, x_{2}\right)
$$

where $x_{0}$ is the level of output and $x_{1}$ and $x_{2}$ are the inputs. It also includes two "marginal-productivity equations":

21. Simultaneob Marschak and William H. Andrews Jr., "Random pp. 143-205

22 Ibid., p. 144 . 


$$
\text { (3-2) } \partial \mathrm{x}_{0} / \partial \mathrm{x}_{1}=\mathrm{p}_{1} / \mathrm{p}_{0} \partial \mathrm{x}_{0} / \partial \mathrm{x}_{2}=\mathrm{p}_{2} / \mathrm{p}_{0}
$$

where $\mathrm{p}_{0}, \mathrm{P}_{1}$, and $\mathrm{p}_{2}$ are respectively the prices of $\mathrm{x}_{0}$ ' $x_{1}$, and $x_{2}$. Those equations are further specified by introducing the concepts of "technical efficiency" and "economic efficiency".

The production function will change, even within the same industry, from firm to firm and from year to year, depending on the technical knowledge, the will, the effort and luck of a given entrepreneur: these factors can be summarized as "technical efficiency".

Assuming that the production function is the same for all firms except for the "technical efficiency" represented by $\varepsilon_{f}(3-1)$ will become:

$$
x_{0}=\phi\left(x_{1}, x_{2}, \varepsilon_{f}\right)
$$

Then "economic efficiency" is defined by Marschak and Andrews as "The ability or willingness to choose, or luck in choosing the most profitable combination of resources". 24

However, in the more recent literature what was called "economic efficiency" by Marschak and Andrews is now referred to as "Price efficiency". "A firm is price efficient if it maximizes profits i.e., it equates the value

Ibid., p. 145.

24

Ibid., p. 145 . 
of the marginal product of each variable input to its price". 25

on the other hand, in the latest literature, the concept of "economic efficiency" is used to refer to the combination of technical and price efficiency. This terminology will be used throughout the remainder of this study. Economic efficiency accounts "for firms that produce different quantities of output from a given set of measure inputs of production. This is the component of differences in echnical efficiency.... It also takes into account that different firms succeed to varying degrees in maximizing profits, i.e., in equating the value of the marginal product of each variable factor of production to its price. This is the component of price efficiency". 26

Introducing price efficiency $\mu_{f}$ and $\theta_{f}$ into the "marginal-productivity equation, "equations (3-2) becomes:

$$
(3-4) \partial x_{0} / \partial x_{1}=\lambda\left(\dot{\mu}_{f}, p_{1} / p_{0}\right), \partial x_{0} / \partial x_{2}=k\left(\theta_{f}, p_{2} / p_{0}\right)
$$

The next step is to find a proper method to estimate these equations and to express the model accordingly.

25

Lawrence J. Lau and Pan A. Yotopoulos, "A Test of Relative Efficiency and Application to Indian Agriculture", American Economic Review, 61 (March, 1971), p. 95.

26

Ibid., p. 95. 
If we desire to estimate the value of $x_{0}$ if $x_{1}$ and $x_{2}$ should be determined not by that set of random causes which existed in the past but by deliberate action then we have to estimate the coefficients in the equation $(3-3) .27$

In fact, since "each of the three variables $x_{0}, x_{1}$, $x_{2}$ changes as the result of variations in the random features $\varepsilon, \mu, \theta$, from firm to firm." 28 one has to estimate simultaneously the system of equations (3-3) (3-4) since least squares estimates of equation $(3-3)$ alone will be biased and inconsistent.

In the case of a production function of the cobbDouglas type:

$$
x_{0}=A x_{1}^{\alpha_{1}} \quad x_{2}^{\alpha_{2}} u_{0}
$$

$u_{0}=$ random variable with mean unity.

Under perfect competition (this assumption will be maintained throughout this chapter) the system of equations to be estimated can be written:

$$
\begin{aligned}
(3-6) & x_{0 i}-\alpha_{1} x_{1 i} & -\alpha_{2} x_{2 i} & =\lambda_{0}+v_{0 i} \\
(3-7) & & x_{\circ i}-x_{1 i} & =\lambda_{1}+v_{1 i} \\
(3-8) & & x_{0 i}-x_{2 i} & =\lambda_{2}+v_{2 i}
\end{aligned}
$$

${ }^{27}$ Marschak and Andrews, "Random Simultaneous Equations and the Theory of Production," p. 151.

28

Ibid., p.150. 
where $x_{j i}=\log x_{j i} \quad J=0,1,2$

$\lambda_{0}=\log \mathrm{A}$

$\mathrm{v}_{o i}, \mathrm{v}_{1 i}, \mathrm{~V}_{2 i}$ are random variables

$\mathrm{E}\left(\mathrm{V}_{\mathrm{ki}}\right)=0 \quad \mathrm{k}=0,1,2$

$E\left(V_{O i}, V_{I i}\right)$ is independent of $i$

$\left\{\mathrm{E}\left(\mathrm{V}_{\mathrm{ki}}\right)\right\}^{2}=\sigma_{\mathrm{k}}^{2}$ for all firms

$\lambda_{1}=\log \left(p_{1} / p_{0} \alpha_{1}\right)$

$\lambda_{2}=\log \left(p_{2} / p_{0} \alpha_{2}\right)$

$\mathrm{p}_{0}, \mathrm{p}_{1}, \mathrm{p}_{2}$ are the respective prices of $\mathrm{x}_{1}, \mathrm{x}_{2}, \mathrm{x}_{3}$

$\mathrm{V}_{\text {oi }}$ can be called "technical disturbance" and $\mathrm{V}_{1 i}$

and $\mathrm{v}_{2 i}$ "price disturbance".

Little was added to Marschak and Andrews' model until Hoch, 29 concerned with the problems stemming from the estimation of the system of equations, added a new element to the theoretical framework. In the early model, $E\left(V_{1 i}\right)=$ $E\left(V_{2 i}\right)=0$, and $V_{1 i}$ and $V_{2 i}$ are measures of the price efficiency ( or inefficiency). "In this approach, however, the 'average' firm is defined to be the optimal firm". 30

${ }^{29}$ Irving Hoch, "Simultaneous Equation Bias in the Contest of the Cobb-Douglas Production", Econometrica, 26 (October, 1958), pp. 566-578.

30

Ibid., p. 567. 
Hoch proposes to keep the properties of $V_{1 i}$ and $V_{2 i}$ unchanged but to introduce a term $R_{j}$ such that in equations $(3-7)$ and $(3-8) \lambda_{j}$ becomes:

$$
\lambda_{j}=\log \left(p_{j} R_{j} / p_{0} \alpha_{j}\right)
$$

In equation (3-9) $R_{j}$ represents the effects of disturbances which affect all the firms and prevent them from maximizing their profit.

"In this formulation, $R_{j}$ can of course vary among firms: but, for a sample of firms, the investigator would be interested in testing whether the average $R_{j}$ is equal to one." 31

This precision added to the accuracy of the traditional model. Yet a problem remained concerning the meaning of $\mathrm{V}_{o i}$. Walters notes, that

Marschak and Andrews interpret the disturbance as analogous to an experimental error. But there is more to it than that. The variation in output of a particular firm from year to year may be due to exogenous random causes (such as the weather) but the differences between one firm and another due to the 'ability' of the entrepreneur will be constant over time for a particular firm. ${ }^{3}$

31

Ibid., p. 568 .

${ }^{32}$ A.A. Walters, "Production and Cost Functions: An Econometric Survey," Econometrica, 31 (January/April, 1963), p. 14 . 
One may add that even for cross-section data the variation in output between different firms may be partly due to "exogenous random causes" such as different quality inputs. If this is so one can write

$$
(3-10)
$$

$$
\mathrm{v}_{\mathrm{oi}}=\mathrm{v}_{\mathrm{oi}}{ }^{+}+\mathrm{v}_{\mathrm{oi}}{ }^{*}
$$

Where $\mathrm{v}_{\text {oi }}$ measures the technical efficiency while $\mathrm{v}_{0 i}{ }^{*}$ is a stochastic disturbance representing the "exogenous random causes". 33 But now output is a function of $v_{0 i}{ }^{*}$. Consequently,

...the production function and profit function for the individual entrepreneur are stochastic...Thus, the rationale for assuming deterministic profit maximixation, as is done in the traditional approach, is at variance with the above interpretation of $\mathrm{V}_{o i}$; an interpretation which appears to be consistent with that in the literature. 34

Recognizing this conflict, Zellner, Kmenta, and Dreze propose a new model where the production function of each firm is stochastic:

$$
\text { (3-11) } \quad x_{0}=\operatorname{Ax}_{1}^{a_{1}} x_{2}^{\alpha_{2}} e^{u_{0 i}}
$$

...Where $u_{0}$ is a random disturbance representing factors su\&h as weather, unpredictable variations in machine or labor performance and so on. Whenever the production process is not instantaneous, the effect of the disturbance on output cannot be known until after the preselected quantities of inputs have been employed in production. 35

33

A. Zellner, J. Kmenta, and J. Dreze, "Specification and Estimation of Cobb-Douglas Production Function Models", onometrica, 34 (October, 1966), p. 786.

34

Ibid. , p. 786 .

35

Ibid., p. 787 . 
It is assumed that the entrepreneur attempts to maximize his expected profit and that the prices are known with certainty.

Expected profit can be expressed as:

$$
\text { (3-12) } \quad E(\pi)=p_{0} E\left(x_{0}\right)-p_{1} x_{1}-p_{2} x_{2}
$$

if $u_{0}$ is normally distributed, $N\left(\bar{u}_{0}, \sigma_{00}\right)$

$$
\text { (3-13) } \mathrm{E}\left(\mathrm{x}_{0}\right)=\mathrm{Ax}_{1}{ }^{\alpha} \mathrm{I}_{2}{ }^{\alpha} \mathrm{e} \mathrm{e}^{\frac{1}{2}\left(\sigma_{00}\right)}
$$

Even if the prices are perfectly known, the entrepreneur may not use the optimum combination of inputs. The production model becomes

$$
\begin{aligned}
(3-14) x_{0 i}-\alpha_{1} x_{1 i}-\alpha_{2} x_{2 i} & =\alpha_{0}+u_{0 i} \\
(3-15) & x_{0 i}-x_{1 i}=k_{1}^{\prime}+u_{0 i}+u_{1 i} \\
(3-16) & x_{0 i}-x_{2 i}=k^{\prime}{ }_{2}+u_{0 i}+u_{2 i}
\end{aligned}
$$

with $k_{j}^{\prime}=\log \left(p_{j} R_{j} / p_{0} \alpha_{j}\right)-\frac{1}{2} \sigma o 0$

Putting the model in reduced form:

$$
\begin{aligned}
& \text { (3-17) } x_{\circ i}=\left\{\alpha_{0}-\alpha_{1} k_{1}^{\prime}-\alpha_{2} k_{2}^{\prime}+\left(1-\alpha_{1}-\alpha_{2}\right) u_{0 i}-\alpha_{1} u_{1 i}-\alpha_{2} u_{2 i}\right\} / \\
& \left(1-\alpha_{1}-\alpha_{2}\right) \\
& (3-18) x_{1 i}=\left\{\alpha_{0}+\left(\alpha_{2}-1\right) k_{1}^{\prime}-\alpha_{2} k_{2}^{\prime}+\left(\alpha_{2}-1\right) u_{\circ i}-\alpha_{1} u_{2 i}\right\} / \\
& \left(1-\alpha_{1}-\alpha_{2}\right)
\end{aligned}
$$




$$
\begin{aligned}
(3-19) x_{21}= & \left\{\alpha_{0}+\left(\alpha_{1}-1\right) k_{2}^{\prime}-\alpha_{1} k_{1}+\left(\alpha_{1}-1\right) u_{2 i}-\alpha_{1} i_{1 i}\right\} / \\
& \left(1-\alpha_{1}-\alpha_{2}\right)
\end{aligned}
$$

It appears that $x_{1 i}$ and $x_{2 i}$ are independent of $u_{0 i}$. This has important practical consequences,

Clearly in the new model with the assumptions that $E\left(u_{o i}, u_{1 i}\right)=E\left(u_{o i}, u_{2 i}\right)=0$, simple least squares estimators are consistent; under normality, or with tically independent of $u_{o i}$, they are also unbiased. 36

This is useful result since it is now possible to obtain estimates of the production function using single least squares estimators of the logarithm of the production function.

Marschak and Andrews' model was criticized, however, because it did not allow for the possible existence of a random element in the variable $v_{0}\left(V_{0}\right.$ was a measure of (kechnical efficiency). The opposite criticism can be directed to the new model for not allowing the possibility of a variable accounting for managerial ability in the term $u_{o i}$.

In practice, however, many economists use single least squares to estimate the logarithmic form of the production function. At the same time they interpret $u_{o i}$ as measuring both exogenous random causes and the technical ability of the entrepreneur. In a study of Indian agriculture Lau and 
and Yotopoulos write

Here we assume that the error in the profits is due to climatic variation,..., imperfect knowledge of the technical efficiency parameter of the farm and differences in technical efficiency among farms within the same size class. 37

Yet they add

Hence one can estimate the natural logarithms of the profit function alone with the least squares estimator which in this case turns out to be minimum variance, linear and unbiased. 38

Despite these difficulties in interpreting the disturbance term, in empirical studies, single equation least squares is

... quite the most popular method of estimating the parameters of the Cobb-Douglas function... The attractive properties of the least squares single equation method are the simplicity of computations, the small standard errors of the coefficients and the high level efficiency in predecting output for given inputs. 39

All the studies of catch function mentioned earlier used that method of estimation. Many instances of that practice can also be found in agricultural economics. 40

${ }^{36}$ Ibid. , p. 789.

${ }^{37}$ Lau and Yotopoulos, "A Tests of Relative Efficiency;" p. 104 .

38

Ibid., pp. 104-105.

39

Walters, "Production and Cost Function," pp. 18-19.

40. Heady and Dillon, Agricultural Production Functions. 
In most cases estimating the production function is but one step of the analysis. Being able to comment on the economic efficiency of the firms or of several groups of firms is just as important for the researcher.

II Measuring Economic Efficiency.

Considering the system of equation (3-6), (3-7), and (3-8) where, now

$$
\begin{aligned}
& (3-20) \lambda_{j}=\log p_{j}+\log R_{j}-\log p_{\circ}-\log \alpha_{j} \\
& (3-21) x_{0 i}-\alpha_{1} x_{1 i}-\alpha_{2} x_{2 i}=\lambda_{0}+v_{\circ i} \\
& (3-22) x_{o i}-x_{1 i}=\log p_{1}+\log R_{1}-\log p_{\circ}-\log \alpha_{1}+v_{2 i} \\
& (3-23) x_{0 i}-x_{2 i}=\log p_{2}+\log R_{2}-\log p_{\circ}-\log \alpha_{1}+v_{2 i}
\end{aligned}
$$

From equation (3-21) it appears immediately that $\mathrm{V}_{\text {oi }}$ cannot be estimated alone and that only the quantity $\mathrm{V}_{0 i^{+}}$ $\lambda_{0}$ can be computed. Consequently, it is impossible to define a perfectly technically efficient firm. Nevertheless, if one distinguishes two groups of firms with the same production function, it is possible to compare the technical efficiency of the two groups by introducing a dummy variable $S$ taking the value 1 for one group, 0 for the other, such that

$$
x_{0}-\alpha_{1} x_{1 i}-\alpha_{2} x_{2 i}=\lambda_{0}+v_{o i}+\delta s
$$

and then test for $\delta=0$. If $\delta=0$ no group of firms is significantly more or less technically efficient than the other. 
To conduct tests on price efficiency note that equations $(3-20)$ and $(3-23)$ can be written:

$$
\begin{aligned}
(3-24) x_{o i} & +\log p_{o i}-x_{j i}-\log p_{j}=\log R_{j}-\log \alpha_{j}+v_{j i} \\
\text { posing: } y_{o i} & =x_{o i}+\log p_{o} \\
y_{j i} & =x_{j i}+\log p_{j}
\end{aligned}
$$

where $y_{o i}$ is the logarithm of the total revenue while $y_{j i}$ is the logarithm of the amount of money spent on input j.

$$
\text { (3-25) } y_{o i}-y_{j i}=\log R_{j}-\log \alpha_{j}+v_{j i}
$$

Two kinds of tests are possible. Taking the averages $\bar{y}_{o i}$ and $\bar{y}_{j i}$ from all firms $i=1 \ldots, n$. one can tests if $\bar{y}_{0 i}-\bar{y}_{j i}$ is significantly different from - log $\alpha_{j}$, which is equivalent to testing for $\log R_{j}=0$ or $R_{j}=1$ since $E\left(V_{j i}\right)=0$ by definition.

An alternative method of computation yields the same results. Instead of using the logarithms of the total revenue and of the various outlays, the same test can be conducted taking the geometric means of the total revenue and the various outlays.

Consider the anti-logarithm of equation (3-25)

$$
\begin{aligned}
& (3-26) \frac{y_{o i}}{y_{j i}}=\frac{R_{j}}{\alpha_{j}} e^{v_{j i}} \\
& \text { where } y_{o i}=\log y_{o i} \text { and } y_{j i}=\log y_{j i}
\end{aligned}
$$


For a sample of $n$ firms $E\left(e^{V_{j i}}\right)=1$ since $E\left(V_{j i}\right)=0$. The maintained hypothesis is then:
$(3-27)$
$H_{0}: \prod_{i=1}^{n}\left(Y_{O l} / Y_{j i}\right)$
$1 / n$
$=1 / \alpha_{j}$

which is the same as testing for

(3-28) $\quad R_{j}=1$

If $\mathrm{H}_{\mathrm{O}}$ is rejected the conclusion is that "firms in the sample (...) exhibit systematic errors, perhaps as a result of institutional or other constraints, with respect to satisfying the first order conditions". 41 This kind of test has often been performed on agricultural production functions. 42

Using either equation (3-25) or equation(3-26) another kind of test can also be conducted.

Since $R_{j}$ tends to be the same for all firms, instead of taking the geometric means $\left(_{i=1}^{n} x_{0 i}\right)^{1 / n}$ and $\left.\prod_{i=1}^{n} x_{j i}\right)^{1 / n}$ for the whole sample, one can divide the sample into classes and compute the geometric means for the firms in each class.

If the sample is divided into two groups containing respectively s and $\mathrm{n}-\mathrm{s}$ firms the maintained hypothesis will be:

${ }^{41}$ Zellner, Kmenta, and Dreze, "Specification and Estimation of the Cobb-Douglas Production Function Models", p. 785. 42 Heady and Dillon, Agricultural Production Functions, p. 570 and ff. 


$$
(3-29) H_{0}: \prod_{i=I}^{s}\left(Y_{O i} / Y_{j i}\right)^{1 / s}=\prod_{i-s+I}^{n}\left(Y_{O i} / Y_{j i}\right)^{1 / n-s}
$$

which is equivalent to testing

$$
\begin{array}{llll}
3-30 & \frac{1}{s} \sum_{i=1} & v_{j i}=\frac{1}{n-s} & \sum_{i=S+1} \\
& v_{j i}
\end{array}
$$

If $\mathrm{H}_{\mathrm{O}}$ is not rejected the two groups of firms are as price efficient (or as price-inefficient). If $H_{0}$ is rejected one group is more price efficient than the other. Finally, one remark concerning the hypothesis of equation (3-26) should be added. If one assumes that $R_{j}$ is always equal to unity then hypothesis $\mathrm{H}_{\mathrm{O}}$ is always true and equation (3-26) provides another method to compute the coefficients of the production function. This is referred to as the factor shares method. Despite its obvious simplicity it has not been used frequently.

The reason for this neglect was probably the desire of early authors to test their estimates of the production function against the known facts about the distribution of income among factors of production. ${ }^{43}$

As mentioned earlier, the classical model, with its assumption of maximized profit, was not adequate to represent the true economic behavior a traditional economic activity. But the introduction of the concept of price efficiency eliminates this objection and it is now possible to conceive a theoretical model, based on the classical approach which will apply to trap and hand line fishing in Puerto Rico.

"Walters, "Production and cost Function", p. 21 


\section{DEFINITION OF THE CATCH FUNCTION}

AND THE TESTS OF EFFICIENCY:

A THEORETICAL APPROACH

In this chapter a model is developed to represent the fishing operations with traps and with lines as well as the costs associated with these activities. The prices of the output and of the input will be assumed constant. In the case of the output the prices recorded by the Puerto Rican Department of Agriculture show very little change over the months and sometimes over the years! As for the inputs such as motors, winches, chicken wire, lines etc., they are sold by the Department of Agriculture and their prices are also quite stable.

The catch functions are defined in Section I and many of the characteristics of the classical models introduced. Next the catch functions are expressed in an econometric form and some simplifications introduced; in section III the concepts of technical and price efficiencies are introduced in the model and the difficulties arising from the designing of statistical tests for the various efficiencies

${ }^{1}$ Commonwealth of Puerto Rico, Department of Agriculture, Status of Fisheries in Puerto Rico, 1972 by Jose A. Suarez bro, Agricultural and Fisheries Contribution, Vol. V, vo. 3, Puerto Rico, p. 48. 
discussed. Finally, in section IV a practical problem dealing with the imputation of some fixed costs among several activities will be examined. 
I Definition of the Catch Functions.

Let $x_{T o i}$ be the annual catch of firm $i$ from traps $i=1 \ldots m$

Let $x_{\text {Loi }}$ be the annual catch of firm i from hand lines $i=m-s \ldots n$

In this notation, $m$ firms practice trap fishing, n-m+s firms practice hand line fishing and s firms practice both.

The catch functions can be written:

$$
\begin{aligned}
& \text { (4-1) } \mathrm{x}_{\mathrm{TOi}}=\mathrm{K}_{\mathrm{T}} \mathrm{M}_{\mathrm{T}} \overline{\mathrm{N}} \underset{\mathrm{q}=1}{\mathrm{Q}} \mathrm{x}_{\mathrm{Tq} i}^{\alpha \mathrm{q}} \\
& \text { (4-2) } x_{L O i}=K_{L} M_{L} \quad \bar{N} \prod_{q=1}^{Q} x_{L q i}{ }^{\beta} q \\
& \mathrm{x}_{\text {Toi }}=\text { annual catch from traps } \\
& \mathrm{x}_{\text {Loi }}=\text { annual catch from hand lines } \\
& \mathrm{K}_{\mathrm{T}} \text { and } \mathrm{K}_{\mathrm{L}} \text { are constant terms } \\
& M_{T} \text { and } M_{L} \text { represent crowding externalities } \\
& \text { and mesh externalities }
\end{aligned}
$$

$\prod_{\mathrm{q}=1}^{Q} \mathrm{x}_{\mathrm{Tq} i}$ and $\prod_{\mathrm{q}=1}^{\mathrm{Q}} \mathrm{x}_{\mathrm{Lq} i}$ are input vectors representing capital, labor and management used by the firm when fishing, respectively, with trap and hand lines.

$\bar{N}$ is the fish population. 
since the model is developed in the framework of comparative statics it is assumed that the fish populations is in equilibrium at $\bar{N}$.

$M_{T}$ and $M_{L}$ measure the effects of the crowding externalities and of the mesh externalities upon the catch from traps and the catch from lines. The crowding factor may be due to the number of boats or to the number of traps on the same fishing grounds which force the fishermen to be more careful or to spend more gasoline to navigate in those areas. The mesh size used to build the traps affects the population of fish caught by lines. It is probable that in reality this effect is aifferent upon the two populations. Yet in both cases the mechanism is the same with the bigger mesh size releasing the bigger fish which can keep participating in the population reproduction process.

The difficulty of assessing the value of $M_{T}$ and $M_{L}$ is obvious but in a study of the fishing industry at a given point in time they are fixed. When estimating the catch Gunctions their value will be embodied in a constant term appearing in front of the equation. 2

The equilibrium population $\overline{\mathrm{N}}$ depends upon some natural factors as well as on the fishing pressure. If no fishing takes place, the fish populations's 2E.C. Pielou, An Introduction to Mathematical Ecology,
Wiley Interscience (New York, 1969). 
growth rate is given by the Verhulst-Pearl equation. 2

$$
(4-3) \mathrm{dN} / \mathrm{dt}=\mathrm{N}(\mathrm{a}-\mathrm{bN})
$$

where dN/dt is the growth rate of the fish population over time

$\mathrm{N}$ is the size of the population at a moment in time

$a$ is the rate of natural increase

$$
a=\phi-\mu
$$

$\phi \quad$ birth rate of each individual

$\mu$ death rate of each individual

$a / b=N^{*}$ is the maximum size that the population can reach. Equation $(4-3)$ can also be written

$$
(4-4) \quad d N / d t=b N(N * N)
$$

If the fishery is exploited it becomes necessary to account for man's effect on the resource. The growth rate of the fish population is then:

$(4-5) d \mathrm{~N} / \mathrm{dt}=\mathrm{bN}\left(\mathrm{N}^{*}-\mathrm{N}\right)-\mathrm{FN}$

where $F N$ is the catch rate and $F$ is the fishing mortality coefficient.

In a steady-state situation $\mathrm{dN} / \mathrm{dt}=0$, which means that there is no change in the level of the population over time.

$$
(4-6) b N\left(N^{*}-N\right)-F N=0
$$

If such an equilibrium is reached, equation (4-6) is valid over any period of time provided that the rates bN and FN correspond to that same period of time.

\footnotetext{
${ }^{2}$ E. C. Pielou, An Introduction to Mathematical Ecology, wiley Interscience (New York, 1969).
} 
If a period of one year is chosen, FN is the annual catch.

In the present study, if it is assumed:

1) that the population is homogeneous and therefore that interspecies relationships can be ignored,

2) that the catch affects the population in the same fashion, whatever the fishing method used, then FN can be divided in three elements

$$
\begin{aligned}
& \sum_{i} x_{\text {Toi }}=\text { total annual catch from traps } \\
& \sum_{i} x_{\text {Loi }}=\text { total annual catch from hand lines } \\
& \sum_{i} z_{i}=\text { total annual catch from all other methods. }
\end{aligned}
$$

Combining equations $(4-1),(4-2)$ and $(4-6)$ the growth rate of the fish population is now

$$
\begin{aligned}
& (4-7) b \bar{N}\left(N^{*}-\bar{N}\right)-\sum_{i}\left(K_{T_{T} M_{T}} \bar{N}\right) \underset{q=1}{Q} x_{T q i}^{\alpha}-\sum_{i}{ }_{T}^{q}\left(K_{L} M_{L} \bar{N} \underset{q=1}{Q} x_{L q i}{ }^{\beta} q\right. \\
& -\sum_{i} z_{i}=0
\end{aligned}
$$

Dividing by $\overline{\mathrm{N}}$, with $\overline{\mathrm{N}} \neq 0$

$$
\begin{aligned}
& (4-8) b\left(N^{*}-\bar{N}\right)-\sum_{i}\left(K_{T} M_{T} \underset{q=1}{Q} \prod_{T q i} x_{i}^{\alpha}\right)-\sum_{i}\left(K_{L} M_{L} \bar{N} \underset{q=1}{Q}{ }_{L q i}^{\beta} x_{L q}^{\beta}\right) \\
& -F_{A}=0
\end{aligned}
$$

where $\mathrm{F}_{\mathrm{A}}$ is the fishing mortality coefficient from other fishing methods.

Equation (4-8) expresses the biological constraint to which the industry is subject when maximizing profit. 
From equation $(4-8)$ it is possible to deduce:

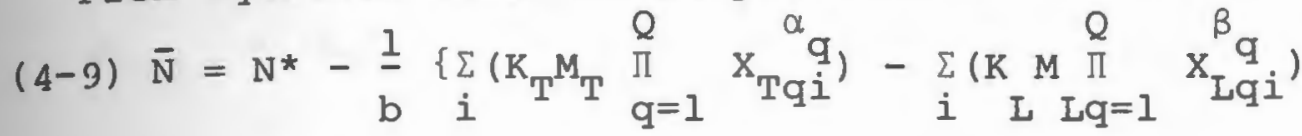
$-F_{A\}}$

Replacing $\bar{N}$ in equations $(4-1)$ and $(4-2)$ by its value from equation (4-9) the catch functions can be written:

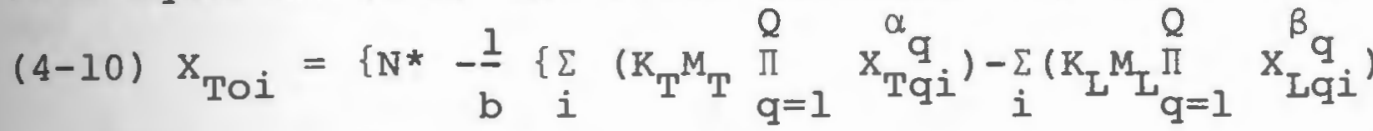

$$
\begin{aligned}
& \left.\left.-\mathrm{F}_{\mathrm{A}}\right\}\right\} \mathrm{K}_{\mathrm{T}^{\mathrm{M}} \mathrm{T}} \stackrel{\mathrm{Q}}{\prod_{\mathrm{q}=1}} \underset{\mathrm{T}{ }_{\mathrm{T} i}^{\mathrm{q}}}{\alpha}
\end{aligned}
$$

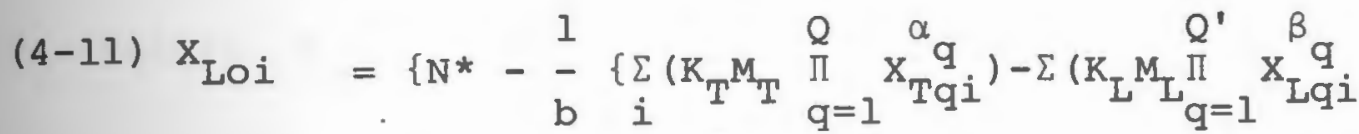

$$
\begin{aligned}
& \left.\left.-F_{A}\right\}\right\} K_{L} M_{L} \prod_{q=1}^{Q} x_{L q i}^{\beta}
\end{aligned}
$$

Equations (4-10) and (4-11) reveal the presence of externalities in the fisheries since the catch of firm $i$ is a function not only of its fishing effort but also of the total fishing effort in the fisheries.

Yet, at a given point in time, $N$ is fixed and for a cosp-production analysis of a fishing industry in a given Year, the catch functions can be estimated in the form given in equations $(4-1)$ and $(4-2)$. 


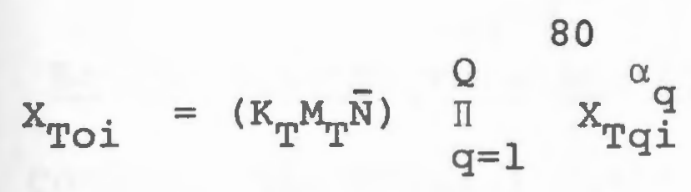

or

$$
\text { (4-12) } x_{\text {TOi }}=A \underset{q=1}{\stackrel{Q}{\Pi}} \underset{\text { Tqi }}{\alpha q}
$$

and

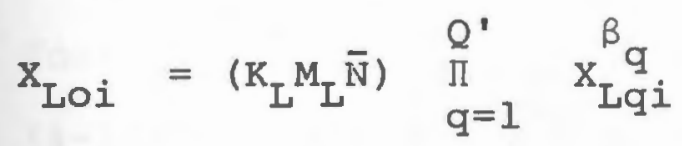

or

$$
\text { (4-13) } x_{L O i}=B \underset{q=1}{\stackrel{Q}{\Pi}} x_{L q i}^{\beta q}
$$


II Econometric Formulation of the Catch Functions

Consider the general catch function:

$$
\text { (4-14) } \quad x_{0}=A \prod_{q=1}^{Q} x_{q}^{\alpha} q
$$

Following Zellner, Kmenta and Dreze ${ }^{3}$ it will be assumed that the catch function of firm $i$ is stochastic and of the form

$$
(4-15) x_{0 i}=A \underset{q=1}{Q} x_{q i}^{\alpha} e^{u_{o i}} \text { with } u_{0 i} \sim N\left(0, \sigma_{0 \circ}\right)
$$

In addition, it is assumed that the prices of the inputs are known with certainty and that the fishermen maximize the expected profit.

$$
(4-16) E\left(\Pi_{i}\right)=p_{o} E\left(x_{o i}\right)-\Sigma p_{q} x_{q i}
$$

where $p_{0}$ is the price of the output and $p_{q}$ is the price of input $q$

From equation (4-15)

$$
(4-17) E\left(x_{o i}\right)=A \prod_{q=1}^{Q} x_{q i}^{\alpha} e^{\frac{1}{2} \sigma} \circ o
$$

$\sigma_{00}$ is the variance of the catch function disturbance.

\section{${ }^{3}$ This expose follows the developments in zellner, Kmenta \& Dreze "Specification and Estimation of Cobb-Douglas Pro- duction Function Models".}


The first order conditions to maximize the expected profit are represented by $q$ equations:

$$
\begin{aligned}
& \text { (4-18) } \frac{\partial E\left(x_{o i}\right)}{\partial x_{q i}}=\frac{p_{q}}{p_{o}} \\
& (4-19) \frac{\partial q x_{o i} e^{\frac{1}{2} \sigma} \circ 0}{\partial x_{q i}}=\frac{p_{q}}{p_{o}}
\end{aligned}
$$

Equation (4-19) can be assimilated to an ex-ante expression. That is, it represents the conditions which should be met if expected profit is to be maximized. It applies to the situation before any fishing takes place. However, after the fishing, ex-post, the catch and the profit become actual values which now differ from the expected ones by the stochastic term $e^{u_{0}}$. Ex-post the situation can be written.

$$
(4-20) \frac{\alpha_{q} x_{o i} e^{\frac{1}{2} \sigma} o o}{x_{q i} e^{u_{o i}}}=\frac{p_{q}}{p_{o}}
$$

or, taking the natural logarithm of equation (4-20)

$$
\text { (4-21) } \ln x_{o i}-\ln x_{q i}=\ln p_{q}-\ln p_{0}-\ln \alpha_{q}-\frac{1}{2} \sigma o o+u_{o i}
$$

In reality, it is likely that the first order conditions for maximizing profit will not be exactly satisfied. Two sets of reasons may concur to lead to a less than optimum combination of inputs: 
83

a) The firms may be subject to a common set of conditions which influence their choice of the quantity of inputs. Those conditions may be due to tradition or to the institutions. In that case, a term $\mathrm{R}_{\mathrm{q}^{\prime}}$ common to all firms, may be introduced in the first order condition equations to account for that disturbance.

$$
\begin{aligned}
(4-22) & \ln x_{o i}-\ln x_{q i}=\ln p_{q}-\operatorname{lng} p_{o}-\ln \alpha_{q}-\frac{1}{2} \sigma_{o o} \\
+ & u_{o i}
\end{aligned}
$$

writing

$$
(4-23) k_{q}=1 n p_{q}-1 n p_{o}-\frac{1}{2} \sigma_{o 0}-1 n \alpha_{q}
$$

Equation $(4-22)$ becomes

$$
(4-24) \text { In } x_{o i}-\ln x_{q i}=k_{q}+R_{q}+u_{o i}
$$

b) Besides the traditional and institutional disturbances common to all firms, each fisherman will perceive differently his own operation as well as the common set of output and input prices. This different perception will make each entrepeneur choose quantities of inputs which, probably, will be at variance from the amounts he ought to use to maximize profit. This can be accounted for by introducing a term $u_{q i} N\left(0, \sigma_{q q}\right)$ in the first order conditions. 


$$
(4-25) \ln x_{o i}-\ln x_{q i}=k_{q}+R_{q}+u_{o i}+u_{q i}
$$

The logarithm of the catch function in (4-15) and the $q$ first order conditions $(4-25)$ represent a system of $q+1$ equations.

Without loss of generality the problem can be reduced to a situation with two inputs and the system of 3 equations can be written:

$$
\begin{aligned}
& \text { (4-26) } \ln x_{0 i}-\alpha_{1} \ln x_{1 i}-\alpha_{2} \ln x_{2 i}=\alpha_{0}+u_{o i} \\
& \text { (4-27) } \quad \ln x_{0 i}-\ln _{1 i}=k_{1}+k_{1}+u_{1 i}+u_{o i} \\
& (4-28) \quad \ln x_{0 i}-\ln x_{2 i}=k_{2}+R_{2}+u_{2 i}+u_{o i}
\end{aligned}
$$

where $\alpha_{0}=\ln A$

From this set of equations it follows that:

$$
\begin{array}{ll}
(4-29) \quad \ln x_{0 i}=\left\{\alpha_{0}-\alpha_{1}\left(k_{1}+R_{1}+u_{1 i}\right)-\alpha_{2}\left(k_{q}+R_{2}\right.\right. \\
& \left.\left.+u_{2 i}\right)+u_{i 0}\left(1-\alpha_{1}-\alpha_{2}\right)\right\} /\left(1-\alpha_{1}-\alpha_{2}\right) \\
(4-30) \quad & \operatorname{lnx} 1 i=\left\{\alpha_{0}+\left(\alpha_{2}-1\right)\left(k_{1}+R_{1}+u_{1 i}\right)\right. \\
& \left.-\alpha_{2}\left(k_{2}+R_{2}+u_{2 i}\right)\right\} /\left(1-\alpha_{1}-\alpha_{2}\right) \\
(4-31) & \ln x_{2 i}=\left\{\alpha_{0}+\left(\alpha_{1}-1\right)\left(k_{2}+R_{2}+u_{2 i}\right)\right. \\
& \left.-\alpha_{1}\left(k_{1}+R_{1}+u_{1 i}\right)\right\} /\left(1-\alpha_{1}-\alpha_{2}\right)
\end{array}
$$

This shows that, assuming that the $u_{1 i}$ and $u_{2 i}$ are statistically independent of $u_{o i}, \ln x_{1 i}$ and $l n x_{2 i}$ are also statistically independent of $u_{O i}$, and consequently, the least square estimate of $(4-26)$ is consistent and unbiased. 
A special case arises in the fishery when any kind of lay system is used to pay the crew members. In what situation the total wage actually paid is a function of the actual output. Yet it can be assumed that the amount of labor hired is a function of the expected output, since the decision of hiring is taken before the fishing trips. In the simplest lay system:

$$
\text { (4-32) } \quad p_{2} x_{2 i}=\gamma\left\{p_{0} E\left(x_{0 i}\right)-p_{3} x_{3 i}\right\}
$$

assuming, in this case, that $E\left(x_{0 i}\right)$ is a function of 3 inputs $x_{1}, x_{2}, x_{3}$, expected profit becomes:

$$
\begin{aligned}
(4-33) & E\left(\Pi_{i}\right)=p_{0} E\left(x_{0 i}\right)-p_{1} x_{1 i}-p_{3} x_{3 i} \\
& -\gamma\left\{p_{0} E\left(x_{0 i}\right)-p_{3} x_{3 i}\right\}
\end{aligned}
$$

The system of equations $(4-26),(4-27)$, and $(4-28)$ must now be written:

$$
\begin{aligned}
& \text { (4-34) } \quad \ln x_{0 i}-\alpha_{1} \ln x_{1 i}-\alpha_{2} \ln x_{2 i}-\alpha_{3} \ln x_{3 i}=\alpha_{\circ}+u_{0 i} \\
& (4-35) \quad \ln x_{0 i}-\ln x_{1 i}=k_{1}+R_{1}+u_{1 i}+u_{0 i}+\ln (1-\gamma) \\
& (4-36) \quad \ln x_{0 i}-\ln x_{3 i}=k_{3}+R_{3}+u_{3 i}+u_{o i}
\end{aligned}
$$

It is immediately apparent that the system of equations $(4-34),(4-35)$, and $(4-36)$ can be solved to show that even when there is a lay system the levelsof the inputs are inlependent of $u_{o i}$. In addition, it appears that another 
equation is necessary to determine the amount of labor $x_{2 i}$. In the present study $x_{2 i}$ will be considered given, or, which is the same, determined by factors outside the model. 


\section{The Measures of Efficiency}

\section{Technical Efficiency}

Considering two groups of firms $A$ and $B$, for each there exists:

$$
\begin{aligned}
& \text { (4-37) } \ln x_{o i}-\alpha_{1} \ln x_{l i}-\alpha_{2} \ln x_{2 i}=\alpha_{0}+u_{o i} \\
& \text { in group } A i=1 \ldots \ldots \text { s-l } \\
& \text { in group } B i=s \ldots \ldots
\end{aligned}
$$

If it is assumed that the two groups of firms have the same production function except for a parameter representing technical efficiency, it is possible to test if this parameter takes significantly different values in each group. This can be done by estimating equation (4-37) separately for group A and group B. This will provide two estimates, $\hat{\alpha}_{O A}$ for group $A$ and $\hat{\alpha}_{O B}$ for group B. Assuming that $E\left(u_{0 i}\right)=0$ for any group of firms, it is possible to test for $H O: \hat{\alpha}_{O A}=\hat{\alpha}_{O B}$.

Another and simpler method consists in estimating:

$$
\text { (4-38) } \ln x_{0 i}=\alpha_{0}+u_{o i}+\delta_{i} s_{i}+\alpha_{1} \ln x_{l i}+\alpha_{2} \ln x_{2 i}
$$

where

$$
\begin{aligned}
& s_{i}=1 \text { for } i=1 \ldots s-1 \\
& s_{i}=0 \text { for } i=s \ldots n
\end{aligned}
$$

If $\hat{\delta}$ is not significantly different from zero the two groups of firms do not have significantly different technical efficiencies. 
Dummy variables can be used to test relative efficiency among more than two groups of firms. For instance, the firms may be divided in group $A$ (fishermen not using that technique). Another classification can be added to those two groups, for instance, firms from region I, region 2 , and region 3 .

In this case, equation $(4-37)$ becomes:

$$
\begin{aligned}
\text { (4-39) } & \ln x_{0 i}-\alpha_{1} \ln x_{1 i}-\alpha_{2} \ln x_{2 i}=\alpha_{0}+u_{0 i}+\delta_{1} s_{1} \\
& +\delta_{2} s_{2}+\delta_{3} s_{3}
\end{aligned}
$$

where the values of $S_{1}, S_{2}$, and $S_{3}$ are 0 or 1 according to the subset to which firm $i$ belongs.

Table IV-I gives the values of $S_{1}, S_{2}, S_{3}$ for the various cases. 4

Each subgroup but one will be characterized by the presence of one or more of the $\delta_{I}$ in its production function as shown by rable IV-2.

For firms of the same region $\delta_{3}$ is a measure of the relative efficiency of technique $B$ over technique A. For firms using the same technique, $\delta_{1}$ and $\delta_{2}$ respectively measure the relative technical efficiency of region 2 and region 3 over region 1 .

Tests can be conducted to check if one coefficient or one group of coefficients is significantly different

${ }^{4}$ Arthur S. Golberger, Econometric Theory, (New York: John wiley \& Sons, Inc., 1964) pp. 222-223. 
TABLE IV-1

THE USE OF DUMMY VARIABLES WHEN TWO

INDEPENDENT CRITERIA DIVIDE THE

SAMPLE IN SEVERAI SUBSETS

$\begin{array}{ccccc}\text { Regions } & \text { Techniques Used } & \mathrm{S}_{1} & \mathrm{~S}_{2} & \mathrm{~S}_{3} \\ \text { I } & \mathrm{A} & 0 & 0 & 0 \\ \text { I } & \mathrm{B} & 0 & 0 & 1 \\ \text { II } & \mathrm{A} & 1 & 0 & 0 \\ \text { II } & \mathrm{B} & 1 & 0 & 1 \\ \text { III } & \mathrm{A} & 0 & 1 & 0 \\ \text { III } & \text { B } & 0 & 1 & 1\end{array}$


TABIE IV-2

COEFFICIENT OF THE DUMMY

VARIABIES IN EACH SUBSET

Regions

A

I

II

III
Techniques

B

$$
\alpha_{0}+\delta_{3}
$$

$\alpha_{0}+\delta_{1}+\delta_{3}$

$\alpha_{0}+\delta_{2}+\delta_{3}$ 
from zero. This would reveal if there is a significant difference in the various levels of technical efficiency. 
II Price Efficiency

Two tests can be conducted concerning price efficiency. One relates to the eventual existence of constraints common to all firms and expressed in the term $\mathrm{R}_{\mathrm{q}}$ of equation (4-22). The second test concerns the term $u_{q i}$ in the same equations, it is a measure of eventual price inefficiency in a given firm or group of firms.

1. Testing for constraints common to all firms.

Equation (4-36) can be written, taking the averages over all firms:

$$
\begin{gathered}
(4-40) \quad \overline{\ln x}_{o i}-\overline{\ln x}_{q i}+\ln p_{o}+\frac{3}{2} \hat{o}{ }_{o o}-\ln p_{q}- \\
\ln (\gamma-1)={\overline{R_{q}}-\ln \alpha_{q}} 5
\end{gathered}
$$

It is not possible to test directly for $\mathrm{R}_{\mathrm{q}}=0$ but it is possible to test if $R_{q}-\ln _{q}$ in equation (4-40) it significantly different from $-\ln \hat{\alpha}_{q}$ as obtained by the ordinary least squares estimator of the logarithm of the production function (equation $(4-26)$ ). If $-\ln \hat{\alpha}_{q}$ is not significantly different from $R_{q}-\ln \alpha_{q^{\prime}}$ the effect of the institutional or traditional constraints, if they exist, does not significantly prevent the fishermen from using the optimum combination of inputs.

5 The following demonstration can be conducted with equation $(4-27)$ or $(4-28)$ the presence of $\ln (1-\gamma)$ does not affect the reasoning. 
2. Test of $u_{q i}$.

Consider the two groups of firms $A$ and $B$ as defined in Section III-I

Group A $i=1 \ldots . . . s-1$

Group $B \quad i=s \ldots n$

The first order condition for a firm in group A

$$
\begin{aligned}
& \text { (4-4l) } \ln x_{o i}-\ln x_{q i}+\ln p_{o}-\ln p_{q}+\frac{3}{2} \hat{\sigma}_{o o}-\ln (\gamma-1) \\
&= R_{q}+u_{q i}+u_{o i}-\ln \alpha_{q} \\
& i=1 . . . .5-1
\end{aligned}
$$

for a firm in group $B$ :

$$
\begin{aligned}
& (4-42) \quad \ln x_{o i}-\ln x_{q i}+\ln p_{o}-\ln p_{q}+\frac{1}{2} \hat{\sigma}_{o \circ}-\ln (\gamma-1) \\
& =R_{q}-\ln \alpha_{q}+u_{q i}+u_{o i} \\
& i=s . . . n
\end{aligned}
$$

Where in group A (equation 4-41) or in group B (equation 4-42), the nature of the terms $u_{0 i}$ is the same and $E\left(u_{O i}\right)=0$. Consequently taking the averages over each group of firms leads to:

$$
\begin{aligned}
& \text { (4-43) } \overline{\ln x}_{o i}-\overline{\ln x}_{q i}+\ln p_{o}-\ln p_{q}+\frac{1}{2} \hat{\sigma}_{o o}-\ln (\gamma-1) \\
& =\overline{R_{q}-\ln \alpha_{q}+u_{q i}} \\
& i=1 . . \quad s-1 \\
& (4-44) \overline{\ln x}_{o i}-\overline{\ln x}_{q i}+\operatorname{lnp} p_{o}-\ln p_{q}+\frac{1}{2} \hat{\sigma}_{o o}-\ln (\gamma-1) \\
& =\overline{R_{q}-\ln \alpha_{q}+u_{q i}} \\
& i=s \cdot . n
\end{aligned}
$$


In both cases the left hand side of the equations can be computed since $\hat{\sigma}_{00}$ is obtained through the estimation of the production function. Then it is possible to test if the right hand sides of the equations are the same. If $\mathrm{H}_{\mathrm{O}}$ :

$$
\left.-\ln \alpha_{q}+u_{q i}\right)_{A}=\left(\overline{\left.R_{q}-\ln \alpha_{q}+u_{q i}\right)_{B}}\right. \text { is not rejected, }
$$

the two groups of firms do not have significantly different price efficiency.

3. Devising statistical tests for price efficiency.

When testing for the constraints common to all firms it is necessary to compare the right hand side of equation $(4-40), \ln x_{o i}-\ln x_{q i}+\ln p_{o}+\hat{k}_{o o}-\ln \hat{p}_{q}-\ln (\gamma-1)$ to $\operatorname{lno}_{q}$ as obtained from equation $(4-26)$.

A problem arises because neither of the terms to be compared has a normal distribution. In equation (4-26), $\hat{\alpha}_{q}$ i.e., $\left(\hat{\alpha}_{1}, \hat{\alpha}_{2}\right)$ has a normal distribution but $\ln \hat{\alpha}_{q}$ does not. In addition, because of the presence of the term $\frac{1}{2} \hat{\sigma}$ oo the right hand side of equation $(4-40)$ is also not normally distributed. Consequently, it is not possible to devise an exact statistical test to compare the two estimates. The comparison must then rely on the judgment of the researcher. 6

On the other hand, when comparing the price efficiency of two groups it is possible to compare.

6

${ }^{6}$ Heady and Dillon, Agricultural Production Functions, p.562 


$$
\ln x_{o i}-\ln x_{q i}+\ln p_{o}-\ln p_{q}-\frac{1}{2} \hat{\sigma}_{o o}-\ln (\gamma-1)
$$

for each group and to treat $\sigma_{00}$ as a constant. Applying the central-limit theorem to these expressions, it appears that they tend toward a normal distribution. The usual test of hypotheses to compare means will then be devised and conducted for these estimates. 
IV The Cost Equation

Although the difficulties arising when defining the cost equation are mainly of a practical nature, one theoretical problem deserves attention. It concerns the imputation of some costs between various productive activities. In the present study only trap and hand line fishing are examined. The fishermen however, are sometimes involved in other activities requiring the use of some of the inputs appearing in the catch function for traps and hand lines (as in the case of the boat). When testing for price efficiency it is essential to find an appropriate way to allocate those inputs and their costs between the various activities.

The following example shows how this problem can be treated. Consider two production functions:

$$
\text { (4-45) } \quad x_{o i}=A x_{11}^{\alpha}{ }^{\alpha} x_{21}^{\alpha}
$$

and

$$
\text { (4-46) } \quad \mathrm{x}_{42}=\mathrm{BX}_{12}{ }_{12}^{{ }^{1}} \mathrm{x}_{32}^{{ }^{\beta}}
$$

using one common input $\mathrm{x}_{1}$, the prices are $\mathrm{p}_{0}, \mathrm{p}_{1}, \mathrm{p}_{3}$, and $\mathrm{p}_{4}$ respectively.

The profit function will be

$$
\text { (4-47) } \pi=\mathrm{p}_{0} \mathrm{Ax}_{11}^{\alpha} \mathrm{x}_{21}^{\alpha}+\mathrm{p}_{4} \mathrm{BX}_{12}^{1} \mathrm{x}_{32}^{\beta_{3}}-\mathrm{p}_{1} \mathrm{x}_{1}-\mathrm{p}_{2} \mathrm{x}_{2}-\mathrm{p}_{3} \mathrm{x}_{3}
$$


The first order condition to maximize profit will be, for

$\mathrm{x}_{1}:$

$$
(4-48) \frac{\partial \pi}{\partial x_{1}}=\alpha_{1} \frac{p_{o} x_{o i}}{x_{1}}+\beta_{1} \frac{p_{4} x_{42}}{x_{1}}-p_{1}=0
$$

or

$$
(4-49) x_{1}=\frac{1}{p_{1}}\left(\alpha_{1} p_{0} x_{0 i}+\beta_{1} p_{4} x_{42}\right)
$$

Assume that $x_{1}$ is a fixed input and that $p_{1}$ is the depreciation. If the equation $(4-36)$ is unknown, one may still want to test for price efficiency knowing equation (4-45) and $p_{4}$ $\mathrm{x}_{42}$. If all the terms of equation (4-49) were known, the depreciation could be inputed in the following fashion to each of the activities:

$$
\begin{array}{ll}
\text { Activity } 1 & \mathrm{z}_{1}=\frac{\alpha_{1} p_{0} x_{01}}{p_{1} x_{1}} \\
\text { Activity 2 } & z_{2}=\frac{{ }_{1} p_{4} x_{42}}{p_{1} x_{1}}
\end{array}
$$

However, since $\beta$ is unknown another solution has to be proposed. If one assumed that $\alpha$ and $\beta$ are not very different, that is, that the input elasticity of factor $\mathrm{x}_{1}$ is the same or nearly the same for Activity 1 and Activity 2.

$$
z_{1}=\frac{p_{0} x_{01}}{p_{0} x_{01}+p_{4} x_{41}}
$$

and

$$
z_{2}=\frac{p_{4} x_{41}}{p_{0} x_{01}+p_{4} x_{41}}
$$


and if $\beta_{1}=\alpha_{1}$

$$
z_{1}=\frac{p_{0} x_{01}}{p_{0} x_{01}+p_{4} x_{41}}
$$

and

$$
z_{2}=\frac{p_{4} x_{41}}{p_{0} x_{01}+p_{4} x_{41}}
$$

It appears, in this Chapter, that if it is assumed that crowding externalities and mesh externalities are negligible, it is possible to use a catch function of the Cobb-Douglas type which can be estimated at one point in time. However, in order to use ordinary least squares for this estimation it is necessary to assume that the fishermen maximize the expected profit rather than the actual profit. Given this assumption, tests of technical efficiency and of price efficiency can be conducted which will provide further information concerning the behavior of the fishermen. 
$\checkmark$ ESTIMATION OF THE

CATCH FUNCTION

A Cobb-Douglas type function was chosen as the theoretical form of the catch function. The production function of equation (4-14) suggested that such a form should be used.

$$
x_{o i}=A \prod_{q=1}^{Q} x_{q i}^{\alpha} q
$$

The advantages of using a function of this form for tests of efficiency was discussed in chapter IV. In addition, it appeared, a posteriori, that the choice of Cobb-Douglas functions was appropriate given the high level of significance of the statistical estimators which were obtained with such a function.

The main problem concerning the estimation of the catch function is the choice of the variables. This was done on the basis of knowledge of the fishing operation and the statistical significance of the variables.

The discussion of the choice of variables is presented jointly for hand line and trap fishing.

Two options existed in the choice of the dependent variable. It could have been measured in dollars or in pounds. In the following developments the annual catch will be measured in pounds. The justification for doing so will be 
given in Section II. The reasons leading to the choice of the independent variables are presented in the preceding section. 
I Choice of the Independent Variables

I Boat and Motor

It is to be expected that the catch or output of either trap or line fishermen will be dependent in some way on the size of the boat and motor used by fishermen. The difficulty is in specifying a variable or set of variables in units which capture the effects of boat and motor. One possibility is to measure the boat and its motor in physical terms. The advantage of this is that the fishermen generally gave some accurate measures of the length of the boat and power of the engines. However, to capture the specificity of a boat and its motor many more variables need to be known some of which (like the degree of maintenance) are difficult to evaluate.

Another problem arises if one chooses physical units. A whole set of variables are available: length of the boat, capacity, power of the engine, etc. One suspects at the outset that they must be highly correlated and consequently it is necessary to choose one which is representative of the boat or to devise a composite variable which would embody most of the characteristics.

This problem is avoided if the boat and motor are measured in monetary terms. This provides a single measurement which captures all the aspects of the input, provided one 
makes the assumption that the input is homogeneous. This choice however also has its drawbacks. Quite often during the interviews it appeared that the fishermen had difficulty evaluating the value of their boats. They were asked for what price they would sell their boats today without the motors. This figure was used as an estimate of the present value of the boat. The fishermen also estimated the number of years remaining in the life of their boats and the average life of their motors. This last figure was checked with an engine dealer and it appeared that 4 years was the average. The prices of the new engines were provided by the Administracion de Servicios Agricolas (Puerto Rican Department of Agriculture) which has been selling equipment to the fishermen for the past ten years.

For those reasons, a priori, none of the options available can be rejected. All are tried in the regressions and the results are compared.

Two monetary measures of capital are introduced: the present value of the boat and the motor and also the depreciation measured as :

$$
\mathrm{TD}=\mathrm{TB}+\mathrm{TE}+\mathrm{M}
$$

TD: Total depreciation plus maintenance

TB: Depreciation on the boat, that is the present value of the boat divided by the estimate of the remaining years of boat's life. 
TE: Price of the new engine divided by 4 (estimated average life).

M: Annual maintenance on the boat and the engine.

Depreciation on the boat (TB), depreciation on the engine (TE), and maintenance (M) were also used as independent variables.

The length of the boat and the power of the motor are also used separetely and concurrently as a measure of this input. The various results are presented in Table V-l.

The regressions in Table $\mathrm{V}-1$ should be read vertically. For instance, the first regression in Table V-l-a is:

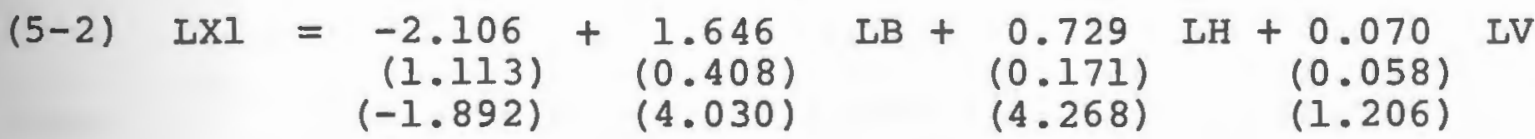

$$
\begin{aligned}
& +0.538 \text { LTT } \\
& (0.147) \\
& \text { (3.659) }
\end{aligned}
$$

(The first number in parentheses is the standard error of the coefficient; the second number is the t-statistic).

LXI: natural logarithm of the catch from traps

$C$ is the constant term,

the other terms are natural logarithms of:

IB: length of the boat

LH: number of man days at sea during the year

IV: number of gallons of gasoline used during the year

LTT: number of traps owned. 


\section{TABLE 104}

COMPARISON OF REGRESSION USING VARIOUS MEASURES OF THE BOATS AND ITS CHARACTERISTICS

(The dependent variable is the annual catch measured in pounds)

$$
\text { a. Traps. }
$$

\begin{tabular}{|c|c|c|c|}
\hline $\begin{array}{l}\text { Wndependent } \\
\text { yariables }\end{array}$ & $\begin{array}{l}\text { Boat } \\
\text { length }\end{array}$ & $\begin{array}{l}\text { Length } \\
\& \text { power }\end{array}$ & $\begin{array}{l}\text { Power of } \\
\text { engine }\end{array}$ \\
\hline Constant & $\begin{array}{r}-2.106 \\
(1.113) \\
(-1.892)\end{array}$ & $\begin{array}{c}-1.153 \\
(1.326) \\
(-0.869)\end{array}$ & $\begin{array}{l}1.650 \\
(0.400) \\
(4.117)\end{array}$ \\
\hline
\end{tabular}

Natural

logarithm of

Length

of boat

power of

motor

man days

at sea

gasoline

used in a

year

traps

owned

$\mathrm{R}^{2}$

$F(4,34)$

$\mathrm{F}(5,23)$
1.646

$(0.408)$

(4.030)

1.187

(0.538)

(2.206)

0.195

(0.151)

(1.293)

0.415

$(0.120)$

(3.464)

0.729

(0.171)

(4.268)

0.668

(0.176)

(3.796)

0.635

(0.185)

(3.432)

0.070

0.091

0.106

(0.058)

$(0.059)$

(1.522)

$(0.062)$

(1.704)

(1.206)

0.523

(0.146)

(3.585)

0.533

$(0.147)$

(3.659)

0.925

81.995
$(0.154)$

(3.459)

0.914

90.930 
TABLE V-1 (continued)

COMPARISON OF REGRESSION USING VARIOUS MEASURES

OF THE BOATS AND ITS CHARACTERISTICS

(The dependent variable is the annual catch measured in pounds.)

a. Traps.

Mandependent variables

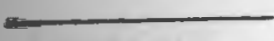

Constant

al de-

preciation

Aepreciation

on motor

Pepreciation on boat

maintenance stock

$-1.132$

(1.065

$(-1.062)$
Capital Depreciation

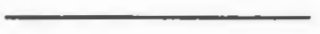

$$
\begin{gathered}
0.131 \\
(0.896) \\
(0.146)
\end{gathered}
$$

Boat Depreciation engine depreciation maint enance
3.137
(1.118)
(2.803)

Natural

logarithm of 0.462 $(0.186)$

$(2.506)$
$-0.340$

$(0.215)$

$(-1.578)$

0.157
$(0.078)$
$(2.005)$

0.115

$(0.122)$

$(0.948)$ present

value

man days

at sea

pasoline

used in a

year

traps

owned

$R^{2}$

$\mathrm{F}(4,34)$

$F(6,32)$
0.599

$(0.182)$

(3.289)
0.716

$(0.203)$

(3.528)

0.059
$(0.067)$
$(0.870)$

0.506

(0.184)

$(3.034)$

0.912 


\section{TABLE V-1 (continued)}

COMPARISON OF REGRESSION USING VARIOUS MEASURES

OF THE BOATS AND ITS CHARACTERISTICS

(The dependent variable is the annual catch measured in pounds.)

b. lines.

Independent

variables

Constant

Boat

length

$-1.536$

$(1.658)$

$(-0.926)$
Length

\& power

$-2.758$

(1.959)

$(-1.408)$
Power of engine

2.667

(1.001)

(2.665)

Natural

logarithm of

length

of boat

power of

motor

man days

at sea

gasoline

used in

a year

$\mathrm{R}^{2}$

F (3-16)

F (4-15)

$$
\begin{gathered}
1.976 \\
(0.546) \\
(3.619)
\end{gathered}
$$

2.923

$(0.993)$

(2.943)

$$
-0.413
$$

(0.351)

$(-1.175)$

$$
\begin{gathered}
0.716 \\
(0.085) \\
(8.419)
\end{gathered}
$$

$-0.016$

$(0.048)$

$(-0.336)$

0.860
32.779
0.675

(0.111)

(6.068)

$-0.026$

$(0.107)$

$(-0.251)$

0.871

25.378
0.438

$(0.240)$

(1.825)

0.728

(0.108)

(6.744)

0.008

$(0.060)$

(0.147)

0.789

19.988

The first number in each group is the coefficient of the variable. The first number in parenthesis is the

standard error and the second number is the t-statistic. 
TABLE V-1 197 continued)

COMPARISON OF REGRESSION USING VARIOUS MEASURES

OF THE BOATS AND ITS CHARACTERISTICS

(The dependent variable is the annual catch measured in pounds.)

b. lines.

Tindependent variables

Snstant

Natural

logarithm of

total

lepreciation

epreciation

of motor

depreciation

of boat

maintenance

0.688

(0.218)

(3.149)

present

value

man days

at sea

gasoline

used in

a year

$\mathrm{R}^{2}$

F (3-16)

F $(5-14)$
Capital Depreciation stock

$\overline{-0.720}$

(1.646)

$(-0.437)$
0.751

(2.154)

$(0.348)$
Boat depreciation engine depreciation maintenance

9.947

(3.174)

(3.133)
0.555
$(0.326)$
$(1.703)$

$-1.140$

$(0.464)$

$(-2.457)$

0.098

$(0.195)$

$(0.501)$

0.032

$(0.192)$

$(0.171)$

$\begin{array}{ccc}0.763 & 0.776 & 0.778 \\ (0.093) & (0.121) & (0.144) \\ (8.130) & (6.386) & (5.377) \\ -0.002 & -0.016 & -0.069 \\ (0.051) & (0.060) & (0.122) \\ (-0.052) & (-0.269) & (-0.570) \\ 0.842 & 0.784 & 0.844 \\ 28.613 & 19.420 & 15.200\end{array}$

The first number in each group is the coefficient of the variable. The first number in parenthesis is the tandard error and the second number is the t-statistic. 
$F$ tests confirm that all the regressions in Table $\mathrm{V}-\mathrm{l}$ are significant at the 1 percent level

$$
\begin{array}{lll}
F(4,34)=3.93 & F(5.33)=3.64 & F(6,32)=3.42 \\
F(3,16)=5.29 & F(4,15)=4.89 & F(5,14)=4.69
\end{array}
$$

When the natural logarithm of the length of the boat, the power of the motor, the total depreciation or the present value are used singly in the regressions their coefficient is significant at the .05 level with the exception of depreciation for hand line operations where the coefficient is significant at the .10 level.

When the natural logarithm of the length of boat and of the power of the motor are used concurrently, the coefficient of the latter is only significant at the .15 level. This is due to the high correlation between the two variables $(.692)$.

When using concurrently the two measures of depreciation (boat and motor) and maintenance, the coefficient of the maintenance is always insignificant. This may be due to the fact that this variable is correlated with many of the others such as the natural logarithm of the depreciation on the engine (.465) the natural logarithm of the number of man days at sea in a year (.490) and the natural logarithm of the number of traps (.632).

A more disturbing characteristic of the latter regression is the negative coefficient of the natural logarithm of 
the depreciation of the boat. This coefficient is significant only at the .15 level for the traps but it is significant at the .05 level for the lines. It seems to indicate that the more one pays for an engine the less fish one catches. This is only an apparent paradox. In the sample of fishermen interviewed in Puerto Rico, some had second hand Chevrolet engines which cost an average of $\$ 340$ but which are more powerful than the usual outboard motor which cost an average of $\$ 525$. At the same time the fishermen with the powerful engines catch more fish annually (an average of $39.822 \mathrm{lbs}$. versus 7,296 lbs. for the fishermen with less powerful engines). This explanation is confirmed when comparing the following regressions:

a) catch from traps for all boats:

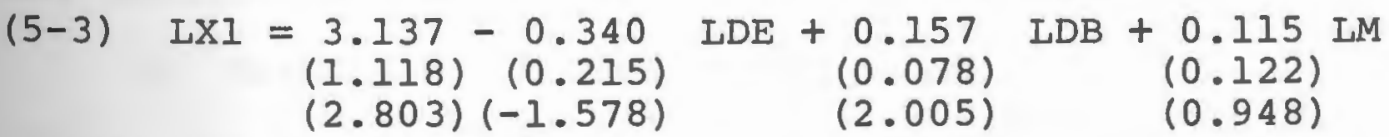

$$
\begin{aligned}
& +\begin{array}{crr}
0.716 & \mathrm{LH}+ & 0.059 \\
(0.203) & (0.067) & \mathrm{LV}+0.506 \\
(3.528) & (0.870) & (0.185) \\
(3.034)
\end{array} \\
& \mathrm{R}^{2}=0.912 \quad \text { F statistic }(6,32)=55.247
\end{aligned}
$$

The symbols in equation (5-3) represent the natural

logarithms respectively:

LXI: annual catch from traps in pounds

LDE: depreciation of the motor

LDB: depreciation of the boat

LM: maintenance

LH: number of man days at sea in a year

LV: number of gallons of gasoline used in a year

LTT: number of traps owned 
b) Catch from traps for the boats with an engine less or equal to $40 \mathrm{HP}$.

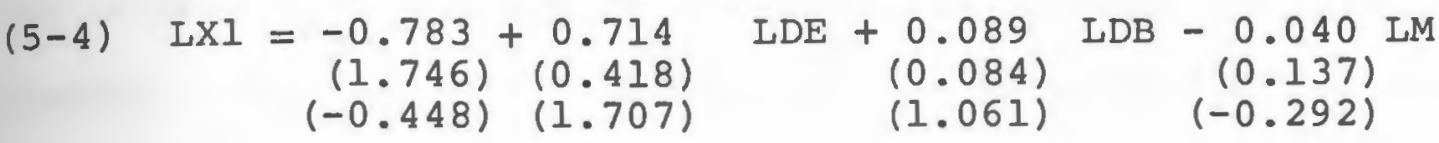

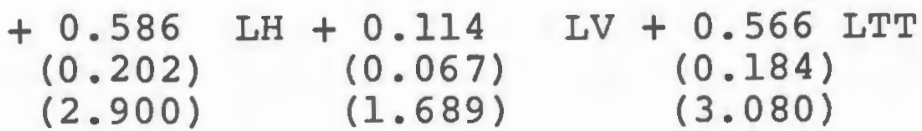

$\mathrm{R}^{2} 0.912 \quad \mathrm{~F}$ statistic $(6.26)=45.070$

All the symbols are the same as in equation (5-3)

Equation (5-4) shows that when the influence of the boats with powerful motors is removed, the coefficient of LDE is positive for the catch from traps. In the case of the catch from lines the comparison between equations (5-5) and $(5-6)$ shows that when the regression is limited to boats which are equipped with an engine of $40 \mathrm{HP}$. or less the coefficient of LDE is not significant.

c) Catch from lines for all boats:

$$
\begin{aligned}
& (5-5) \quad \mathrm{LX} 6=9.947-1.140 \mathrm{LDE}+0.098 \quad \mathrm{LDB}+0.032 \mathrm{LM} \\
& \begin{array}{lrrr}
(3.174) & (0.464) & (0.195) & (0.192) \\
(3.133) & (-2.457) & (0.501) & (0.171)
\end{array}
\end{aligned}
$$

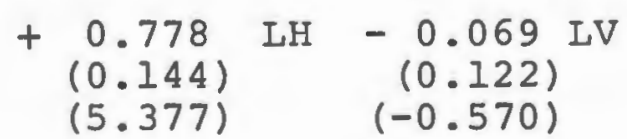$$
R^{2} \quad 0.844 \quad F \text { statistic }(5.14)=15.200
$$

d) Catch from lines for less powerful boats (40 HP. or less).

$$
\begin{aligned}
& (5-6) \quad \text { LX6 }=10.590-0.964 \mathrm{LDE}+0.007 \mathrm{LDB}-0.368 \mathrm{LM}
\end{aligned}
$$

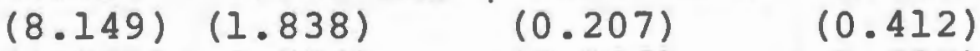

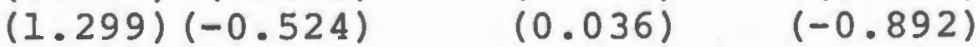

$$
\begin{aligned}
& -0.060 \mathrm{LV}+0.690 \mathrm{LH} \\
& (0.079) \quad(0.140) \\
& (-0.757) \quad(4.924)
\end{aligned}
$$




$$
R^{2}=0.893 \quad \text { F statistic }(5.10)=16.685
$$

LX6 = natural logarithm of the catch from lines measured in pounds. All the other symbols are the same as in equation $(5-3)$

Aside from the special case just presented, Table V-l shows that the coefficient measuring the influence of the length of the boat is significantly positive. This is not surprising. Bigger and more powerful boats allow the fishermen to go on more distant grounds and, for instance, to fish at the edge of the continental shelf which is more productive. The larger boats can also fish under rougher weather conditions. They can go at sea more often land this will be accounted for in another variable) and they can also stay at sea longer. On a given day when the weather becomes menacing, the smaller boats have to return sooner. This means that they cannot fish a long time with their lines. Given the high significance of the regressions, a case can be made to use any of them as representative of the fishing operation. Later in this chapter when additional independent variables are introduced, the comparison of the results is made using the regression with the length of the boat since it has the highest $R^{2}$ and $F$ statistics. On the other hand, in subsequent chapters, it will be more convenient to use others, particularly when testing for price efficiency. However it should be noted that because of the 
high significance of all the regressions and of their similarity, comparable results could be obtained no matter which regression is used.

\section{Traps}

The natural logarithm of the number of traps owned appears to be an important variable in the explanation of the size of the catch. In all the regressions of Table V-1-a the coefficient of that variable is highly significant, except in the case where it is used in combination with the present value of the boat.

The number of traps in the water would be more appropriate. However, the interviews revealed that it was impossible to obtain a good estimate of that value from the fishermen. The reason is that the number of traps in the water varies all the time. Some are lost and not replaced immediately; others are pulled out to be repaired. Consequently the fishermen are unable to give an estimate of the average number of traps in the water during the year. On the other hand, they try to keep constant the number of traps they have available. It was thought that probably there was a constant relationship between the number of traps owned and the number of traps in the water. This assumption seems to be confirmed by the significance of the coefficient of the logarithm of the number of traps owned. 


\section{3}

Another approach to deal with the effect of the number of traps on the catch is proposed below although in this case it does not give satisfying results. It attempts to take into account the average number of soak days for each trap. Munro found ${ }^{l}$ that for a given trap

$$
\text { (5-7) } \quad \begin{aligned}
C_{S}= & C_{s-1} \text { I } \\
C_{S}= & \text { catch on day } s \\
r= & \text { probability of retention in a trap } \\
A= & \begin{array}{l}
\text { daily availability or true rate of } \\
\text { ingress into a trap }
\end{array}
\end{aligned}
$$

or

$$
\text { (5-8) } \begin{aligned}
C_{s} & =A r \frac{1-r^{s}}{1-r}=A D \\
s & =\text { number of soak days }
\end{aligned}
$$

A term $D$ is then introduced into the equation of the catch from traps. A being embodied in the constant term of the regression.

No value of $r$ is available for Puerto Rico but since $r$ is fairly constant (between .874 and .901$)^{2}$ whatever the Caribbean island studied, it was decided to use an average $r=.884$. In addition, the assumption is made that the fishermen go at sea at a constant rythm during the year, at least during the months for which catch from

$$
\begin{aligned}
& \text { IJ.L. Munro. The Mode of Operation of Antillan Fish Traps, } \\
& \text { and the Relationship Between Ingress, Escapement, Catch and } \\
& \text { Soak. Fisheries Ecology Research Project, (Kingston, Jamaica, } \\
& \text { University of West Indies, Port Royal Marine Laboratory, } \\
& \text { Preprint: } \\
& { }^{2} \text { Ibid., p. } 16 .
\end{aligned}
$$


traps was reported. For instance, if a fisherman had 100 tickets for 10 months of the year, and no sale tickets for the rest of the year, it is assumed that he went fishing regularly every three days during those ten months, and not at all the two other months. This could at best be an approximation but it is the only way to estimate the number of soak days per trap. Personal observation and discussions with the fishermen suggested that no more than 60 traps are lifted on an average day. From this, the following regression is computed:

$$
\text { (5-9) LXI }=c+\alpha_{1} L B+\alpha_{2} L H+\alpha_{3} L V+\alpha_{4} L T^{\prime}+\alpha_{5} L D
$$

where LXI = natural logarithm of the annual catch in pounds. $\mathrm{C}=$ constant

other symbols are the natural logarithm of

$$
\begin{aligned}
\mathrm{LB} & =\text { length of the boat } \\
\mathrm{LH} & =\text { number of man days at sea used in a year } \\
\mathrm{LV} & =\text { number of gallons of gasoline used in a year } \\
\mathrm{LTT}^{\prime} & =\text { maximum number of traps which can be lifted } \\
& \text { by one boat in one day } \\
T^{\prime} & =60 \text { if the fishermen owns more than } 60 \text { traps, } \\
& \text { otherwise TT' is the number of traps owned. } \\
\mathrm{LD} & =\text { soak factor, such that: }
\end{aligned}
$$

$$
(5-10) D=.884 \quad \frac{\left(1-.884^{2}\right)}{(1-.884)}
$$

with

$$
(5-11) \mathrm{S}=\frac{30 \mathrm{FM} \times \mathrm{TT} "}{60 \times \mathrm{TI}}
$$

FM: number of months for which sale tickets reporting catch from traps are available.

TI: number of sale tickets reporting catch from traps 
TT" 60 if the fisherman owns less than 60 traps, otherwise TT" is the total number of traps owned.

This approach gave unsatisfactory results as shown by equation $(5-12)$.

$$
\begin{array}{rrr}
(5-12) \quad L X I= & 2.254+1.158 \mathrm{LB}+1.304 \mathrm{LH}-0.078 \\
(1.168)(0.414) & (0.169) & (0.058) \\
(1.929)(3.830) & (7.715) & (-1.338) \\
& -0.091 \mathrm{LTT}-0.005 \mathrm{LD} & \\
(0.130) & (1.147) & (-0.362) \\
(-0.700) & \text { Fstatistic }(5.33)=68.806
\end{array}
$$

where

LXI = natural logarithm of the catch in pounds

The other symbols are the natural logarithm of

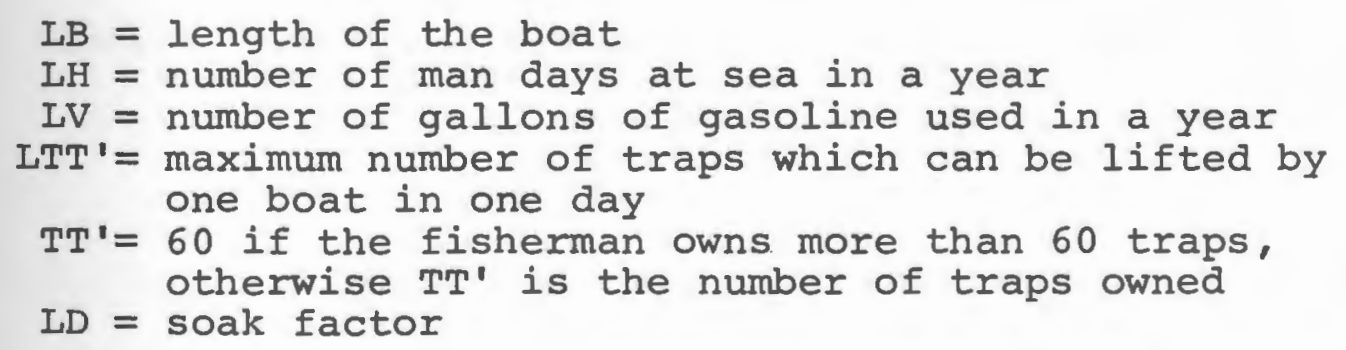
one boat in one day otherwise TT' is the number of traps owned

In this case one would have expected the coefficient of the soak factor LD to be close to one; in fact it turned out to be insignificant as did the coefficient of ITT'. Various explanations are possible. The most obvious one is that one or several of the assumptions on which the design of $D$ is based are too unrealistic. The second set of objections to that approach lies in the difference between Munro's experiment and the fishermen's practices. Equation (5-8) applies to traps which are laid in the same location. 
on the other hand, if a fisherman owns many traps he will put them in quite different areas in order to spread the various risks, risk of catching fish of course, but also risk of having his traps stolen or lost. Then, this belnavior is better accounted for by introducing in the regression a variable which represents the number of traps owned as in the regressions of Table V-l-a.

\section{Lines}

The number of lines used during a fishing trip is introduced as an independent variable to attempt to explain the catch from lines. Interestingly, it is insignificant.

$$
\begin{aligned}
& \text { (5-13) LX6 }=-1.428+1.986 \mathrm{LB}+0.736 \mathrm{LH}-0.022 \mathrm{LV} \\
& \begin{array}{llll}
(1.690) & (0.554) \quad(0.090) & (0.050)
\end{array} \\
& \begin{array}{llll}
(-0.845) & (3.581) & (8.115) & (-0.440)
\end{array} \\
& -0.323 \mathrm{LL} \\
& (0.447) \\
& (-0.722) \\
& \mathrm{R}^{2}=0.864 \quad \text { F statistic }(4.15)=23.981
\end{aligned}
$$

LX6 natural logarithm of the catch from lines in pounds

Other symbols are the natural logarithm of

$$
\begin{aligned}
& \mathrm{LB}=\text { length of the boat } \\
& \mathrm{LH}=\text { man days at sea } \\
& \mathrm{LV}=\text { gallons of gasoline } \\
& \mathrm{LL}=\text { Iines used each trip }
\end{aligned}
$$


This can be explained by examining the composition of the sample. Of the 20 fishermen who reported fishing with lines, 11 use one line per man in the boat; 6 use one line fewer than they have men in the boat; 3 use one line more than they have men. Equation (5-13) would indicate that when one man in the boat does not fish but keeps the boat steady, the other members of the crew are able to catch as much fish as the boats which have the same number of men on board but where everyone is fishing. On the other hand, when one man attends more than one line he is no more efficient than the crew using one line per man. Understandably, it is a small sample and it is difficult to argue that if the 6 boats using fewer lines than men or the 3 boats using more lines than men operated exactly as many lines as men they would be more or less efficient. Probably the combination lines-men chosen by each crew corresponds to the characteristics of this particular crew, and one suspects that the fishermen of each boat chose the optimum combination in most cases.

IV Measuring Labor

Labor is measured as the number of man days at sea. The number of men in the boat is multiplied by the number of days the boat went to sea.

In trap fishing as well as in line fishing, the coefficient of man days at sea during the year is highly signifi- 
cant. This is not surprising since the dependent variable is the annual catch. However, where the daily catch is used as the dependent variable and the number of men in the boat is the measure of labor input the coefficient of the latter variable is significant for traps but not for hand lines as shown by equations (5-14) and (5-15).

$$
\begin{aligned}
& \text { (5-14) } \quad \mathrm{DLXI}=-2.489+1.720 \mathrm{LB}+0.587 \mathrm{LHD} \\
& \begin{array}{lll}
(1.143) & (0.417) \quad(0.261)
\end{array} \\
& \begin{array}{lll}
(-2.176) \quad(4.118) \quad(2.224)
\end{array} \\
& \begin{array}{cc}
+0.009 \\
(0.048) \\
(0.198) & (0.101) \\
(0.08 D & (4.080)
\end{array} \\
& \mathrm{R}^{2}=0.699 \quad \mathrm{~F} \text { statistic }(4.34)=19.819
\end{aligned}
$$

The symbols are the natural logarithms of:

$$
\begin{aligned}
& \text { DLXI = daily catch from traps } \\
& \mathrm{LB}=\text { length of the boat } \\
& \text { LHD = men in the boat for each trip } \\
& \text { LVD = gallons of gasoline per trip } \\
& \text { LTT }=\text { traps owned } \\
& \text { (5-15) } \mathrm{DLX}=-2.866+2.401 \mathrm{LB}-0.518 \mathrm{LHD} \\
& \begin{array}{lll}
(1.742) & (0.592) & (0.449)
\end{array} \\
& (-1.644)(4.052) \quad(-1.153) \\
& -0.043 \text { LVD } \\
& (0.054) \\
& (-0.805) \\
& \mathrm{R}^{2}=0.520 \quad \text { F statistic }(3-16)=5.799 \\
& t_{.15}=1.071 \quad F .01(3-16)=5.29
\end{aligned}
$$

DLX6= daily catch from lines

One would expect the number of men in the boat to be a significant explanatory variable as far as catch from traps are concerned. Having two men instead of one will 
allow the placing of more traps in deeper water since it will be easier for two men rather than just for one to pull the traps. When the effects of using a pot hauler are investigated in the next chapter, it will be shown that being able to pull the traps from deeper water is an important factor.

As far as line fishing is concerned, the coefficient of the labor variable would tend to be negative although it is significant only at the $15 \%$ level. This suggests that given a fixed number of lines, having an extra man to keep the boat still is not productive. This already appeared in equation (5-13) where it was shown that given a fixed number of men in the boat it was just as productive to have everyone attend a line. However, the same caution is necessary here concerning the size and the structure of the sample.

$V$ Role of the Fishing Grounds

No direct attempt was made to determine the effect on the catch from fishing in the various fishing grounds. During the field interviews it appeared that the fishermen often changed fishing grounds. In addition, they were rarely able (or willing) to state with precision where they fished. For these reasons another approach was substituted: The fishermen were asked how many gallons of gasoline they 


\section{0}

used on each trip, on the average. This was expected to give an indication as to how far from their home port they went fishing. Since the dependent variable is the yearly catch, the number of gallons of gasoline used on each trip has been multiplied by the number of trips. As shown in Table $\mathrm{V}-1$ the coefficient of that variable is not significant for trap fishing only at low degrees of confidence. one of the reasons for this comes from the difficulty for the fishermen to give an accurate measure of the number of gallons of gasoline used during one trip. During many interviews it seemed that the fishermen did not have a good idea of this figure. Futhermore, discussions with a boat dealer showed that, given a 16-foot boat of the type used in Puerto Rico, a $6 \mathrm{HP}$. motor would consume 1 to $1 / 2$ gallons of gasoline in one hour at $4.5 \mathrm{mph}$. while an $18 \mathrm{HP}$. motor would consume 2 to $2-1 / 2$ gallons in one hour at $10 \mathrm{mph}$. In other words, to go the same distance, the two motors would use the same amount of gasoline providing that the boat with a small motor goes at half the speed of the other boat. And even if they go the same distance at the same speed the difference in consumption of gasoline is likely. to be small. This suggests that it is not such a good variable to estimate how far the fishermen go fishing. In addition, the small amount of gasoline involved explains why the fishermen could not give a value which was precise enough to be significant in the regression. 
121

Another variable was then introduced. Instead of using the number of gallons of gasoline, the average number of hours of a fishing trip was selected. It was then multiplied by the number of days at sea, giving the total time spent at sea in a year; the coefficient of the natural logarithm of this value is revealed to be significant.

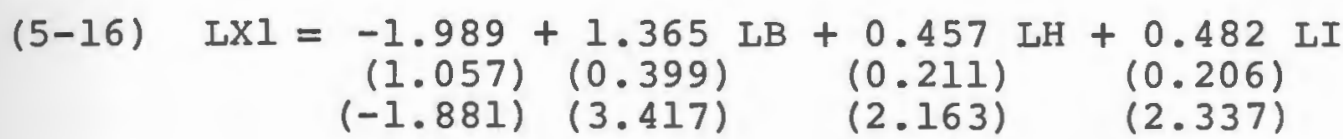

$$
\begin{aligned}
& +0.392 \text { LTT } \\
& \text { (0.141) } \\
& \text { (2.773) } \\
& \mathrm{R}^{2}=0.929 \quad \text { F statistic }(4,34)=112.375
\end{aligned}
$$

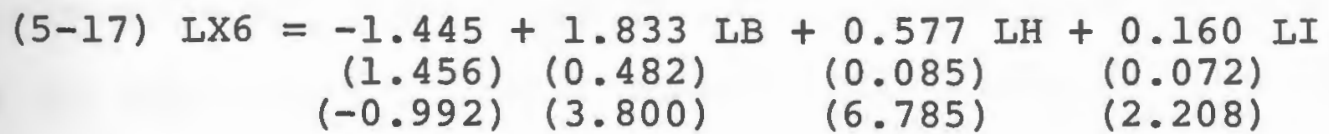

$$
\begin{aligned}
& \mathrm{R}^{2}=0.892 \quad \mathrm{~F} \text { statistic }(3,16)=44.042
\end{aligned}
$$

When the daily catch was the dependent variable and

LID the natural logarithm of the daily length of the trip the following results are obtained:

$$
\begin{aligned}
& \text { (5-18) DLXI }=-2.197+1.446 \quad L B+0.331 \text { LHD } \\
& (1.085) \quad(0.415) \quad(0.275) \\
& (-2.025) \quad(3.482) \quad(1.201) \\
& +\begin{array}{cc}
0.444 \\
(0.213) \\
(2.079) & (0.095) \\
(3.075 & (3.757)
\end{array} \\
& \mathrm{R}^{2}=0.733 \quad \mathrm{~F} \text { statistic }(4,34)=23.384 \\
& \text { (5-19) DLX6 }=-2.683+2.119 \mathrm{LB}+0.237 \text { LID-0.237 LID } \\
& \begin{array}{llll}
(1.745) & (0.651) \quad(0.276) \quad(0.476)
\end{array} \\
& \begin{array}{llll}
(-1.537) & (3.256) \quad(0.857) \quad(-0.708)
\end{array} \\
& \mathrm{R}^{2}=0.523 \quad \text { F statistic }(3.16)=5.857
\end{aligned}
$$


In equations $(5-16)$ to $(5-19)$ the symbols represent:

1) Dependent variables, the natural logarithm of

LXI annual catch from traps

DLXI daily catch from traps

LX6 annual catch from lines

DLX6 daily catch from lines

2) Independent variables, the natural logarithm of

LB length of the boat

LH man days at sea in a year

LI total time spent at sea in a year

LTT traps owned

LHD men in the boat for each trip

LID length of the daily trip (in hours)

In this case the daily catch from traps is significantly altered by the time spent at sea each day, independent of the number of traps owned. This suggests that the fishermen who spend the longest time at sea every day probably do so in order to reach more productive grounds, either to the edge of the continental shelf or along the coast but further from their port.

On the other hand, it is surprising to note that the time spent fishing with hand lines does not help explain the catch. This phenomenon is to be paralleled with the observation that many of the coefficients of other variables which could be expected to influence the catch were also not significant. In fact, the $R^{2}$ 's and $F$ statistics for the regressions dealing with the catch from hand lines were constantly lower than the $\mathrm{R}^{2}$ 's and $F$ statistics for the regressions dealing with the 
catch from traps. These findings tend to emphasize a characteristic of hand line fishing, that is, the higher skill required from the fishermen. When trap fishing and hand line fishing were described earlier it was mentioned that to be a successful hand line fisherman required that the fisherman have a knowledge of fish behavior and their feeding habits. This is not as important in trap fishing although it will be shown later that the skill factor can also make a difference in the catch from traps. However, since no measure of the fishermen's skill was introduced in the regression, if it is an important factor in determining the catch, the absence of this variable would explain the low $\mathrm{R}^{2}$ 's and F statistics as well as the lack of significance of the coefficients of the other variables. Subsequent findings will be presented which tend to confirm this hypothesis. 
II The Dependent Variable

Both trap and hand line fishing produce a mixed species catch, in the case of traps primarily bottom species and for hand lines bottom and midwater species. Although some species are more valuable than others, there is little or no opportunity for the fishermen to selectively fish, using these two techniques, for the higher priced species.

On the contrary, if there are changes in the prices from one port to another, their effects will be eliminated by measuring the catch in pounds. In fact, those variations are very small and the regressions are quite comparable whatever the unit in which the catch is measured. Those regressions are shown in Table $\mathrm{V}-2$.

To conclude this chapter it is necessary to make a remark concerning the missing sale tickets.

The Puerto Rican Department of Agriculture assumes that the missing sale tickets represent 25 percent of the fishermen's trips but also 25 percent of their catch. Regressions were computed after the catch and the number of days at sea had been divided by .75 . The effect of this transformation is to change the constant term as it can be shown in a simple example. 
125

TABLE $V-2$

COMPARISONS OF REGRESSIONS USING POUNDS AND DOLLARS TO MEASURE THE CATCH.

\begin{tabular}{|c|c|c|c|c|}
\hline & \multicolumn{2}{|c|}{ Traps } & \multicolumn{2}{|c|}{ Lines } \\
\hline & pounds & dollars & pounds & dollars \\
\hline Constant & $\begin{array}{c}-2.106 \\
(1.113 \\
(-1.892)\end{array}$ & $\begin{array}{c}-2.545 \\
(1.070) \\
(-2.377)\end{array}$ & $\begin{array}{r}-1.536 \\
(1.658) \\
(-0.926)\end{array}$ & $\begin{array}{c}-1.701 \\
(0.806) \\
(-1.991\end{array}$ \\
\hline \multicolumn{5}{|c|}{$\begin{array}{l}\text { Natural } \\
\text { logarithm of }\end{array}$} \\
\hline $\begin{array}{l}\text { length } \\
\text { of the } \\
\text { boat }\end{array}$ & $\begin{array}{c}1.646 \\
(0.408) \\
(4.030)\end{array}$ & $\begin{array}{l}1.550 \\
(0.392) \\
(3.947)\end{array}$ & $\begin{array}{l}1.976 \\
(0.546) \\
(3.619)\end{array}$ & $\begin{array}{l}1.805 \\
(0.496) \\
(3.639)\end{array}$ \\
\hline $\begin{array}{l}\text { man days } \\
\text { at sea }\end{array}$ & $\begin{array}{c}0.729 \\
(0.171) \\
(4.268)\end{array}$ & $\begin{array}{c}1.053 \\
(0.164) \\
(6.407)\end{array}$ & $\begin{array}{c}0.716 \\
(0.085) \\
(8.419)\end{array}$ & $\begin{array}{c}0.748 \\
(0.077) \\
(9.679)\end{array}$ \\
\hline $\begin{array}{l}\text { gallons } \\
\text { of } \\
\text { gasoline }\end{array}$ & $\begin{array}{c}0.070 \\
(0.058) \\
(1.206)\end{array}$ & $\begin{array}{c}-0.042 \\
(0.055) \\
(-0.754)\end{array}$ & $\begin{array}{c}-0.016 \\
(0.048) \\
(-0.336)\end{array}$ & $\begin{array}{c}-0.005 \\
(0.044) \\
(-0.126)\end{array}$ \\
\hline $\begin{array}{l}\text { traps } \\
\text { owned }\end{array}$ & $\begin{array}{c}0.538 \\
(0.147) \\
(3.659)\end{array}$ & $\begin{array}{c}0.253 \\
(0.141) \\
(1.792)\end{array}$ & & \\
\hline & 0.921 & 0.918 & 0.860 & 0.891 \\
\hline$F(3,16)$ & 100.093 & 95.871 & 32.779 & 43.593 \\
\hline
\end{tabular}

The first number in each group is the coefficient of the variable. The first number in parenthesis is the standard error and the second is the t-statistic. 
Given a Cobb-Douglas type production function:

$$
\mathrm{Y}=\mathrm{Ax}_{1}^{\stackrel{\alpha}{{ }_{1}}} \mathrm{x}_{2}^{\alpha_{2}} \mathrm{x}_{3}^{\alpha_{3}}
$$

If some of the variables (the catch and those which are a multiple of the number of trips) are multiplied (or divided) by a constant $c$.

$$
\begin{aligned}
c Y & =A x_{1}^{\alpha}\left(c x_{2}\right)^{\alpha_{2}}\left(c x_{3}\right)^{\alpha_{3}} \\
Y & =c^{\left(\alpha_{2}+\alpha_{3}-1\right)} x_{1}^{\alpha} x_{2}^{\alpha_{2}} x_{3}^{\alpha_{3}}
\end{aligned}
$$

Table $\mathrm{V}-3$ shows the change in the constant term of the regression when adjustments are introduced for the missing sale tickets.

In fact, the constant term is only slightly changed; this is because the sum of the coefficients of $\mathrm{LH}$ and $\mathrm{LV}$ is close to one. $\mathrm{LH}$ and $\mathrm{LV}$ are the independent variables which were divided by .75 to adjust for the missing sale tickets. This chapter shows that the boat and its motor are the most important factors to explain the level of the catch from hand lines and from traps. The second significant independent variable is the number of man days at sea. In fact, those two elements are the only ones which were found to be significant to explain the catch from lines. To explain the catch from traps, the number of traps owned is also an important explanatory variable.

Among the variables which might have been important 


\section{TABLE V-3}

CHANGES IN THE CONSTANT TERM OF THE REGRESSION CORRECTED FOR THE MISSING SALE TICKETS.

(Catch in pounds.)

Traps

Before adjustment

Lines

\section{$F_{1}$ fter}

adjustment

$$
\begin{array}{cc}
-2.106 & -2.049 \\
(1.113) & (1.113) \\
(-1.892) & (-1.839)
\end{array}
$$

Before adjustment adjustment

$$
\begin{gathered}
-1.536 \\
(1.658) \\
(-0.926)
\end{gathered}
$$$$
-1.450
$$$$
(1.664)
$$$$
(-0.871)
$$

After

(The coefficients of the other variables are the same before and after adjustment.)

$$
\begin{gathered}
1.646 \\
(0.408) \\
(4.030) \\
0.729 \\
(0.171) \\
(4.268)
\end{gathered}
$$$$
1.976
$$$$
(0.546)
$$$$
\text { (3.619) }
$$

man days

at sea

gallons of gasoline

$$
\begin{gathered}
0.070 \\
(0.058) \\
(1.206)
\end{gathered}
$$$$
0.716
$$$$
(0.085)
$$$$
\text { (8.419) }
$$$$
-0.016
$$$$
(0.048)
$$$$
(-0.336)
$$

$$
\begin{gathered}
0.538 \\
(0.147) \\
(3.659) \\
0.921 \\
100.093
\end{gathered}
$$

$R^{2}$
$F(4,34)$
$F(3,16)$ traps

owned
The first number in each group is the coefficient of the variable. The first number in parenthesis is the standard error and the second number is the t-statistic. 
it must be noted that the number of gallons of gasoline used in a year is not a good explanatory variable.

It is also interesting to recall the conclusion concerning the number of men in the boat. For trap fishing, it was found that, everything else being equal, there was a positive correlation between the number of men in the boat and the size of the catch, however, for line fishing, the number of men in the boat does not affect the catch.

Despite the various problems encountered in defining and measuring several of the inputs, the results of the regression are, in general, very significant, and they provide a useful basis forfurther analysis of the fishermen's behavior. 


\section{TESTS OF EFFICIENCY}

Having estimated the catch functions for traps and hand lines it is now possible to test for technical and price efficiency. For technical efficiency the test is

conducted as described in Chapter IV. A dummy variable is introduced to measure the technical efficiency of one group of boats as compared to the technical efficiency of another. Tests of price efficiency and comparisonsare then conducted for the entire sample of fishermen, and for various groups. Finally a test is conducted to determine if, given the present level of the other inputs, it is profitable to invest in a winch. 
The technical efficiency tests are based on the assumption that for the same fishing methods all the boats have the same catch function except for one parameter which embodies the difference in technical efficiency.

The catch function has the general form

$$
(6-1) \quad \text { LXI }=C+\delta S+\sum_{i=1}^{n} \alpha_{i} L X_{i}
$$

LXl natural logarithm of the catch

$\mathrm{Lx}_{i}$ natural logarithm of input level $\mathrm{x}_{i}$

Dummy variable:

$$
\begin{array}{ll}
s=1 & i=1 \ldots . . s \\
s=0 & i=s-1 \ldots . n
\end{array}
$$

For this test the catch functions used were the same as those described in Chapter V.

Various criteria were used to divide the sample of boats in two groups, then, technical efficiency was compared between groups.
Division I: (1) motor less than or equal to $30 \mathrm{hp}$
(2) motor over $30 \mathrm{hp}$.
Division II: (1) motor less than or equal to $40 \mathrm{hp}$
(2) motor over $40 \mathrm{hp}$.
Division III:
(I) fishermen using a winch
(2) fishermen not using a winch
Division IV:
(1) fishermen fishing with traps only
(2) fishermen fishing with lines and traps
Division V: (1) fishermen fishing with lines only
(2) fishermen fishing with lines and traps 


\section{1}

For each division a regression was computed where the dependent variable was the annual catch, while the independent variables,were,

(1) for the trap fishing operations:

(a) the length of the boat

(b) the number of man-days at sea

(c) the number of gallons of gasoline used in one year

(d) the number of traps owned

(2) for the line fishing operations:

(a) the length of the boat

(b) the number of man days at sea

(c) the number of gallons of gasoline used in a year

In addition in each regression a dummy variable was introduced such that:

First regression, Division I:

$$
\begin{aligned}
& S=0 \text { if motor } \leq: 30 \mathrm{HP} \\
& S=1 \text { if motor }>30 \mathrm{HP}
\end{aligned}
$$

Second regression, Division II:

$$
\begin{aligned}
& S=0 \text { if motor } \leq 40 \mathrm{HP} \\
& S=1 \text { if motor }>40 \mathrm{HP}
\end{aligned}
$$

Third regression, Division III:

$S=0$ if the boat is not equipped with a winch

$s=1$ if the boat is equipped with a winch

Fourth regression, Division IV:

$S$ - 0 if the fishermen fish with traps only 
$s=1$ if the fishermen fish with traps and hand lines Fifth regression, Division V:

$S=0$ if the fishermen fish with lines only

$S=I$ if the fishermen fish with traps and lines.

The coefficient of $s$ obtained in the successive regression is presented in Table VI-I. 
TABLE VI-1

TESTS OF TECHNICAL EFFICIENCY

(Using the length of the boat

as an independent variable.)

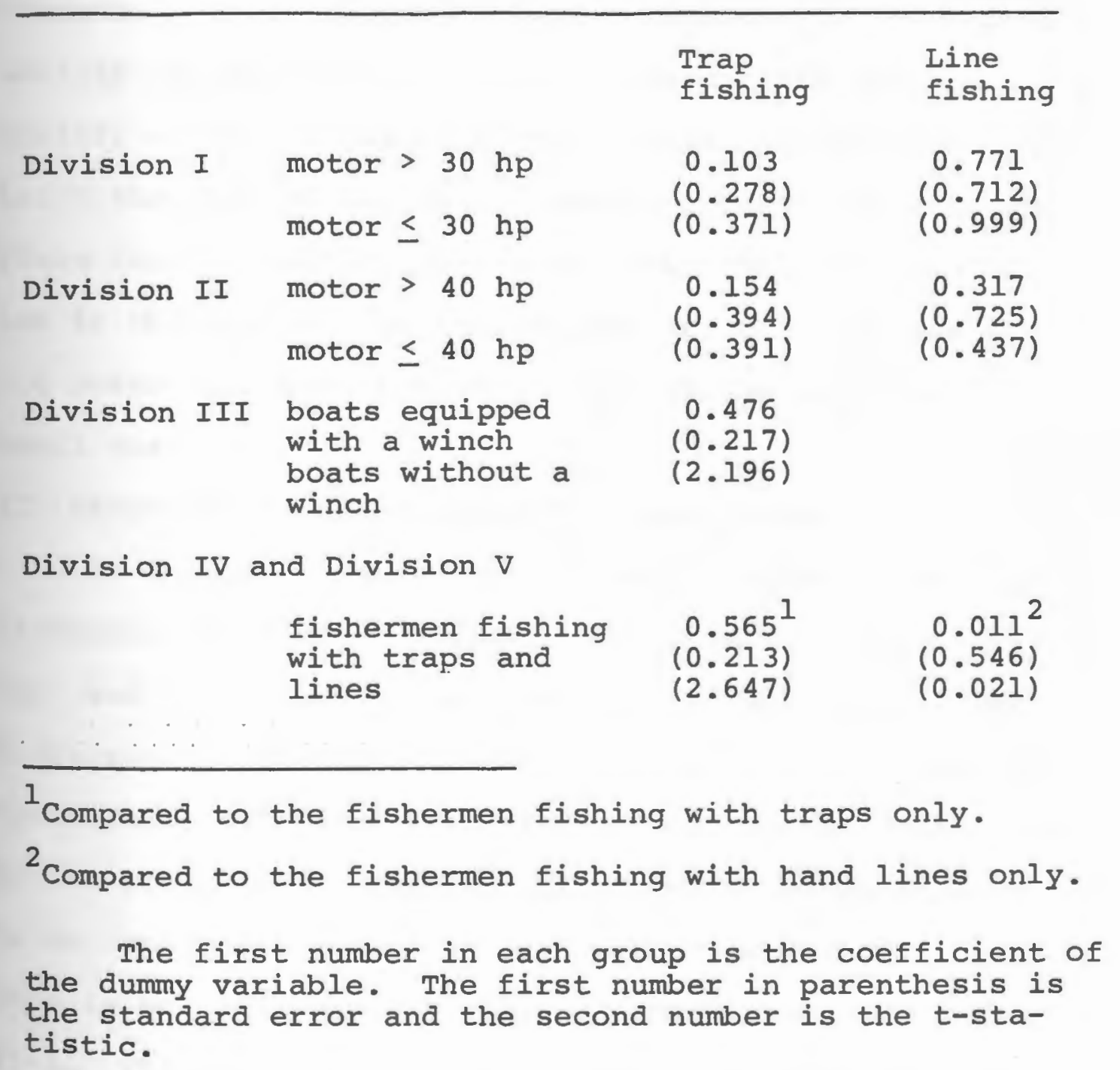


I Big Boats and small Boats

The first important finding is the non-significance of the coefficient of the dummy variable for powerful boats. This is the case for fishermen using either traps or hand lines. It is also true whether the boats are divided on the basis of motors more or less powerful than $30 \mathrm{HP}$ or more or less powerful than $40 \mathrm{HP}$. This means that there is no significant difference between the technical ability of the captains of big boats and the technical ability of the captains of small boats. As shown in Chapter $\mathrm{V}$ the size of the boat is an important factor to explain the size of the catch but what Table VI-1 indicates is that, given the same equipment, the captains of big boats will have the same catch as the captains of small boats.

II Traps and Lines as a Combined Enterprise On the other hand, this is not the case if the trap fishermen are divided between those fishing with traps only and those fishing with both traps and lines. The fishermen practicing both methods are on the average more technically efficient than the fishermen using traps only. In the preceding chapter it was suggested that skill could be an important element in explaining the catch from lines. This is now reinforced by the estimates given in Table VI-1. This shows that, all other inputs being equal, the 
fishermen who fish with lines and traps catch more fish in their traps. This is not a surprising finding. It is usually recognized that line fishing requires better knowledge of fish behavior. In this study it appears that the fishermen who have this knowledge use it to improve the catch from traps. It is not possible to tell if this knowledge is acquired through the practice of line fishing or if the fishermen decide to fish with lines because they already know the fish's behavior. Whatever the answer, this result emphasizes the importance of the skill as an input factor. Everything else being equal, the fishermen using both traps and lines, on the average, catch 77 percent more than the fishermen using traps only.

When the line fishermen are divided into two groups, those using lines only and those using lines and traps, it appears that there is no significant difference of skill between those groups. This means that trap fishing does not require any special knowledge nor does it teach anything that is not already necessary for line fishing. III Efficiency of a winch

If the trap fishermen are divided between those using a winch and those using a winch, Table VI-1 shows that the coefficient of the dummy variable representing the winch is significantly positive. However, the coefficient of the dumny variable is more difficult to interpret. To a large extent it measures the effects of the winch itself. 
Yet it is conceivable that some fishermen decided to buy a winch because they had chosen to fish in more productive and deeper grounds. If this is so the coefficient of the dummy variable reflects both the effects of the winch and the technical efficiency of the captains. For these reasons it is not surprising to find that using a winch makes a significant difference in the catch $(61$ percent). In Chapter $\mathrm{V}$ it was shown that the number of men in the boat was significant, that is, the more power there was to pull the traps, the larger the catch. The positive coefficient of the dummy variable associated with the winch confirms this finding. The fishermen using pot haulers can lay the traps at greater depths. This gives them a larger choice of fishing grounds and therefore they can fish the more profitable deeper waters.

Despite the fact that the use of a winch makes a significant difference, this does not mean that it is profitable to own one. The added cost may not be compensated by the increase in the catch. This will be tested in the last section.

In addition, the last criteria can be used in combination to account at the same time for the fishermen who fish with traps and lines as well as for the fishermen who use a winch. In this case the following regression was obtained. 


$$
\begin{aligned}
& \text { (6-3) LPRI }=-1.285+0.395 \mathrm{Q}+0.274 \mathrm{~W}+0.793 \mathrm{LB}+1.190 \mathrm{LH} \\
& \begin{array}{llll}
(0.206) & (0.206) & (0.156) & (0.156)
\end{array} \\
& \begin{array}{lll}
(1.916) \quad(1.384) \quad(7.622)
\end{array} \\
& (7.622) \\
& -0.077 \mathrm{LV}+0.332 \mathrm{LTT} \\
& (0.055) \quad(0.139) \\
& (-1.399) \quad(2.394) \\
& \mathrm{R}^{2}=0.929 \quad \mathrm{~F} \text { statistic }(6,32)=68.288 \\
& 8_{00}=0.4738
\end{aligned}
$$

LPRI = natural logarithm of the total revenue from traps (in dollars)

$Q=1$ when the fisherman fishes with traps and lines

$Q=0$ when the fisherman fishes with traps only

$W=1$ when the boat is equipped with a winch

$W=0$ when the boat is not equipped with a winch

The other variables are the natural logarithm of

$$
\begin{aligned}
\mathrm{LB} & =\text { length of the boat } \\
\mathrm{LH} & =\text { number of man days at sea in a year } \\
\mathrm{LV} & =\text { number of gallons of gasoline used in a year } \\
\mathrm{LTT} & =\text { number of traps owned }
\end{aligned}
$$

Equation (6-3) shows that, even when measured concurrently, the effects of fishing with traps and lines and using a winch can alter the regression equation. However in this case the effect of the winch is not as important as before. This tends to confirm that, in fact, when the efficiency of using a winch is tested independently, two elements are measured, the effect of the winch itself and the captain's efficiency. Here the captain's efficiency is already partly embodied in $Q$.

B) Test of technical efficiency when the input boatmotor is measured in monetary terms. 
The average power of the boat, the average price of a horsepower and the value of the dummy variable when the present value of the boat and of the motor is used to measure the combined input boat-motor are shown in Table VI-2.

The technical efficiencies which were proven to be significantly different earlier are confirmed to be so in Table VI-2. But a significant difference between more powerful boats and less powerful boats appears here. It means that everything else being equal, per dollar of present value of boat and motor, the captains of the big boats catch more fish. This can be explained when comparing the average cost of one horsepower for each group. The captains of the more powerful boats get more power per dollar than do the captains of the less powerful boats. For this reason, for the same value of boat and motor they have a bigger catch, since there is a positive correlation between catch and power (See Table V-1).

In this case, the dummy variable does not measure fishing ability, it is only an effect of the cost structure. 
TESTS OF TECHNICAL EFFICIENCY

(Using the Present Value of the Boat and the Motor as an Independent Variable)

Trap Fishing

$\begin{array}{lll}\text { Average } & \text { Average } & \text { Dummy } \\ \text { power of } & \text { price of } & \text { variable } \\ \text { the motor } & \text { one hp. } & \end{array}$

In HP In $\$$

\begin{tabular}{|c|c|c|c|}
\hline DIVISION I & & & \\
\hline motor $>30 \mathrm{HP}$ & 60.42 & 11.79 & $\begin{array}{c}0.418 \\
(0.263)\end{array}$ \\
\hline motor $\leq 30 \mathrm{HP}$ & 15.26 & 38.79 & $(1.590)$ \\
\hline DIVISION II & & & \\
\hline motor $>40 \mathrm{HP}$ & 80.83 & 4.84 & $\begin{array}{l}0.687 \\
0.277\end{array}$ \\
\hline motor $\leq 40 \mathrm{HP}$ & 19.76 & 35.15 & $(2.476)$ \\
\hline DIVISION III & & & \\
\hline boats with winch & 50.82 & 21.31 & $\begin{array}{c}0.698 \\
(0.195)\end{array}$ \\
\hline boats without winch & 19.65 & 34.25 & $(3.579)$ \\
\hline $\begin{array}{l}\text { DIVISION IV and } \\
\text { DIVISION V } \\
\text { fishermen fishing }\end{array}$ & & & \\
\hline with traps \& lines & 47.90 & 16.76 & $\begin{array}{l}0.630^{1} \\
(0.216) \\
(2.913)\end{array}$ \\
\hline
\end{tabular}

fishermen fishing

with traps only

22.60

34.95

flshermen fishing with lines only

I Compared to fishermen fishing with traps only. 
TABLE VI-2 (continued)

TESTS OF TECHNICAL EFFICIENCY

(Using the Present Value of the Boat and the Motor as an Independent Variable)

\section{Line Fishing}

Average

power of

the motor
Average

price of

one hp.
Dummy

variable

In HP

In $\$$

DIVISION I

motor > $30 \mathrm{HP}$

75.2

5.65

1.437

motor $\leq 30 \mathrm{HP}$

19.00

31.28

$(0.451)$

(3.185)

DIVISION II

motor $>40 \mathrm{HP}$

84.00

2.38

1.658

motor $\check{\leq} 40 \mathrm{HP}$

20.31

36.49

$(0.501)$

$(3.305)$

DIVISION III

boats with winch

boats without winch

DIVISION IV and

DIVISION V

fishermen fishing

with traps \& lines

47.90

16.76

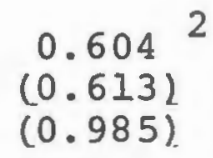

ILshermen fishing with traps only

fishermen fishing with lines only

18.36

32.48

${ }^{2}$ Compared to fishermen fishing with lines only. 
II Price Efficiency

In this section, tests are conducted to determine if the fishermen are price efficient, that is to see if they choose the optimum combinations of inputs, given the set of prices and the technical coefficients:

Equation $(4-40)$ gave:

$\begin{aligned} & 1 / n \sum_{i=1}^{n}\left(\ln x_{q i}-\ln x_{0 i}\right)+\ln p_{0}-\ln p_{q}-1 / 2600+\ln 3 / 2=R \\ &+\ln \alpha\end{aligned}$

As mentioned in Chapter IV, because of the statistical distribution of the left hand side of equation (4-40) as well as of $\log \left(\alpha_{q}\right)$ it was not possible to conduct a statistical test to compare those two terms. For this reason some caution will be necessary when interpreting the results.

I Trap Fishing

a) Price efficiency of the investment in the boat and the motor.

When testing for the price efficiency of investment in boat and motor for the 39 fishermen fishing with traps equation $(4-40)$ becomes:

$$
\begin{aligned}
(6-4) \quad 1 / 39 \sum_{i=1}^{39}\left\{-\ln x_{O i}+\ln B_{i}-\operatorname{lnp} p_{0}+\operatorname{lnpB}\right\}-1 / 2 \hat{\theta}_{O 0}+\ln (\gamma-1)= \\
R_{B}+\ln \alpha_{B}
\end{aligned}
$$

where each symbol is

$\mathrm{x}_{\mathrm{oi}}$ catch in pounds

$B_{i}$ length of the boat

$P_{0}$ price of a pound of fish 
$\mathrm{P}_{\mathrm{B}}$ price of one foot of boat

$\hat{\theta}_{\text {oo }}$ standard error of the regression using the same variables

$\gamma$ crew's share under the lay system

$R_{B}$ disturbance term accounting for possible price inefficiency

$\alpha_{B}$ coefficient of $\ln B$ in the regression

Note that:

$$
L x_{o i}+l n p_{0}=L P R I_{i}
$$

where PRI is the total catch in dollars

and

$\operatorname{lnB_{i}}+\operatorname{lnp}_{B}$ is the cost of the boat.

Consequently it is possible to write equation (6-4);

$(6-5) \quad 1 / 39 \sum_{i=1}^{30}\left(L D T_{i}-L P R I_{1}\right)-1 / 20_{00}+\ln (3 / 2)$

LPRI $_{i}$ natural logarithm of the total revenue from
trap fishing

LDT $_{i}$ natural logarithm of the depreciation of the boat and motor plus maintenance imputed to trap fishing:

This share DT for trap fishing is equal to:

$\mathrm{DT}=\mathrm{TD} 1 \times \mathrm{Z} 1$

TD total depreciation on the boat and motor plus maintenance

Zl proportion of the total revenue stemming from traps Computing equation (6-5) gives:

$$
(6-5 a) \quad 1 / 39 \sum_{i=1}^{39}\left(\operatorname{LDT}_{i}-\operatorname{LPR} 1\right)-1 / 20_{00}+\ln (3 / 2)=1.1778
$$

where $\sigma_{00}$ is the standard error in the regression $(6-6)$.

Total for price efficiency, the value of equation

$(6-5 a)$ must be compared to the coefficient of IDT in equation $(6-6)$. 


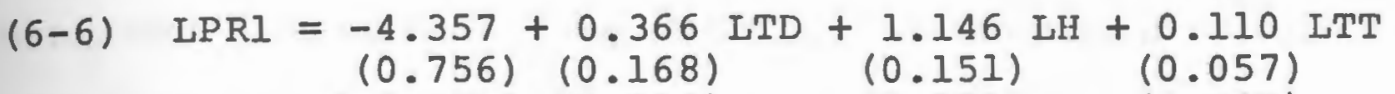

$$
\begin{aligned}
& \begin{array}{llll}
(-5.759) & (2.174) & (7.582) & (2.747)
\end{array} \\
& -0.058 \mathrm{LV}+0.398 \mathrm{Q}+0.435 \mathrm{~W} \\
& (0.052) \quad(0.221) \quad(0.185) \\
& (-1.112) \quad(1.797) \quad(2.344)
\end{aligned}
$$

The symbols are the same as in equation $(6-3)$

The value of equation $(6-5 a):-1.177$ is to be compared with $\ln (0.366)=-1.005$. In this case the difference between the two values is small and does not allow the conclusion that the fishermen are not price efficient.

b) Price efficiency of the investment in traps

To test if the fishermen are using the right number of traps given their present level of the other inputs, the following analysis was conducted.

$$
(6-7) \frac{1}{39} \sum_{i=1}^{39}\left(\operatorname{LTT}_{i}-\operatorname{LPRI}_{i}\right)+\ln (20)+\ln (3 / 2)=\frac{-0.970}{(1.266)}
$$

$\$ 20.00$ is the expected cost of a trap. The price of a trap is $\$ 16$. On the whole island the fishermen lose $1 / 4$ of their traps every year. For this reason the annual cost of owning for instance, 100 traps is $100 \times 16 \times \frac{5}{4}=100$ $x 20=\$ 2000$. (from equation $(6-7)$ and using $\hat{\sigma}_{00}=.0532$ (from equation 6-6). An important note should be added foncerning the price of the traps. Most of the fishermen presently use steel framed traps. They usually buy the frame already made and put the chicken wire around it themselves. In that case the material costs them $\$ 16$. Using 


\section{4}

mangrove framed traps, the material is cheaper. However, the life of a mangrove framed trap is shorter than the life of a steel framed one. Consequently, it is reasonable to estimate the expected annual cost of a trap at $\$ 20$. regardless of the type of frame.

$$
(6-8) \quad \frac{1}{39} \sum_{i=1}^{39}\left(\operatorname{ITT}_{i}-\operatorname{LPR}_{i} L+\ln (20)-1 / 28_{00}+\ln (3 / 2)=\right.
$$

This is to be compared with the natural logarithm of the coefficient of LTT in equation $(6-6)$ in $(0.110)=-2.227$. The difference between those two numbers is sufficiently large to conclude that, given the present level of the other inputs, the fishermen are investing too much in traps.

\section{Line Fishing}

In this case the test of price efficiency was conducted for the input boat-motor only. None of the other inputs, except labor, had a significant regression coefficient.

For this test the following regression was used:

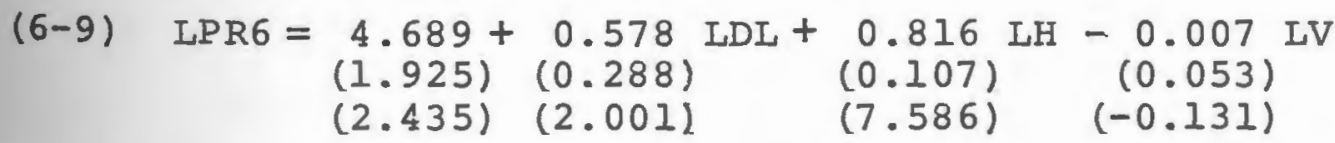

$R^{2}=0.840 \quad F(3,16)=28.131 \quad \hat{\sigma}_{00}=0.527$

Where LPR6 is the natural logarithm of the total revenue from lines. The cost of capital was computed in the same fashion as for trap fishing.

$$
\text { (6-10) } \mathrm{DL}=\mathrm{TD} \times \mathrm{Z} 2
$$

DL depreciation on the boat and the motor, plus maintenance imputed to line fishing. 
TD total depreciation on the boat and the motor plus maintenance.

It was noted in Chapter IV that this motor of imputing cost was acceptable if the coefficients of capital in the regressions were similar. This is almost the situation since for trap fishing the capital coefficient is 0.366 while for hand line fishing it is 0.578 .

From equation $(6-9)$ In $(0.578)=-0.548$, which is to be compared with: $(6-11) \frac{1}{20} \sum_{i=1}^{20}\left(\right.$ In DL - In PR6) $-1 / 2 \hat{0}_{00}+\ln (3 / 2)=-1.679$ In this case the difference between the two values seems large enough to conclude safely that, given the present level of other inputs, the fishermen would increase their profit if they had larger boats. 
II Comparison of the Price Efficiencies for Various Groups of Fishermen

The fishermen were divided into groups according to power of the motor, presence of a winch and those using one method of fishing only compared to those fishing with both traps and lines.

For each division the following relationship was

computed :

I) For trap fishing

A) Input boat-motor

$(6-12) \frac{1}{n} \sum_{i=1}^{n}\left(\ln \mathrm{DT}_{i}-\ln \mathrm{PRI}_{i}\right)-1 / 2 \hat{\sigma}_{00}+\ln (3 / 2)=\theta_{\mathrm{T}}$

B) and traps

$(6-13) \frac{1}{n} \sum_{i=1}^{n}\left(\ln D T_{i}-\ln P R I_{i}\right)-1 / 28_{00}+\ln (3 / 2)=\varnothing$

II) For line fishing

Input boat-motor

(6-14) $\frac{1}{n} \sum_{i=1}^{n}\left(\ln \mathrm{DL}_{i}-\ln \mathrm{PRI}_{i}\right)-1 / 2 \hat{\theta}_{00}+\ln (3 / 2)=\theta I$

The result of those computations are summarized in Table VI-3.

In Division IV the sample is divided between those using both traps and lines and those using traps only. In Division $v$, fishermen using both traps and lines are compared to those fishing with lines only. The analysis 
TABLE VI-3

COMPARISON OF PRICE EFFICIENCY BETWEEN GROUPS OF FISHERMEN.

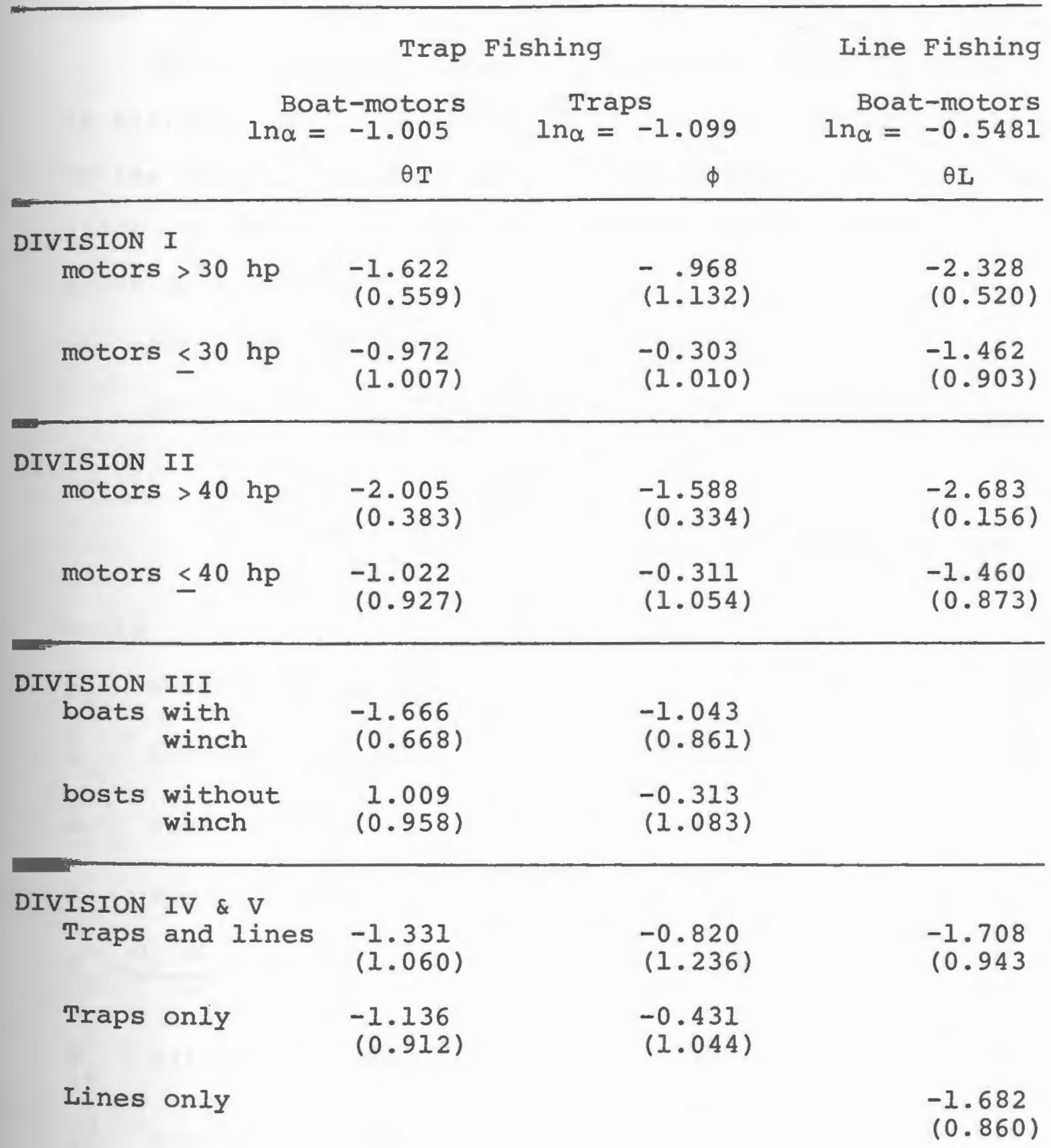


of price efficiency is between groups within divisions by computing $T, L$ and $\varnothing$ (Table VI-3) as shown in equations $(6-12),(6-13),(6-14)$.

Tests of hypothesis were conducted for T, L and $\varnothing$ in each division. Treating $1 / 2$ oo as a constant, according to the central limit theorem, the left hand sides of equations $(6-12),(6-13)$ and $(6-14)$ have a distribution which tends to be normal.

Null hypothesis

$$
\mathrm{H}_{0}: \quad \mu_{1}=\mu_{2}
$$

Alternative hypothesis $\mathrm{H}_{1}: \quad \mu_{1} \neq \mu_{2}$

$$
\begin{aligned}
& (6-15) \quad t=\frac{\bar{x}_{1}-\bar{x}_{2}}{\sigma_{00}} \sqrt{\frac{n_{1} n_{2}}{n_{1}+n_{2}}} \\
& \text { with } n_{1}+n_{2}-2 \text { degrees of }
\end{aligned}
$$

where

$\bar{x}_{1}$ average of sample 1

$\overline{\mathrm{x}}_{2}$ average of sample 2

$\mathrm{n}_{1}$ size of sample 1

$\mathrm{n}_{2}$ size of sample 2

$\theta_{\mathrm{OO}}^{2}=\frac{\mathrm{n}_{1} \mathrm{~s}_{1}+\mathrm{n}_{2} \mathrm{~s}_{2}}{\mathrm{n}_{1}+\mathrm{n}_{2}-2}$

$\mathrm{s}_{1}^{2}$ variance of sample 1

$\mathrm{s}_{2}^{2}$ variance of sample 2

Table VI-4 summarizes the results of the tests. 
TABLE VI-4

t-TESTS FOR COMPARIIV PRICE EFFICIENCY

AMONG GROUPS OF FISLIERMEN.

\begin{tabular}{lccc} 
& $\begin{array}{c}\text { Trap Fishing } \\
\text { Boats } \\
\text { of } \theta T\end{array}$ & $\begin{array}{c}\text { Traps } \\
\text { of } \varnothing\end{array}$ & $\begin{array}{c}\text { Line Fishing } \\
\text { Boats } \\
\text { to of } \text { eI }\end{array}$ \\
\hline Division I & 2.039 & 1.779 & 1.888 \\
Division II & 2.490 & 2.812 & $2.720^{*}$ \\
Division III & 1.846 & 1.949 & \\
Division IV & 0.524 & 0.936 & \\
Division V & & & 0.061 \\
\hline
\end{tabular}

*reject null hypothesis at the 2.58 level. 
If 2.5 percent is chosen as the risk of type I error the null hypothesis is rejected for the values of $t$ marked (*). At the 5 percent level the null hypothesis is always rejected except for groups IV and V. This indicates that the fishermen in the various groups behave quite differently.

a) Comparison between the levels of investment in boat-motor.

Both in Divisions I and II the owners of small boats seem to be more efficient when they invest in boat and motor regardless of whether they fish with traps or with lines. This is an apparent conflict with the conclusions of Section I.

In fact it is another effect of the cost structure which was presented earlier in Table VI-2. An example will explain the present situation. A fishermen using an outboard motor of $40 \mathrm{hp}$ may have invested too much because such a motor cost him $\$ 900$. On the other hand, a fisherman using a used inboard motor of $80 \mathrm{hp}$ may not have invested enough because such a motor cost him only $\$ 200$. In such a case it may appear that the fishermen of the big boats do not invest too much. At the same time, it is possible that, when all the fishermen are included into one sample, the results show that more investment should be undertaken. In the extreme example proposed 


\section{1}

above this would suggest that the fishermen should invest in powerful inboard motors because they can buy them at relatively lower prices.

b) Comparison between the levels of investment in traps.

In Table VI-4 it is also shown that there is a significant difference between the price efficiency of the owners of small boats when they invest in traps. Earlier it was found that, as a whole, the fishermen had a tendency to have too many traps but, as it appears now, this varies considerably among the groups within divisions. In Table VI-3 it appears that the owners of boats with an engine over 30 hp are price efficient, while if the sub-group is limited to the fishermen who have a boat with a motor over $40 \mathrm{hp}$ there is even a tendency to have too few traps. This significant difference between the positions of the various groups of fishermen is probably due to the fact that the fishermen tend to fix the number of their traps according to the common amount of traps owned by the other fishermen in their community rather than according to their real needs. 
IV Investing in an Winch

When testing for the technical efficiency of a winch the catch function for firm $i$ had the form:

$$
\text { (6-16) } L X I_{i}=C_{i}+n s_{i}+\alpha_{1} L_{i}+\alpha_{2} L_{i}+\alpha_{3} L V_{i}+\alpha_{4} L_{T T}
$$

$S=I$ if the fisherman used a winch

$\mathrm{S}=0$ if the fisherman did not use a winch

or $(6-17) x l_{i}=A_{i} e^{n} B_{i}^{\alpha 1} H_{i}^{\alpha 2} v_{i}^{\alpha 3} \operatorname{Tr}_{i}^{\alpha 4} e^{u_{0 i}}$

The expression of the expected profit can be stated:

$$
\begin{aligned}
& \begin{array}{lllll}
\alpha_{1} & \alpha_{2} & \alpha_{3} & \alpha_{4} & 1 / 2 \delta_{00}
\end{array} \\
& \text { (6-18) } \quad \mathrm{E}(\pi)=\mathrm{p}_{0} \mathrm{~A}_{i} e^{n_{\mathrm{B}_{i}}} \mathrm{H}_{i} \mathrm{v}_{i} \mathrm{TT}_{i} \text { e }-\mathrm{p}_{W}-\mathrm{DT}_{i}-\mathrm{p}_{\mathrm{V}} \mathrm{Vi}
\end{aligned}
$$

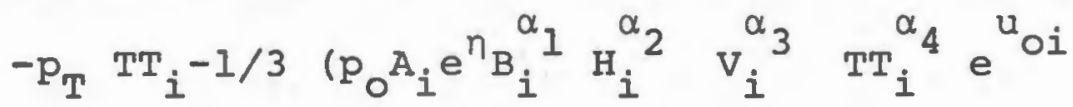

$$
\begin{aligned}
& \left.-p_{v} v_{i}\right)
\end{aligned}
$$

where $P_{0}$ price of one pound of fish

$\mathrm{P}_{\mathrm{W}}$ price of the winch

DT depreciation on boat and motor imputed to trap fishing

$P_{v}$ price of gasoline

$\mathrm{P}_{\mathrm{T}}$ price of a trap

$I / 3\left(\mathrm{p}_{\circ} \mathrm{A} \mathrm{e}^{\eta_{B_{i}^{\alpha 1}} \mathrm{H}_{i}^{\alpha 2}} \mathrm{v}_{i}^{\alpha 3} \mathrm{TT}_{i}^{\alpha 4} \mathrm{e}^{\mathrm{u}} \mathrm{oi}^{\mathrm{i}}-\mathrm{p}_{\mathrm{v}} \mathrm{v}_{i}\right)$ price of labor according to the lay system.

If the expected profit is to be maximized, the first order condition to invest in an optimum size winch is:

$$
\text { (6-19) } \frac{\partial E(\pi) i}{\partial e}=\frac{p_{0}{ }^{X I_{i}} e^{n}}{(3 / 2) e \frac{1 / 28}{1 / 00}}
$$


or ex-post,

$$
\text { (6-20) In } p_{0}+\ln x l_{i}-\ln (3 / 2)-1 / 280_{00}+\eta=\ln p_{w}+u_{i 0}
$$

For the group of 11 fishermen fishing with winches equation $(6-18)$ becomes

$$
(6-21) \frac{1}{11} \sum_{i=1}^{11}\left(\ln p_{0}+\ln x l_{i}-\ln (3 / 2)+1 / 28_{00}\right)+n=8.005
$$

from which

8.005

$$
\text { e } \quad=1488
$$

This means that as long as the pot hauler costs less than $\$ 1488$, the fishermen who use one are justified in doing so. The prices of the pot haulers used by the Puerto Rican fishermen were not recorded during the interview. However, mechanical pot haulers are available in Puerto Rico at a price of less than $\$ 500$.

To conclude this chapter it is important to emphasize the difference in technical efficiency between the fishermen fishing both with traps and hand lines. It should also be noted that the captains of the larger, more powerful boats are not more technically efficient than the captains of the smaller boats.

Among the fishermen exclusively trap fishermen exclusively trap fishing a sizeable difference in their catch was recorded when they use a winch.

The meaning of the tests of price efficiency should also be recalled. They indicate whether the fishermen perceive the prices of the inputs correctly. When it is found 


\section{4}

that the fishermen invest too much or too little in one input it is always given the level of the other inputs. In this chapter it was determined, that with that constraint, in general, the fishermen invest too much in traps and not enough in boats and motors. This means that they perceive the price of the traps as lower than it really is and the price of the combination boat-motor as higher that it really is. Yet, when maximizing profit with all levels of inputs variables, it may be found that bigger and more powerful boats are needed, and it could happen that the number of traps presently owned is optimum, for those larger boats. But this would be an accident.

The results of this chapter suggest that the Puerto Rican fishermen have a poor idea of the real prices of the inputs especially boats and traps they are using. In the absence of any other action their returns could be improved if they acquired a better notion of those prices. 
VII SOME POLICY SUGGESTIONS TO INCREASE THE INCOME OF THE PUERTO RICAN FISHERMEN

Chapters $V$ and VI provided a structural and a behavioral description of trap and line fishing. From the findings of those two chapters, it is possible to suggest policies for improving the economic situation of the fishermen.

Before considering policy alternatives this chapter first describes more fully the present economic situation of the fishermen, and then develops a model suitable for evaluating policy measures. 
I The Present Economic Performance

The total value of the annual catch, the return to the captain and the crew, and the return on the present value of the boat plus motor by various motor sizes and equipment types for trap fishermen are given in Table VII-1. Similar information for line fishermen is presented in Table VII-2.

1) The total annual catch is measured in dollars TR

2) The total annual return to the captain, TRC, includes his profit plus his return on capital and on labor and management. It is what he has left after he has paid all his fixed and variable costs.

(7-1) TRC = TR - Depreciation - maintenance - crew's sharecost of gasoline - cost of the traps for cost of the lines)

The depreciation in this case is the straight line depreciation on the boat, the motor, and the winch.

3) Annual net income to the captain

This was computed by subtracting from the total annual return the interest the captain pays on his boat and motor. An interest of 5 percent was used because it is the cost of capital to the fishermen taking loans from the Puerto Rican Department of Agriculture.

This represents the return to the captain's labor, management and profit. 
4) The annual crew's share CS, is equal to:

$$
(7-2) \text { CS }=1 / 3(T R \text { - cost of gasoline) }
$$

This is the most common way of remunerating the crew, although there are other systems.

5) The average annual return on the present value of the boat and the motor ${ }^{2}$ is computed as follows:

$$
\text { (7-3) } \quad r=\frac{T R-D-M-2 C S-V-T}{P E+P B}
$$

TR total revenue

D depreciation on the boat, the motor, and the winch

$M$ maintenance

2 CS twice the crew's share. In this way the captain's labor is remunerated as much as his crew's

$\checkmark$ cost of gasoline

$T$ cost of the traps or the lines

$P E$ present value of the motor

PB present value of the boat

In order to compute this return it was necessary to arbitrarily assign a value to the captain's labor. By deciding to give him the same remuneration as his crew, it provided a basis to compare the rate of return $r$ to the interest rate the captain has to pay. With this kind of imputation if $r>5$ percent the captain is financially better off than his crew, but if $r<5$ percent the captain would make more money being a deckhand provided that there is only one deckhand in addition to the captain. Note that the same conclusion can be reached by comparing the captain's net income to his crew's share.

If a fisherman is involved in both trap and line fishing, the returns are computed for each activity. The va- 
lues are calculated for each of the activities according to the relative contribution to the total revenue. If a fisherman derives 10 percent of his total revenue from line fishing and 90 percent from trap fishing, when computing the return on the boat and motor from line fishing, only 10 percent of the total depreciation 10 percent of the maintenance, and 10 percent of the sum of the present value of the boat and motor are included.

It appears in Tables VII- 1 and VII-2 that the more powerful boats yield higher returns and the highest returns are obtained when fishing with lines rather than with traps. Actually, when fishing with traps, only the boats having a motor over $40 \mathrm{HP}$, and the boats equipped with a winch yield positive returns on the present value of boat plus motor. The boats equipped with an engine between 30 and 40 HP have very low returns. In fact in this case, the captain's net annual income is only about half of the crew's share. In most cases when fishing with traps the net annual income of the captain is lower than the crew's share precisely because of the negative returns on boat and motors.

When fishing with lines all the returns on boat and motor are positive. The difference in the returns on boat and motor between lines and traps can be explained by the fact that trap fishing requires a higher level of investment, and this is further accentuated by the fact that given the present prices and catch rates the fishermen have overinvested in traps. 
TABLE VII- 1

ECONOMIC RETURNS TO THE TRAP FISHING OPERATIONS IN 1972

\begin{tabular}{|c|c|c|c|c|c|}
\hline & $\begin{array}{l}\text { Total } \\
\text { value } \\
\text { of } \\
\text { annual } \\
\text { catch }\end{array}$ & $\begin{array}{l}\text { Total } \\
\text { annual } \\
\text { return } \\
\text { to } \\
\text { captain }\end{array}$ & $\begin{array}{l}\text { Net } \\
\text { annual } \\
\text { income } \\
\text { of the } \\
\text { captains }\end{array}$ & $\begin{array}{l}\text { Annual } \\
\text { crew's } \\
\text { share }\end{array}$ & $\begin{array}{l}\text { Annual } \\
\text { return on } \\
\text { the present } \\
\text { value of } \\
\text { boat and } \\
\text { motor }\end{array}$ \\
\hline & In $\$$ & In $\$$ & In $\$$ & In $\$$ & In $q$ \\
\hline All traps & $\begin{array}{c}5575 \\
(9726)^{1}\end{array}$ & $\begin{array}{c}1750 \\
(3252)\end{array}$ & $\begin{array}{l}1684 \\
(3216)\end{array}$ & $\begin{array}{l}1696 \\
(2019)\end{array}$ & $\begin{array}{l}-45 \\
\quad(1.4184)\end{array}$ \\
\hline Traps \& lines & $\begin{array}{c}9978 \\
(9987)\end{array}$ & $\begin{array}{c}4519 \\
(5292)\end{array}$ & $\begin{array}{c}4419 \\
(5222)\end{array}$ & $\begin{array}{c}3144 \\
(3178)\end{array}$ & $\begin{array}{r}-19 \\
(2.2892)\end{array}$ \\
\hline Traps only & $\begin{array}{c}4402 \\
(4705)\end{array}$ & $\begin{array}{c}1011 \\
(2013)\end{array}$ & $\begin{array}{c}954 \\
(2000)\end{array}$ & $\begin{array}{c}1310 \\
(1426)\end{array}$ & $\begin{aligned}-52 \\
(1.1308)\end{aligned}$ \\
\hline Motor > $30 \mathrm{HP}$ & $\begin{array}{c}10854 \\
(13756)\end{array}$ & $\begin{array}{c}3917 \\
(4544)\end{array}$ & $\begin{array}{c}3795 \\
(4509)\end{array}$ & $\begin{array}{l}3300 \\
(2521)\end{array}$ & $\begin{aligned}-21 \\
\quad(1.9614)\end{aligned}$ \\
\hline Motor $\leq 30 \mathrm{HP}$ & $\begin{array}{c}3139 \\
(3797)\end{array}$ & $\begin{array}{c}749 \\
(1809)\end{array}$ & $\begin{array}{c}709 \\
(1799)\end{array}$ & $\begin{array}{c}956 \\
(1198)\end{array}$ & $\begin{array}{l}-56 \\
(1.1157)\end{array}$ \\
\hline Motor $>40 \mathrm{HP}$ & $\begin{array}{l}14506 \\
(7588)\end{array}$ & $\begin{array}{c}6645 \\
(4451)\end{array}$ & $\begin{array}{c}6483 \\
(4437)\end{array}$ & $\begin{array}{c}4502 \\
(2545)\end{array}$ & $\begin{array}{l}87 \\
(1.0508)\end{array}$ \\
\hline Motor $\leq 40 \mathrm{HP}$ & $\begin{array}{c}2662 \\
(3643)\end{array}$ & $\begin{array}{r}832 \\
(1980)\end{array}$ & $\begin{array}{c}784 \\
(1969)\end{array}$ & $\begin{array}{l}1170 \\
(1419)\end{array}$ & $\begin{array}{l}-70 \\
\quad(1.3439)\end{array}$ \\
\hline $\begin{array}{l}\text { Boats with a } \\
\text { winch }\end{array}$ & $\begin{array}{l}10365 \\
(8577)\end{array}$ & $\begin{array}{c}3943 \\
(4755)\end{array}$ & $\begin{array}{l}3830 \\
(4711)\end{array}$ & $\begin{array}{c}3229 \\
(2705)\end{array}$ & $\stackrel{2}{(1.3721)}$ \\
\hline $\begin{array}{l}\text { Boats without } \\
\text { a winch }\end{array}$ & $\begin{array}{l}3571 \\
(4073)\end{array}$ & $\begin{array}{c}845 \\
(1833)\end{array}$ & $\begin{array}{c}799 \\
(1821)\end{array}$ & $\begin{array}{c}1057 \\
(1240)\end{array}$ & $\begin{array}{r}-63 \\
(1.3721)\end{array}$ \\
\hline$\leq_{\leq}^{30} \mathrm{HP} \leq \mathrm{motor}$ & $\begin{array}{c}7203 \\
(6923)\end{array}$ & $\begin{array}{c}1189 \\
(2734)\end{array}$ & $\begin{array}{c}1108 \\
(2775)\end{array}$ & $\begin{array}{c}2098 \\
(2010)\end{array}$ & $\begin{array}{l}-242 \\
(1.2806)\end{array}$ \\
\hline
\end{tabular}

Source: Field Survey of 39 fishermen, 1973-74 and Department of Agriculture sale tickets for the period.

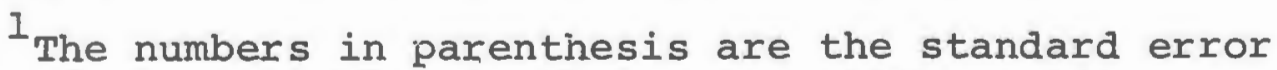
of the variables in their respective samples. 
160

TABLE VII-2

ECONOMIC RETURNS TO THE LINE FISHING

OPERATIONS IN 1972

Total Total Net

value

of

annual

catch annual annual return income

to of the

captain captains
Annual Annual

crew's return on

share the present value of boat and motor

In $\$$ In $\$$ In $\$$ In $\$$ In 8

All lines

1550

$(1367)^{1}$

471

(818)

123

(729)

(629)

2212

(1415)

627

(1038)

451

(813)

118

(623)

Lines only

Motor > $30 \mathrm{HP}$

1045

(801)

471

(445)

599
$(1036)$

458

(436)

Motor $\leq 30 \mathrm{HP}$

1718
$(1494)$

471

(922)

449
$(918)$

514

(502)

(905)

460

(892)
1658
$(1463)$
Field Survey of 20 fishermen, 1973-74 and Department of Agriculture sale tickets for the period.

$1_{\text {The number in parenthesis is the standard error }}$ of the variables in their respective samples. 


\author{
TABLE VII-3 \\ ECONOMIC RETURNS TO THE FISHERMEN USING \\ BOTH TRAPS AND LINES IN 1972
}

Annual Catch

Total annual returns to

the captain

Annual net income to the captain:

Annual crew's share:

Annual return on present value of the boat and motor

\section{$\$ 10707$}

$\$ 4633$

$\$ 4548$

$\$ 3259$

-18.1 percent

Source: Field survey of 9 fishermen, 1973-74 and Department of Agriculture's sale Tickets for the same period. 
II Use of the Model for Policy Development

In Chapter $V$ and Chapter VI the estimated catch functions were given as:

$$
\text { (7-5) } x_{o i}=A{\underset{q}{q=1}}_{q}^{Q} x_{q i}^{\alpha} e^{u_{o i}}
$$

In Chapter IV however, it was shown that the full expression of equation (7-5) was

$$
\begin{aligned}
\text { (7-6) } x_{\circ i} & =\left\{N^{*}-\frac{1}{b} \sum_{i=1}^{n}\left(k M \prod_{q=1}^{Q} x_{q i}^{\alpha} e^{u_{0 i}}\right\}\right. \\
K M & \stackrel{Q}{q=1} x_{q i}^{\alpha} e^{u_{o i}}
\end{aligned}
$$

When estimating the catch functions at a single point in time $A$ was a constant. For the purpose of policy development it is not acceptable treatment of A. Difficulties arise since it is not possible given present knowledge of fish population dynamic to estimate the components of $A$. Neither $N^{*}$, the maximum level that the population could reach naturally, the coefficient $b$, nor the effects of crowding externalities embodies in $M$ are known.

Nevertheless, one important observation can be made concerning the relationship expressed by equation (7-6) which is useful for better estimating the effects of given policies: if $\mathrm{A}$ is not a constant any increase (decrease) in the fishing power of the firms will have less (more) effect on the catch than if $A$ is treated as a constant. 
1) Change in the fishing power which does not effect M directly.

If the fishermen's skill improves there will be no direct effect on the crowding externalities. However, the catch will not increase by as much as it would if $A$ were a constant. The reason for this is that as the fishing pressure increases, $\frac{I}{b} \sum_{i=1}^{n}\left(K M_{q} \prod_{q=1}^{Q} x_{q i}^{q} e^{u_{o i}}\right)$ will also increase and this will lower A. Even in this case it is possible that the economic position of the fishermen improves. If this is so it is likely that new fishermen will enter the fisheries which would directly affect $M$ through the crowding externalities, further reducing the catch.

2) Change in fishing power which affect $M$ directly. This could happen if either the number of boats or the number of traps were increased or if the fishermen went to sea more often. In this eventuality similar adjustments as described above would take place.

Because it is difficult to forecast exactly the effects of a policy decision, the findings presented in the following section serve only as an indication of the direction in which the changes can be expected to occur. In the absence of better information on $\mathrm{N}^{*}, \mathrm{~b}$, and $\mathrm{M}$, caution will be necessary when formulating policy. For instance, a size 
boat which would maximize profit if A were constant may be too large because of the cumulative effects of all the fishermen on stocks (through increase in $\sum_{i=1}^{n}$ (K M $\prod_{q=1}^{Q}$ $x_{q i}^{\alpha} e^{u_{o i}}$. However, keeping those caveats in mind, it is possible to suggest some policy directions for improving the economic situation of the Puerto Rican fishermen. 


\section{Policy Direction: Increasing technical efficiency for the trap fishermen}

For trap fishing it is possible to suggest some limited measures which would increase profit. In addition, one can make recommendations in order to attempt to maximize profit, which apply to line fishing as well.

In Chapter VI it was shown that the fishermen fishing also with lines caught on the average 77 percent more fish in their traps than the fishermen fishing with traps alone. In addition, the fishermen who owned a winch caught 61 percent more fish. When both factors were combined their individual effect was reduced but it was still significant. Equation $(6-3)$ gave:

$$
\begin{aligned}
L\{E(P R I)\}= & -1.285+0.395 Q+0.274 \mathrm{~W}+0.793 \mathrm{LB}+ \\
& (1.126)(0.206) \quad(0.198)(0.428) \\
& (-1.140)(1.916) \quad(1.384) \quad(1.852) \\
& -0.077 \mathrm{LV}+0.332 \mathrm{LTT}+\frac{1}{2}(0.473)^{2} \\
& (0.055) \quad(0.139) \\
& (-1.399) \quad(2.394)
\end{aligned}
$$

$L\{E(P R I)\}$ natural logarithm of the expected value of the total revenue from traps.

$Q=1$ if the fishermen fishes with traps and lines

$Q=0$ if the fisherman fishes with traps only

$W=1$ if the boat is equipped with a winch

$W=0$ if the boat is not equipped with a winch

The other variables are the natural logarithm of

LB $=$ length of the boat

$\mathrm{LH}=$ number of man days at sea

$L V=$ number of gallons of gasoline used in a year

LTT $=$ number of traps owned 
(0.4738) being the standard error of the regression. $1 / 2(0.4738)^{2}$ is the correcting term necessary to obtain the expected value $L\{E(P R I)\}$.

This suggests two actions which could be taken to improve the income of the trap fishermen. First is to train the fishermen in order to improve their knowledge of the fish behavior and second to equip all the boats with a winch.

Some notions of the effects of these actions, under the assumption of A constant (no stock externality) can be seen from the following analysis.

The expected value of the total revenue from trap fishing is expressed by equation (7-7). Equation $(6-3)$ would become:

$$
\begin{aligned}
& (7-7) L\{E(P R I)\}=-0.615+0.793 \mathrm{LB}+1.190 \mathrm{LH}-0.077 \mathrm{LV}+ \\
& \begin{array}{llll}
(0.257) & (0.428) \quad(0.156) \quad(0.055)
\end{array} \\
& \begin{array}{llll}
(-2.439) & (1.852) \quad(7.622) & (-1.399)
\end{array} \\
& 0.332 \mathrm{LT}+\frac{1}{2}(0.473)^{2} \\
& (0.139) \\
& (2.394)
\end{aligned}
$$

The data in Table VII-4 gives some indication of the average effect on the value of the catch and the returns if equation (7-7) was the actual catch function. Since the returns to the captain are what remains from total revenue after payment for all variable and fixed inputs they are a good measure of the fishermen's performance. For this reason the percentage increase in return to the captain, as shown in the last column of Table VII-4, is a good indica- 
POTENTIAL RETURNS TO THE TRAP FISHERMEN AFTER ADDITIONAL TRAINING AND USING BOATS EQUIPPED WITH A WINCH

\begin{tabular}{|c|c|c|c|}
\hline & $\begin{array}{l}\text { Total } \\
\text { value of } \\
\text { annual } \\
\text { catch }\end{array}$ & $\begin{array}{l}\text { Total } \\
\text { annual } \\
\text { return to } \\
\text { captain }\end{array}$ & $\begin{array}{l}\text { Net } \\
\text { annual } \\
\text { income } \\
\text { of the } \\
\text { captain }\end{array}$ \\
\hline & In $\$$ & In $\$$ & In $\$$ \\
\hline All traps & $\begin{array}{c}9120 \\
(9106)^{1}\end{array}$ & $\begin{array}{c}4077 \\
(5018)\end{array}$ & $\begin{array}{c}4011 \\
(4982)\end{array}$ \\
\hline Traps and lines & $\begin{array}{l}13405 \\
(13297)\end{array}$ & $\begin{array}{c}6779 \\
(7498)\end{array}$ & $\begin{array}{c}6779 \\
(7421)\end{array}$ \\
\hline Traps only & $\begin{array}{c}7977 \\
(7530)\end{array}$ & $\begin{array}{c}3357 \\
(4001)\end{array}$ & $\begin{array}{c}3300 \\
(3986)\end{array}$ \\
\hline Motor > $30 \mathrm{HP}$ & $\begin{array}{l}15984 \\
(9282)\end{array}$ & $\begin{array}{c}7315 \\
(5568)\end{array}$ & $\begin{array}{c}7194 \\
(5527)\end{array}$ \\
\hline Motor $\leq 30 \mathrm{HP}$ & $\begin{array}{c}5952 \\
(7191)\end{array}$ & $\begin{array}{l}2582 \\
(4034)\end{array}$ & $\begin{array}{c}2542 \\
(4024)\end{array}$ \\
\hline Motor > $40 \mathrm{HP}$ & $\begin{array}{l}21752 \\
(6886)\end{array}$ & $\begin{array}{l}11467 \\
(3924)\end{array}$ & $\begin{array}{l}11305 \\
(3932)\end{array}$ \\
\hline Motor $\leq 40 \mathrm{HP}$ & $\begin{array}{c}6751 \\
(7392)\end{array}$ & $\begin{array}{c}2691 \\
(3873)\end{array}$ & $\begin{array}{c}2644 \\
(3861)\end{array}$ \\
\hline $\begin{array}{l}\text { Boats with a } \\
\text { winch }\end{array}$ & $\begin{array}{l}13947 \\
(10913)\end{array}$ & $\begin{array}{l}6331 \\
(6295)\end{array}$ & $\begin{array}{l}6218 \\
(6240)\end{array}$ \\
\hline $\begin{array}{l}\text { Boats without } \\
\text { a winch }\end{array}$ & $\begin{array}{c}7036 \\
(7520)\end{array}$ & $\begin{array}{c}3107 \\
(4123)\end{array}$ & $\begin{array}{c}3061 \\
(4108)\end{array}$ \\
\hline
\end{tabular}

The number in parenthesis is the standard error of the variables in their respective samples. 
TABLE VII-4 (continued)

POTENTIAL RETURNS TO THE TRAP FISHERMEN AFTER ADDITIONAL TRAINING AND USING BOATS EQUIPPED WITH A WINCH

\section{Annual \\ crew's \\ share}

Annual

return

on the

present

value of

boat and

motor
\& Change

in captain's return from

present situation

In $\$$ In 8

All traps

2878

Traps only

Motor > $30 \mathrm{HP}$

Motor $\leq 30 \mathrm{HP}$

Motor > 40 HP

Motor $\leq 40 \mathrm{HP}$

Boats with a winch

Boats without a winch
(2898)

4287

(4275)

$$
2502
$$

(2369)

5010

(2963)

1894

(2319)

6918

(2264)

47

(2.221).

16

(3.190)

56

(1.951)

55

(2.672)

44

(2.039)

202

(1.529)

2120

(3873)

18

(2.227)

81

(1.714)

(3484)

35

(2. 370)
133

50

232

87

244

73

224

61

161 
tion of the magnitude of change which could be expected: These are calculated as:

(7-8) Potential Returns - Actual Returns $\times 100$ Actual Returns

The values given in Table VII-4 must be interpreted with caution. They indicate only very roughly the level which might be reached if the actions suggested above were taken. In addition, since the assumption regarding $A$ as a constant may not be fully satisfied, the computation itself adds to the need for a careful interpretation of the results. This is partly reflected in the relatively large standard deviations of the estimates. Despite these limitations, if all the fishermen had the skill of the fishermen who fish with lines and traps, and if all the boats were equipped with a winch, it is clear that economic performance would be increased. This is demonstrated by the estimates of the annual returns on the boat and the motor given in Table VII-4 which are all positive, while, in most cases, today they are negative. Not surprisingly, the biggest improvement is possible for the small boats. Today few of them are equipped with a winch and most of their owners fish only with traps. As expected, the smallest changes are for the boats which are already equipped with a winch or for fishermen who currently fish with both traps and lines. 
IV Policy Directions for Both Traps and Lines Fishermen

I Improving price efficiency when investing in traps.

In section II of Chapter VI it was shown that, in general, fishermen had a tendency to underestimate the price of the traps although it was pointed out this varied considerable between groups.

If the number of traps owned by the fishermen were adapted to their actual needs, returns could also be increased. In order to demonstrate some of the effects which could be expected from such a measure, the optimum number of traps was computed for each fisherman given his present level of the other inputs: boat, motor presence of a winch, and number of men days at sea. Equation (7-9) was obtained by maximizing profit for the number of traps, keeping all other input levels constant. (7-9) $\quad L\{E(T T)\}=\frac{1}{1-0.332} \quad\{\ln (0.332)-1.285+0.395 Q$ $+0.274 \mathrm{~W}+0.793 \mathrm{LB}+1.190 \mathrm{LH}-0.077 \mathrm{LV}-\ln (20)-\ln (3 / 2)+$ $\left.\frac{3}{2}(0.473)^{2}\right\}$

IfE(TT) \} natural logarithm of the expected value of the optimum number of traps given the present level of the other inputs.

0.332 coefficient of the natural logarithm of the trap factor in equation (7-7).

All the other coefficients are also from equation (7-7). 


\section{1}

$Q=I$ if the fisherman fishes with traps and lines

$Q=0$ if the fisherman fishes with traps only

$W=1$ if the boat is equipped with a winch

$W=0$ if the boat is not equipped with a winch

The other symbols are the natural logarithms of:

IB length of the boat

LH number of man days at sea in a year

LV number of gallons of gasoline used in a year

20 iexpected price of a trap

$-\ln (3 / 2)$ is a term which already appeared when testing for price efficiency and which stems from the existence of the lay system

$1 / 2(0.473)^{2} 1 / 2 \hat{0}_{00}$ is the correcting term to obtain the logarithm of the expected value of the optimum number of traps.

$L\{E(T T)\}$ was first computed for each fisherman. Then the natural logarithm of the expected value of the return from traps was determined for each of them using equation $(7-10)$

$$
\begin{aligned}
(7-10) & L\{E(P R I)\}=1.285+0.395 \mathrm{Q}+0.274 \mathrm{~W}+0.793 \mathrm{LB}+ \\
& 1.190 \mathrm{LH}-0.077 \mathrm{LV}+0.332 \mathrm{~L}\{\mathrm{E}(\mathrm{TT})\}+1 / 2(0.473)^{2}
\end{aligned}
$$

From the value of $L\{E(P R I)\}$ obtained for each fishermen $E(P R I)$ was computed. This allows calculation of the measures used previously to estimate the performance of the fishermen. The average of those estimates for the different groups are presented in Table VII-4. In addition, the geometric means of the optimum number of traps are given for each group. This allows a comparison with the results of the test for price efficiency given in chapter VI.

For comparative purposes the percentage change in return to the captain resulting from optimal investment 
in traps was also computed.

Table VII-5 shows that some substantial improvements would be obtained if the fishermen used the proper number of traps. Although the potential changes in returns are not as great as from increasing skill and using winches, it appears that helping the fishermen to choose the correct number of traps would increase their returns from fishing. To that effect, equation (7-9) could be used as a guide. Many factors specific to each fisherman will affect the optimum number of traps he can handle. In most cases, however, substantial deviation from the estimate obtained from equation (7-9) should be corrected.

II Maximizing Profit

In order to maximize profit fishermen must not only choose the optimum level of variable inputs but they must also operate an optimum size boat. Practically this corresponds to two different types of decisions. In one case the fisherman will consider his boat as a constraint and he will want to invest in the number of traps which maximizes his profit given his present boat. In the second case, at other time, he will want to change boat and choose one which will maximize his profit, given some of his firm's characteristics like the number of days he goes at sea. It is this kind of situation which is discussed here. The decision process for this choice is the same for trap fishing and hand line fish- 
POTENTIAL RETURNS TO THE TRAP FISHERMEN PROVIDED THAT THEY USED THE OPTIMUM NUMBER OF TRAPS GIVEN THE PRESENT LEVEL OF THE OTHER INPUTS

\begin{tabular}{|c|c|c|c|c|}
\hline & $\begin{array}{l}\text { Total } \\
\text { value of } \\
\text { annual } \\
\text { catch }\end{array}$ & $\begin{array}{l}\text { Total } \\
\text { annual } \\
\text { return to } \\
\text { captain }\end{array}$ & $\begin{array}{l}\text { Net } \\
\text { annual } \\
\text { income } \\
\text { of the } \\
\text { captain }\end{array}$ & $\begin{array}{l}\text { Annual } \\
\text { crew's } \\
\text { share }\end{array}$ \\
\hline & In $\$$ & In $\$$ & In $\$$ & In $\$$ \\
\hline All traps & $\begin{array}{c}8450 \\
(13746)\end{array}$ & $\begin{array}{l}2944 \\
(5736)\end{array}$ & $\begin{array}{c}2878 \\
(5969)\end{array}$ & $\begin{array}{c}2654 \\
(4485)\end{array}$ \\
\hline Traps \& lines & $\begin{array}{c}22725 \\
(24109)\end{array}$ & $\begin{array}{c}9126 \\
(10119)\end{array}$ & $\begin{array}{c}9026 \\
(10031)\end{array}$ & $\begin{array}{c}7393 \\
(7880)\end{array}$ \\
\hline Traps only & $\begin{array}{c}4643 \\
(5439)\end{array}$ & $\begin{array}{l}1396 \\
(1989)\end{array}$ & $\begin{array}{c}1239 \\
(1977)\end{array}$ & $\begin{array}{r}1390 \\
\text { C1684 }\end{array}$ \\
\hline Motor > $30 \mathrm{HP}$ & $\begin{array}{c}19668 \\
(19440)\end{array}$ & $\begin{array}{c}7217 \\
(8505)\end{array}$ & $\begin{array}{c}7096 \\
(8464)\end{array}$ & $\begin{array}{c}6238 \\
(6435)\end{array}$ \\
\hline Motor $\leq 30 \mathrm{HP}$ & $\begin{array}{c}3272 \\
(5008)\end{array}$ & $\begin{array}{c}972 \\
(2013)\end{array}$ & $\begin{array}{c}932 \\
(2006)\end{array}$ & $\begin{array}{l}1000 \\
(1596)\end{array}$ \\
\hline Motor > $40 \mathrm{HP}$ & $\begin{array}{c}33448 \\
(18533)\end{array}$ & $\begin{array}{l}13429 \\
(8056)\end{array}$ & $\begin{array}{l}13268 \\
(8036)\end{array}$ & $\begin{array}{l}10816 \\
(6174)\end{array}$ \\
\hline Motor $\leq 40 \mathrm{HP}$ & $\begin{array}{c}3762 \\
(5149)\end{array}$ & $\begin{array}{r}978^{\circ} \\
(1880)\end{array}$ & $\begin{array}{l}930 \\
(1873)\end{array}$ & $\begin{array}{l}1124 \\
(1599)\end{array}$ \\
\hline $\begin{array}{l}\text { Boats with a } \\
\text { winch }\end{array}$ & $\begin{array}{c}19349 \\
(20988)\end{array}$ & $\begin{array}{c}7340 \\
(8966)\end{array}$ & $\begin{array}{c}7226 \\
(8914)\end{array}$ & $\begin{array}{l}6224 \\
(6885)\end{array}$ \\
\hline $\begin{array}{l}\text { Boats without } \\
\text { a winch }\end{array}$ & $\begin{array}{c}3957 \\
(5269)\end{array}$ & $\begin{array}{l}1143 \\
(2059)\end{array}$ & $\begin{array}{l}1097 \\
(2051)\end{array}$ & $\begin{array}{l}1186 \\
(1647)\end{array}$ \\
\hline
\end{tabular}


TABLE VII-5 (continued)

POTENTIAL RETURNS TO THE TRAP FISHERMEN PROVIDED THAT THEY USED THE OPTIMUM NUMBER OF TRAPS GIVEN THE PRESENT LEVEL OF THE OTHER INPUTS

$\begin{array}{llll}\text { Annual } & \text { \& change } & \text { present* } \\ \text { in } & \text { optimum* } \\ \text { on the } & \text { captain's } & \text { of } & \begin{array}{l}\text { of } \\ \text { number }\end{array} \\ \text { present } & \text { return } & \text { traps } & \text { of } \\ \text { value of } & & & \\ \text { boat and } & & & \\ \text { motor } & & & \end{array}$

In 8

\begin{tabular}{|c|c|c|c|c|c|}
\hline All tr & raps & $\begin{array}{l}4 \\
(0.7818)\end{array}$ & 68 & 42.1 & 24.6 \\
\hline Traps & $\&$ lines & $\begin{array}{l}60 \\
(1.2822)\end{array}$ & 102 & 43.2 & 39.8 \\
\hline Tradps & only & $\begin{array}{r}-10 \\
10.5215\end{array}$ & 28 & 41.9 & 21.6 \\
\hline Motor & $>30 \mathrm{HP}$ & $\begin{array}{l}38 \\
(1.1411)\end{array}$ & 84 & 69.3 & 82.0 \\
\hline Motor & $\leq 30 \mathrm{HP}$ & $\begin{array}{r}-11 \\
(0.5010)\end{array}$ & 30 & 33.5 & 14.0 \\
\hline Motor & $>40 \mathrm{HP}$ & $\begin{array}{l}111 \\
\quad(1.1272)\end{array}$ & 102 & 75.7 & 305 \\
\hline Motor & $\leq 40 \mathrm{HP}$ & $\begin{array}{r}-15 \\
(0.5096)\end{array}$ & 18 & 36.8 & 15.3 \\
\hline $\begin{array}{l}\text { Boats } \\
\text { winc }\end{array}$ & $\begin{array}{l}\text { with a } \\
\text { ch }\end{array}$ & $\begin{array}{l}39 \\
(1.1897)\end{array}$ & 86 & 62.7 & 80.7 \\
\hline Boats & without & $\stackrel{9}{(0.4940)}$ & 35 & 35.4 & 15.4 \\
\hline
\end{tabular}

*Geometric means

The number in parenthesis is the standard error of the variables in their respective samples. 


\section{5}

ing, and therefore the following discussion applies equally to both methods.

When investing in a boat and a motor the fishermen usually have to choose between boat types already built and available at a given price. For this reason, it is more useful to provide the fishermen with an equation which would allow them to decide if a given combination of boat and motor is optimum for their operation. A demand equation would give the size of the theoretically optimum boat. Since the cost is not a linear function of the number of feet of length, nor of the number of horsepower, this would not provide sufficient information for decision making. On the other hand, a guide by which to judge given combination of boat and motor is more practical.

Consider the equation of the expected profit.

$$
\begin{aligned}
& \text { (7-11) } E(\pi)=p_{O} A B^{\alpha}{ }_{1} H^{\alpha}{ }_{2} T^{\alpha}{ }_{3} V^{\alpha}{ }_{4} e^{1 / 2 \delta}{ }_{O O}-D-\gamma\left(p_{O} A^{A B}{ }_{1}\right. \\
& \left.\mathrm{H}^{\alpha}{ }_{2} \mathrm{~T}^{\alpha}{ }_{3} \mathrm{~B}_{4}^{\alpha} \mathrm{e}^{1 / 2 \hat{\theta}} \circ \mathrm{OO}-\mathrm{p}_{1} \mathrm{~V}\right)-\mathrm{p}_{\mathrm{T}} \mathrm{T}-\mathrm{p}_{\mathrm{V}} \mathrm{V}
\end{aligned}
$$

where

$p_{0}$ price of the fish

A constant

$B$ length of the boat (as a measured of the combined input boat and motor)

$\mathrm{H}$ number of man days at sea in a year

$T$ number of traps owned

$V$ number of gallons of gasoline used during a year

$D$ annual cost of the boat (depreciation on the boat and the motor and maintenance)

$\sigma_{\text {oo }}$ share under the lay system given to the crew 
$\mathrm{P}_{\mathrm{T}}$ price of a trap

$\mathrm{P}_{\mathrm{v}}$ price of a gallon of gasoline

Assuming that $\mathrm{H}$ is given, taking the first order conditions, a boat is of optimum size if

$$
\begin{aligned}
& (7-12) \quad \ln \{E(D)\}=\frac{1}{\left(1-\alpha_{1}-\alpha_{3}\right)}\left\{\ln p_{0}+\ln A+\alpha_{1} \ln B+\alpha_{2} \ln H\right. \\
& \left.+a_{i}\left(1-\alpha_{3}-\alpha_{4}\right)+\alpha_{3}\left(a_{3}-\ln p_{T}\right)+\alpha_{4}\left(a_{4}-p_{v}\right)+\ln (1-\gamma)+1 / 2 \delta_{0 \circ}\right\} \\
& \text { where } a_{i}=\ln \alpha_{i}
\end{aligned}
$$

If In $D$ is larger than the right hand side of the equation the boat would be an over-investment; if $\ln D$ is smaller it would be an under-investment.

If the boat was to be used in more than one activity Ind should be replaced by $1 \mathrm{nD}+\ln \mathrm{z}$, where $\mathrm{z}$ would be the share of the activity studied in the total revenue.

Here too, it is necessary to recall the previous notes of caution, that because of the effect of externalities these equations should only be considered as a guide. In addition, in this study none of the boats were equipped with echo sounders, radar, nor radio, all of which might increase the productivity of a given boat. To decide if it is judicious to invest in a boat equipped with such aids, simply by using equation $(7-12)$ there could be erroneous results.

It was shown earlier that the fishermen underinvested in their boats, and that large boats with inboard motors 
were more profitable. Despite these findings, before undertaking any government program to increase boat size, it must be kept in mind that large boats require more harbor facilities, and these represent an added cost to the program. In the present study they are not.

Using the coefficients of equation (6-3), equation

(7-12) becomes:

(7-13) $\ln \{E(D)\}=\frac{1}{0.7442}\{\operatorname{lnp} 0-0.9379+0.3958 Q+$ $0.2743 W+0.7938 L B+1.1903 \mathrm{LH}-0.771$ $\left.\left(-2.5770-1 n p_{\mathrm{T}}\right)+0.3329\left(1.10110-1 n p_{\mathrm{v}}\right)\right\}$

Equation (7-13) can be used to test if a boat of a certain size B with an annual depreciation of $D$ will be an optimum investment, provided the number of man days at sea is $H$ and $p_{O}$ is the average price of a pound of fish, $p_{T}$ the price of a traps, and $p_{v}$ the price of a gallon of gasoline. If the captain displays a skill comparable to those who fish with both traps and lines or if he, himself. fishes with traps and lines $Q=1$, otherwise $Q=0$. If the boat is equipped with a winch $W=1$, otherwise $W=0$.

Before closing this part of the section one important note must be added. It appeared in Chapter VI that the catch increased with the size and the power of the boats presumably because the larger, more powerful boats allow the captains to fish at the edge of the continental shelf. 
The sub samples of powerful boats, however, were small; there were only six boats over $30 \mathrm{HP}$., and four over 40 HP., all of the latter from Puerto Real. Suggesting that more powerful boats will catch more fish implies that the difference of productivity between the edge of the continental shelf and the closer fishing grounds is everywhere as significant as in Puerto Real. There is presently insufficient data to prove such an assumption. However, the exploratory fishing and gear tests which have been conducted off Puerto Rico suggest that the edge of the continental shelf is always more productive than the on-shore grounds. 1

III Chosing between trap fishing and line fishing Comparing the information in Table VII-I and Table VII-2 it appears that, presently, line fishing gives the higher return on the boat and the motor. It should be remembered however, that various measures could be taken to improve the returns from both activities and particularly from trap fishing. Consequently, it is difficult to compare the potential returns from each activity and to make recommendations as to the optimum combination between trap fishing and line fishing. Despite those limitations, some remarks can be made

IEstado Libre Asociado de Puerto Rico. A Report on ExLoratory Fishing and Gear Tests in Puerto Rico From 1969 S 1972 by Rolf Juhl. 
concerning a profitable combination. In some areas the choice must be limited because of the geographical conditions, but from many ports it is possible to fish with traps and lines. If the fishermen had the proper training more could fish with lines. For the fishermen who fish only a few days a month it is certainly a more profitable method than trap fishing because of the lower level of investment required.

For the fishermen who fish more regularly, the present combination displayed by the more powerful boats seem to be quite profitable as the returns in Table VII-1, Table VII-2 and Table VII-3 show.

Whatever the potential returns this model could exhibit for both activities, it would be unwise to give up completely one method for the other. In the present model the fish population has been treated as homogeneous, but in Chapter II it was shown that the catch from lines did not have the same species composition as the catch from traps. Abandoning one method for the other, or even changing drastically the balance, would affect the fish population in a way that would make the assumption of the model unacceptable and therefore would render the conclusions inaccurate. Despite the various limitations due to the analytical framework, or to the lack of information, this chapter shows that many measures could be undertaken which would improve the economic conditions of the Puerto Rican fisher- 
men. Not all those measures would require higher investment. The effects of a higher fishing skill would, for instance be very significant.

Another measure which would have important financial consequences for the fishermen concerns the price and the life of the traps. In Table VII-l it was shown that in 1972 the average annual return to the captains fishing with traps was $\$ 1750$ while they owned an average of 44.2 traps (Table II-7). It is clear that if the price of the traps could be reduced or their life lengthened it would affect condiserably the captain's returns.

In addition, it should also be recalled that the number of days the fishermen go to sea is an important element in the selection of the other inputs. If the fishermen went to sea more often, larger, more powerful boats would be justified.

Finally it is important to emphasize that the results of this chapter indicated the direction of the changes which can be expected if some policies are implemented. They should not be taken to represent exact magnitudes of those changes. 
CONCLUSION

This study should only be considered as the first step of an economic analysis of the Puerto Rican artisanal fishery. Much more research remains to be done. This survey however, revealed some important facts concerning the two most important fishing methods: trap fishing and hand line. Although many of the results are not surprising retrospectively, their confirmation provides the decision makers with firm grounds on which to base their policy.

It was shown that it was possible to estimate catch functions with a good level of precision. Not surprisingly, the size and power of the boats turned out to be an important element to explain the level of the catch. Where trap fishing was concerned, the number of traps owned by the fishermen and the number of men aboard were also significant factors to explain the catch. For line fishing no other input was found to have a significant influence on the catch. Comparing the regressions for catch from trap fishing and catch from line fishing it appeared that the former ones had higher $R^{2}$ 's and $F$ statistics suggesting the possibility that some input more important for line fishing than for trap fishing had been omitted from the equations. The tests of technical efficiency revealed that 
fishing skill might be such an input, since they showed that line fishermen were, as a whole, more skillful than trap fishermen.

The tests of price efficiency showed that the fishermen were not price efficient. They indicated that somewhat larger boats than the ones presently used would be more profitable. Concerning the optimum number of traps, the tests also revealed that some fishermen underestimated it while others overestimated it, depending upon the size of their fishing operations.

The results of their tests led to policy recommendations. Two kinds of measures should be taken. It was demonstrated that improving the fishing skill of the fishermen and generalizing the use of a winch for trap fishermen would considerably increase the catch.

At the same time, helping the fishermen choose the optimum number of traps and the optimum size boats would improve their profits.

All those results are important to anyone interested in the development of the Puerto Rican fishery much more remains to be done however, if a comprehensive management program is to be drawn.

Many more studies could be undertaken to improve the present one in order to provide information on economic aspects which have been ignored here. 
For instance, it was not possible to evaluate with precision the effects of the policy measures suggested by the present analysis. This was due to the lack of knowledge concerning the level and actual growth function of the fish population and the crowding externalities, since it is difficult to design a management program without some knowledge of the fish population.

In addition, it is essential to know what the factors are which motivate entrance into the fishing industry. Profit is probably an important one, but the policy maker must know the effect his decisions will have on the number of persons who will enter into fishing. This will require analyzing the role of other factors outside fishery such as the general level of employment or the demand for labor from the agricultural sector. In this study, the number of days at sea was assumed constant. In fact, it is likely that an increase in the profit will encourage the fishermen to fish more often and this will lead to an increase in the catch. The policy maker should be aware of that effect.

Finally, no global management scheme for fishery was proposed. This should, in the future, be an important area of research. The analysis of fish marketing in Puerto Rico could also suggest important decisions to develop fishery. 
Much is still unknown of the economics of the Puerto Rican fishery. The points mentioned above are but a few of the possible areas of research, and the results of the present survey should encourage further study. 
APPENDIX I: Data Collection and Field Method

The data used in the present study can be classified in two categories according to their sources. The catch figures were obtained from the Puerto Rican Department of Agriculture, which gathers these statistics from sale tickets recorded on a fishing trip basis throughout the year. On the other hand the information concerning the type and quantity of inputs used by the fishermen were obtained through direct interviews.

An important point needs to be emphasized. The purpose of this study being to analyze some of the production processes in the fisheries rather than the economic situation of all the fishermen, it was decided to interview only the captains of the boats in order to avoid including twice the same firm in the sample. (In the following the word "fishermen" will refer to the captains unless otherwise specified).

The Commercial Fisheries Laboratory of the Department of Agriculture keeps lists of all the fishermen in Puerto Rico. The sample for Cabo Rojo was built by choosing every third name on those lists. Since the lists were not set up in any particular order, this method was in fact systematic random sampling. However, it appeared 
that some of the fishermen selected in that fashion did not report their catch to the Department of Agriculture. Although, in the questionnaire, all the fishermen were asked to estimate the value of their catch, those estimates turned out to be quite different from the catch reported to the government. This suggested that the answer to that part of the questionnaire might not be highly reliable.

The answers given in the questionnaires were constantly understated, they averaged $\$ 3693$ against $\$ 6321$ on the sale tickets for the same fishermen. At the same time the smaller standard error (1432) instead of (6270) suggests that in the survey, the fishermen with the highest revenues tended to lower them to what they perceived as closer to the community's average.

Consequently, if systematic random sampling was used and if one was to discard the information given by the fishermen who did not report their catch to the government, this could have reduced considerably the size of the actual sample. For that reason, it was decided to interview, in the selected communities, all the fishermen for whom the government had catch figures and to limit the study to those fishermen.

A priori this method could have introduced a bias, but, as it will be shown later, it is likely to be negligible since often the fact that his catch is recorded 
or not is independent of the fishermen. This means the recorded catches are not systematically the highest or the lowest ones. For all pratical purposes, it is possible that whether a catch is reported or not may be a random process. For that reason it was thought that the risk of introducing a slight bias was more than compensated for by the fact that the information obtained in that fashion was more reliable. 
Since 1968 the Commercial Fisheries Laboratory of the Puerto Rican Department of Agriculture has been gathering statistics on the fisheries. ${ }^{1}$ under this program, the Laboratory continuously keeps up to date a list of all the fishermen of Puerto Rico. In addition, the catches are reported using sale tickets. Every time a fishermen goes at sea, a sale ticket is filled out, either by the fisherman himself or, more often, by the dealer who bought the fish. The slip is supposed to record the total catch in weight and value. In addition, it gives a breakdown of the catch per species in weight and value and it indicates the fishing method used to catch the fish.

of all the informations given on the sale tickets the breakdown by species is the least reliable. The reason is that, in reality, many sale tickets are not filled out completely and, more often than not, only report the total catch. In addition, sometimes the fish are classified in three groups according to their price per pound rather than by species. From that information the staff of the Laboratory divide the catch among the various species, according to past experience.

In 1968 and 1969 the Department of Agriculture's project attempted to collect sale tickets from all the Puerto

${ }^{1}$ This project is conducted under the PL 88-309 Fishery Research and Development Program. 
Rican fishermen. This turned out to be a very difficult task. From 1970 on, the collection of sale tickets was limited to the larger fishing communities. It has been estimated that those communities are responsible for 80 percent of the catch in Puerto Rico.

If a sale ticket was in fact available every time a fisherman of those communities went to sea, it would provide not only an accurate estimate of the annual catch, but it would also indicate how many days a fisherman goes fishing in a year. Sometimes the sale tickets are not filled out, however; at other times the agents of the laboratory fail to collect them. Given these possible mishaps, it is thought that the sale tickets are available for only 75 percent of the fishing trips. ${ }^{2}$

The limits of the sale tickets project suggest that one must be careful when inferring annual figures or islandwide estimates from the information collected in that fashion. However, it seems that the sale tickets give good estimates of the average daily catch. This was confirmed by personal observation of the way the tickets were filled out by some of the dealers when the fishermen come back from a fishing trip.

${ }^{2}$ This is according to Dr. Suarez-Caabro Director of the Commercial Fisheries Laboratory in Guanajibo, Puerto-Rico. 
II The Questionnaire

Personal interviews of the fishermen constitute the second source of information for this study. A questionnaire was used to conduct the interviews. Before devising it, however, several fishing communities were visited and informal conversations with the fishermen took place. Then, a first draft was designed and translated into Spanish by the staff of the Laboratory. With the help of an employee of the Laboratory the first questionnaire was field tested in Mayaguez. This port was chosen for pre-testing the questionnaires because it is not very different from the type of community in which this survey was to be applied. Following this test, the questionnaire was revised with the help of the staff of the Laboratory and 41 interviews were then conducted in Cabo Rojo during a first stay in Puerto Rico. During a second stay other interviews were conducted in other communities around the island.

The interviews were all conducted with the help of an interpreter. The fishermen were usually cooperative. out of 70 fishermen contacted only two refused to answer. The survey dealt with the fishing in 1972, but since the interviews were conducted at first during the summer of 1973, and then during the winter of 1974, 19 of the fishermen who were listed in 1972 were not fishing anymore. 
Some had taken other jobs; others had moved to the continental United States. In general, there is no reason to doubt the reliability of the answers given by the fishermen except, as mentioned earlier, when they were asked to evaluate the value of their annual catch.

All the answers concerning the equipment owned or used are highly reliable. Most of the time the interviews were conducted on the beach and often it was possible to observe directly that the information provided by the fishermen was correct.

During the first stay in Puerto Rico, the study was intended to address itself more specifically to the way the fishermen allocated their resources between various economic activities. For this reason the year had been divided into three periods and to some of the questions the fishermen were expected to give an answer for each period of the year. This was the case for the number of days at sea for example. After analyzing the results of the first part of the survey, when it appeared that few fishermen had other economic activities, it was decided to ignore this aspect of the problem. Consequently, during the second set of interviews the fishermen were asked to give only one aggregate answer for the whole year 1972 . 
Bell, Frederick W. "The Relation of the Production Function to the Yield on Capital for the Fishing Industry." Recent Developments and Research in Fisheries Economics. Edited by F.W. Bell and J. E. Hazleton (Dobbs Ferry, New York: Oceana Publications, Inc., 1967).

----. "Technological Externalities and Common Property Resources: An Empirical study of the U. S. Northern Lobster Fishery." Journal of Political Economy, 80 (January/February, 1972), pp. 148-158.

Blay, Federico G. A study of the Relevance of Selected Ecological Factors Related to Water Resources and the Social Organization of Fishing Villages in Puerto Rico (water Resources Research Institute, University of Puerto Rico, Mayaguez, Puerto Rico, 1972).

Bohlke and Chaplin. Fishes of the Bahamas and Adjacent Tropical Waters. Wynnewood: Livingston Publishing Company, 1968 .

Cochran, william G. Sampling Techniques. New York: John Wiley and Sons, 1963.

Commonwealth of Puerto Rico. Department of Agriculture, Centralized and Ancillary Operation Services. Contribuciones Agropecuarias y Pesqueros. San Juan, $\overline{\text { Puerto }}$ Rico: Vol. II, no. 1, March, 1970.

--- - Department of Agriculture, Centralized and Ancillary Operation Services. Contribuciones Agropecuarias y Pesqueras. San Juan, Puerto Rico; Vol. II, no. 3, May, 1970 .

----. Department of Agriculture, Centralized and Ancillary Operation Services. La Pesca en Puerto Rico, 1970. San Juan, Puerto Rico: Vol. III, no. 1, March, 1971.

----. Department of Agriculture, Centralized and Ancillary Operation Services. Status of Fisheries in Puerto Rico, 1971. San Juan, Puerto Rico: Vol. IV, no. 1. April, 1972 . 
----. Department of Agriculture, Centralized and Ancillary Operation Services. A Report on Fisheries Statistics program in Puerto Rico from 1967 to 1972. San Juan, Puerto Rico: Vol. IV, no. 4, November, 1972 .

----. Department of Agriculture, Centralized and Ancillary Operation Services. A Report on Exploratory Fishing and Gear Tests in Puerto Rico from 1969 to 1972. Cabo Rojo, Puerto Rico: Vol. IV, no. 3, November, 1972.

--.-. Department of Agriculture, Centralized and Ancillary Operation Services. Status of Fisheries in Puerto Rico, 1972. Cabo Rojo, Puerto Rico: Vol. V, no. 3. April, 1973.

Copes, Parzival. "The Backward-Bending Supply Curve of the Fishing Industry". Scottish Journal of Political Economy, 17-18 (February, 1971), p. 70 .

Ferguson, C. E. Microeconomics Theory. Homewood, Illinois: Richard D. Irwin Inc. 1969.

Fullenbaum, Richard F.; Carlson, Ernest W.; and Bell, Frederick W. "Economics of Production from Natural Resources: Comment." American Economic Review, 61 (June, 1971), pp. 483-487.

----. "On Models of Commercial Fishing: A Defense of the Traditional Literature". Journal of Political Economy, 80 (July/August, 1972), pp. 761-768.

Goldberger, Arthur S. Econometric Theory. New York: John Wiley \& Sons, Inc., 1964.

Gordon H. Scott. "The Economic Theory of a Common-Property Resource: The Fishery". Journal of Political Economy, 62 (April, 1954).

Heady, Earl O., and Dillon, John L. Agricultural Production Functions. Ames, Iowa: Iowa State University Press, 1961 .

Henderson, James M., and Quandt, Richard E. Microeconomic Theory, A Mathematical Approach. New York: McGrawHill, 1971. 
Hoch, Irving. "Simultaneous Equation Bias in the Context of the Cobb-Douglas Production". Econometrica, 26 (October, 1958), pp. 566-578.

Holmsen, Andreas A. "The Economics of the Small Trawler Fleet". Recent Developments and Research in Fisheries Economics. Ed. by F. W. Bell and J. E. Hazleton. Dobbs Ferry, New York: Oceana Publications Inc., 1967.

Johnston, J. Econometric Methods. New York: McGrawHill, $19 \overline{63 .}$

Lau, Lawrence J., and Yotopoulos, Pan A. "A Test of Relative Efficiency and Application to Indian Agriculture". American Economic Review, 61 (March, 1971).

Marschack, Jacob, and Andrews, William H., Fr. "Random Simultaneous Equations and the Theory of Production". Econometrica, 12 (July/October, 1944).

Noetzel, Bruno G., and Norton, Virgil J. Cost and Earnings in the Boston Large-Trawler Fleet. Economics of Marine Resources, 8. University of Rhode Island Experiment Station no. 1329, Kingston, Rhode Island 1969.

Perloff, Harvey S. Puerto Rico's Economic Future. Chicago, Illinois: The University of Chicago, Press, 1950.

Phillips, Charles F., Jr. The Economics of Regulation. Homewood, Illinois: Richard D. Irwin, 1969.

Pico, Rafael. Nueva Geografia de Puerto Rico. Universidad de Puerto Rico: Editorial Universitoria, 1969.

Pielou, E. C. An Introduction to Mathematical Ecology. New York: Wiley Interscience, 1969.

Puerto Rico and the Sea, An Action Program for Marine Affairs (Preprint). A Report to the Governor, San Juan, 1972.

Randall, John E. Caribbean Reef Fishes. Jersey City: T.F.H. Publications, Inc., 1968. 
Scott, Anthony. "The Fishery: The Objectives of Sole Ownership". Journal of Political Economy, 63

(April, 1955), pp. 116-124.

Smith, Vernon L. "Economics of Production from Natural Resources". American Economic Review, 58 (June, 1968), pp. 409-431.

----. "Economics of Production from Natural Resources: Reply". American Economic Review, 61 (June, 1971), pp. 488-491.

---. "On Models of Commercial Fishing." Journal of Political Economy, 77 (March/April, 1969), pp. 1811981

----. "On Models of Commercial Fishing: The Traditional Literature Needs No Defenders". Journal of Political Economy, 80 (July/August, 1972), pp. 776-778.

Spaulding, Irving A. Puerto Rico Fisheries and Mariculture Development Project. Unpublished Inter-Ägency Report, University of Rhode Island, 1974.

Speight, H. Economics and Industrial Efficiency. London: MacMillan \& Co. Ltd., 1962 .

Study of the Fisheries Potential of the Virgin Islands. Special Report, Caribbean Research Institute Contribution, No. 1. Virgin Island Ecological Research Station, August, 1969.

Theil, Henri. Principles of Econometrics. New York: John Wiley and Sons Inc., 1971.

Tumin, Melvin M., and Feldman, Arnold S. Social Class and Social Change in Puerto Rico. Indianapolis: The Bobbs-Merrill Company Inc., 1971.

Turvey, Ralph. "Optimization in Fishery Regulation". American Economic Review, 54 (March, 1964), pp. 64-76.

U.S. Bureau of the Census Statistical Abstract of the United States, 1972 (93rd Edition). Washington, D. C., 1972 . 
U.S. Department of Commerce. National Oceanic and Atmospheric Administration. "Cross Section Production Functions of North Atlantic Ground Fish and Tropical Tuna Seine Fisheries". Ernest $W$. Carlson in Ocean Fishery Management: Discussions and Researeh. Ed. by A. A. Sokoloski, NOAA Technical Report 371, November, 1970. (Seattle, Washington, April, 1973), pp. 42-56.

U.S. Department of Interior. Fish and wildlife Service. Bureau of Commercial Fisheries. Economic Aspects of the Pacific Halibut Fishery by $\mathrm{J}$. Crutchfield and ${ }^{-} \mathrm{A}$. Zeliner. Fishery Industrial Research Vol. 1, no. 1, April 1962. Washington, D.D.: Government Printing Office, 1963.

Walters, A.A. "Production and Cost Functions: An Econometric Survey". Econometrica, 31 (January/April, 1963).

Wonnacott, Ronald J., and Wonnacott, Thomas H. Econometrics. New York: John Wiley \& Sons Inc., 1970 .

Yamone, Taro. Statistics: An Introductory Analysis. New York: Harper \& Row, Publishers, 1973.

Zellner, A.; Kmenta, J.; and Dreze, J. "Specification and Estimation of Cobb-Douglas Production Function Models". Econometrica, 34 (October, 1966). 